\title{
Localized proton MRS of animal brain in vivo: Models of human disorders
}

\author{
T. Michaelis *, S. Boretius, J. Frahm \\ Biomedizinische NMR Forschungs GmbH am Max-Planck-Institut für biophysikalische Chemie, 37070 Göttingen, Germany
}

\section{A R T I C L E I N F O}

\section{Article history:}

Received 1 September 2008

Accepted 6 November 2008

Available online 14 November 2008

\section{Keywords:}

Magnetic resonance spectroscopy

Brain metabolism

Animal models

Transgenic mine

Nonhuman primates

Alzheimer's disease

Huntington's disease

Parkinson's disease

Cerebral ischemia

Multiple sclerosis

\section{Contents}

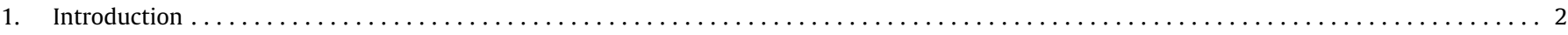

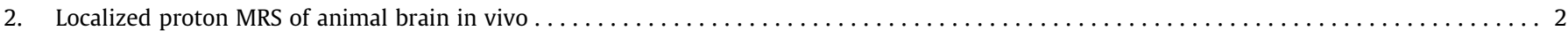

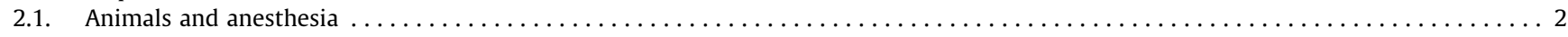

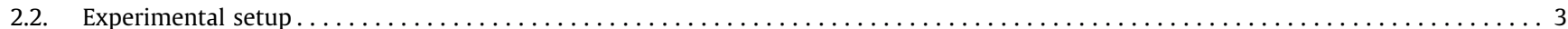

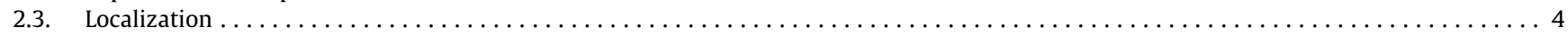

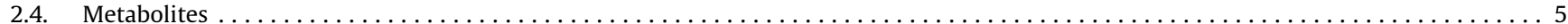

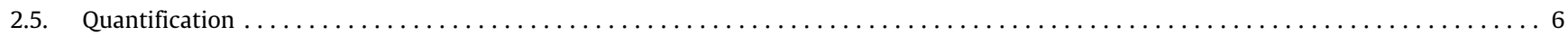

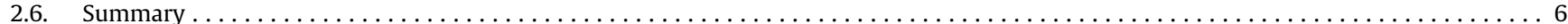

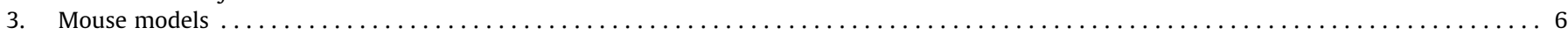

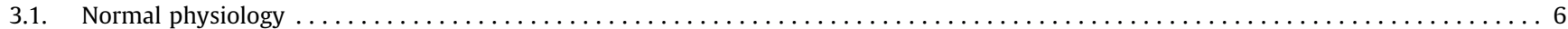

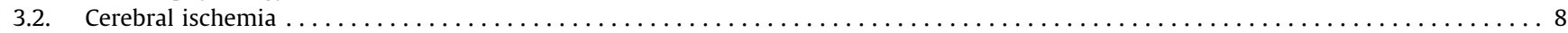

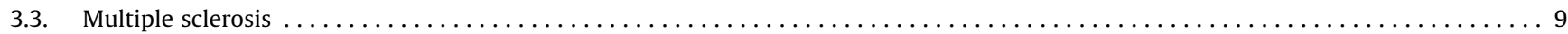

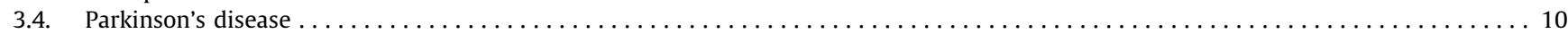

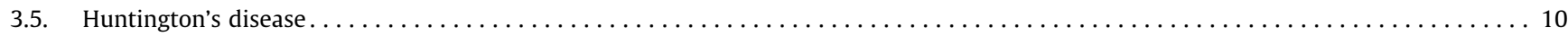

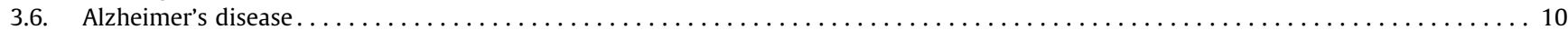

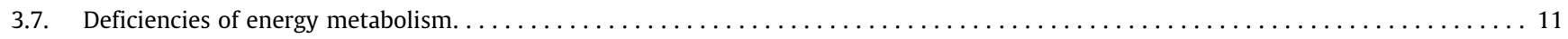

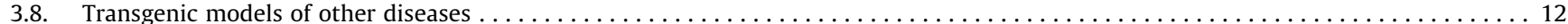

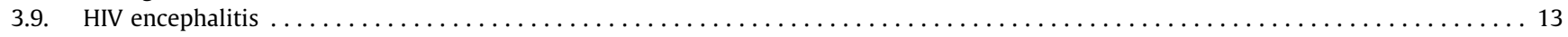

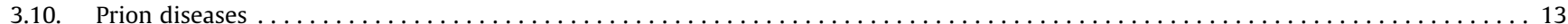

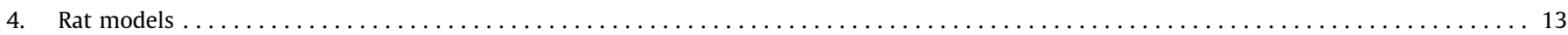

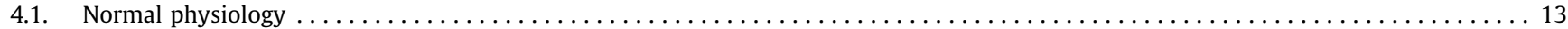

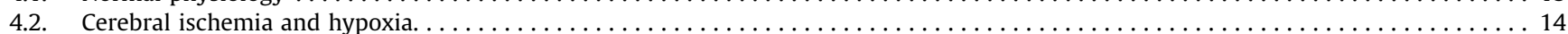

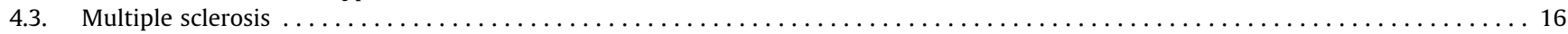

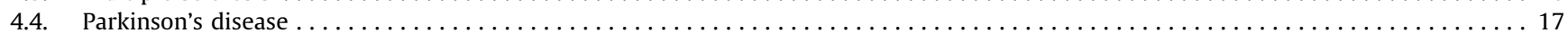

\footnotetext{
* Corresponding author. Tel.: +49 551201 1090; fax: +49 5512011307.

E-mail address: tmichae@gwdg.de (T. Michaelis).
} 


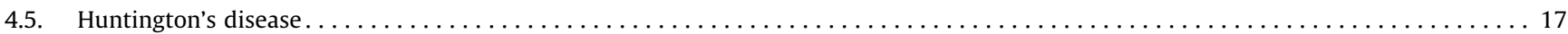

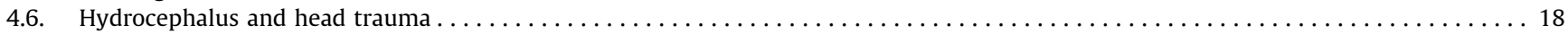

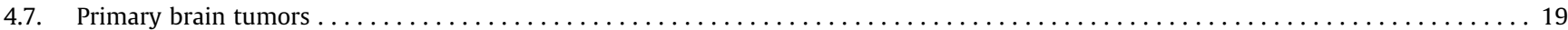

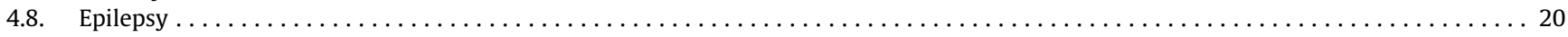

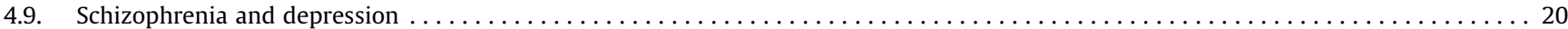

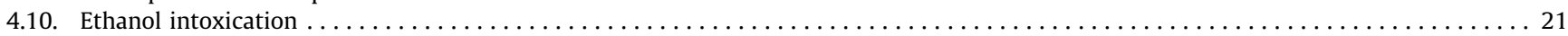

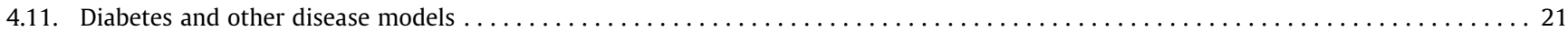

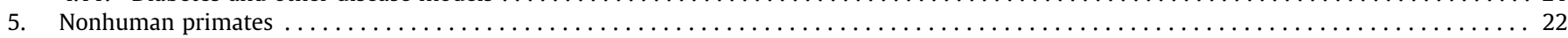

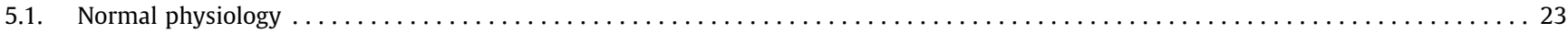

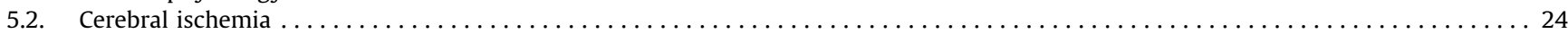

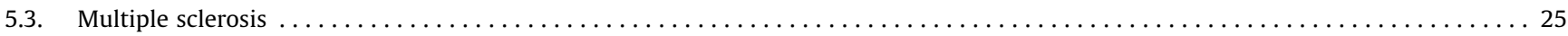

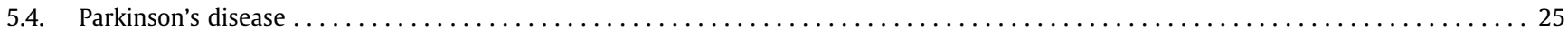

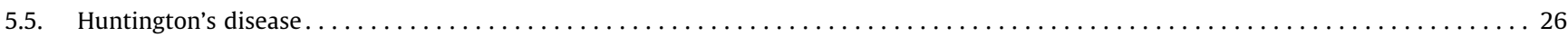

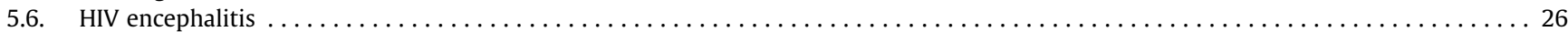

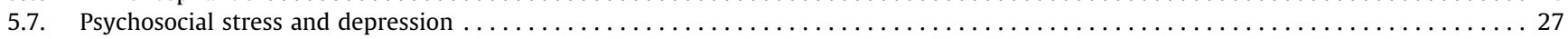

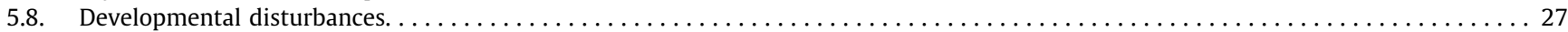

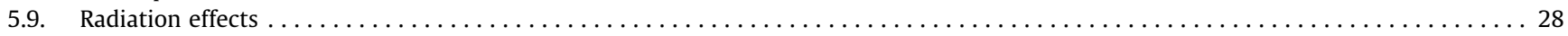

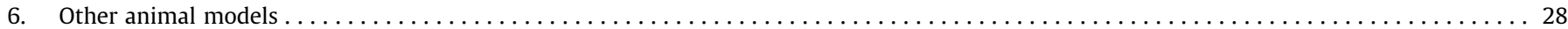

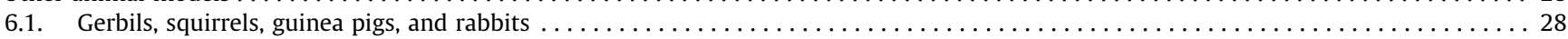

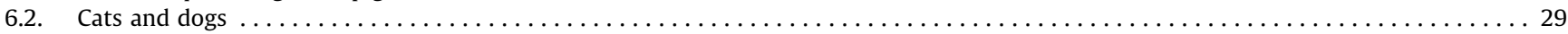

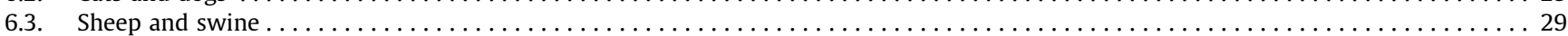

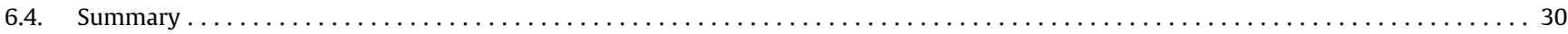

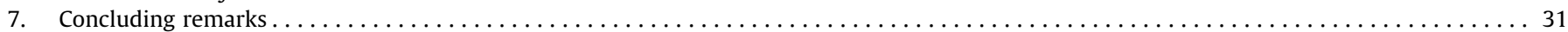

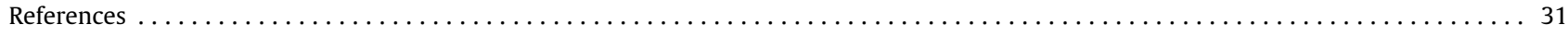

\section{Introduction}

After decades of methodologic developments and groundbreaking applications in basic and clinical neuroscience, in vivo magnetic resonance spectroscopy (MRS) has become a mature technique for metabolic studies of the central nervous system. In particular, localized proton MRS significantly adds to the increasingly important role of magnetic resonance imaging (MRI) in translational medicine. Complementing advances in fluorescence microscopy at the lower spatial scale, noninvasive MRI and MRS are indispensable tools that offer unique links between molecular neurobiology and clinical research.

This work reviews proton MRS studies of mammalian brain and ignores sparse applications to other vertebrates and insects. It focuses on mice [1-30], rats [31-101], and nonhuman primates [102-130] with a complementary section on gerbils [131], squirrels [132], cats [133-140], dogs [141-146], sheep [147,148], and swine $[149,150]$. Moreover, this contribution entirely features in vivo MRS studies and leaves out investigations of organs in situ, excised tissues, brain slices, or cell cultures.

The main purpose is to illustrate the potential of cerebral MRS in preclinical research. Rather than providing a comprehensive survey, emphasis will be placed on animal models of human brain disorders that rely on rodents and nonhuman primates. This selection is motivated by the fundamental advances in mouse neurogenetics and the close homology of monkeys with humans. As far as technical considerations are concerned, most current MRS studies achieve spatial localization with the use of a point-resolved spectroscopy (PRESS) [151-153] or stimulated echo acquisition mode (STEAM) $[154,155]$ sequence. Early studies without spatial localization are only included if of historic interest. Moreover, MRS reports that failed to present a single spectrum are usually discarded because such publications do not allow for a proper judgement of the scientific quality and significance of the MRS findings.

In humans, proton MRS studies of the central nervous system have repeatedly been reviewed, for example see [156-163]. On the other hand, reviews of animal studies have mainly addressed specific aspects of technical feasibility [164-168] or the occurrence of metabolic alterations in selected disease conditions [169-180]. In contrast, this review first discusses the basic requirements for a successful MRS study of animal brain and then focuses on the most common models of human brain disorders.

\section{Localized proton MRS of animal brain in vivo}

\subsection{Animals and anesthesia}

The choice of a species for answering a particular biological or medical question with the use of an animal experiment is a complex decision taking into account animal welfare, practicality, and scientific rationale. Apart from ensuring the best scientific suitability, experimental considerations have to include availability, cost, animal husbandry, and possible transportation. Because models of human brain disorders are often not restricted to a specific species, the majority of localized proton MRS studies have hitherto been performed in rats. These studies are less expensive than those of nonhuman primates, and rats offer a larger brain than mice. In fact, in comparison to mice, rat studies often achieve a higher signal-to-noise ratio (SNR) and offer more robust and better controllable physiological conditions under anesthesia. However, due to the rapid development of mouse neurogenetics, mouse models are becoming increasingly important for investigations of the genetic control of cellular metabolism and physiological processes as well as related disturbances.

Complementary, nonhuman primates are the only species that offer a close similarity to humans in terms of anatomical, physiological, immunological, and functional properties of the central nervous system. Although monkey models are likely to remain limited in number and expected to preferentially address novel therapeutic trials previously developed in rodents, they will be required for specific neurological disorders (e.g., multiple sclerosis) and psychiatric syndromes (e.g., stress and depression).

An obvious difference between human and animal MRI and MRS studies is the need for anesthesia in the animal studies in order to minimize stressful effects and to avoid undesired artifacts due to movements. Protocols for anesthesia vary for different species and sometimes also for different sites. They may also depend on the initial access to the awake animal, the total examination time, and the actual scientific question. If the animal is required for subsequent histology and does not need to recover from anesthesia, invasive approaches such as tracheotomy might be appro- 
priate. However, because of the growing demand for follow-up MRS measurements, alternative techniques are intravenous injections, spontaneous breathing of an anesthetic gas via a mask, or endotracheal intubation with artificial ventilation which is the standard procedure in this laboratory. Once established the latter strategy outperforms other methods with respect to animal safety and recovery rate, the ability to perform adjustments during the experiment, and the realization of measuring times of up to several hours. Although experimentally demanding, intubation has turned out to be extremely valuable for investigations of young and aged animals, severely affected animals, and rare mutants with an often unknown pathophysiological background.

After initiation of anesthesia animals are commonly placed in a prone or supine position on a commercially available or custom-built bed (animal slider). In many cases a stereotaxic device is used to immobilize the head. Noninvasive monitoring of basic life functions such as breathing amplitude and frequency, blood oxygenation level, and rectal temperature are usually sufficient to control anesthesia and ensure adequate survival rates. Other features involving permanent catheters or electrodes for electrophysiological recordings may be necessary for special applications.

\subsection{Experimental setup}

The majority of animal MRS studies employ a surface coil for signal reception either in transmit/receive mode or in combination with a homogeneous radiofrequency (RF) excitation coil. Although this choice is generally motivated by clear SNR advantages for volumes-of-interest (VOI) close to the surface coil, it may also suffer from a fading signal for VOIs at increasing distance from the coil. The coils must be perpendicular to the static magnetic field and geometrically and/or actively decoupled. Best results in terms of SNR are obtained by placing the head of the animal (partly) within a single-looped circular or elliptic surface coil. When actively decoupled, slightly bent coils may be adapted to the shape of the
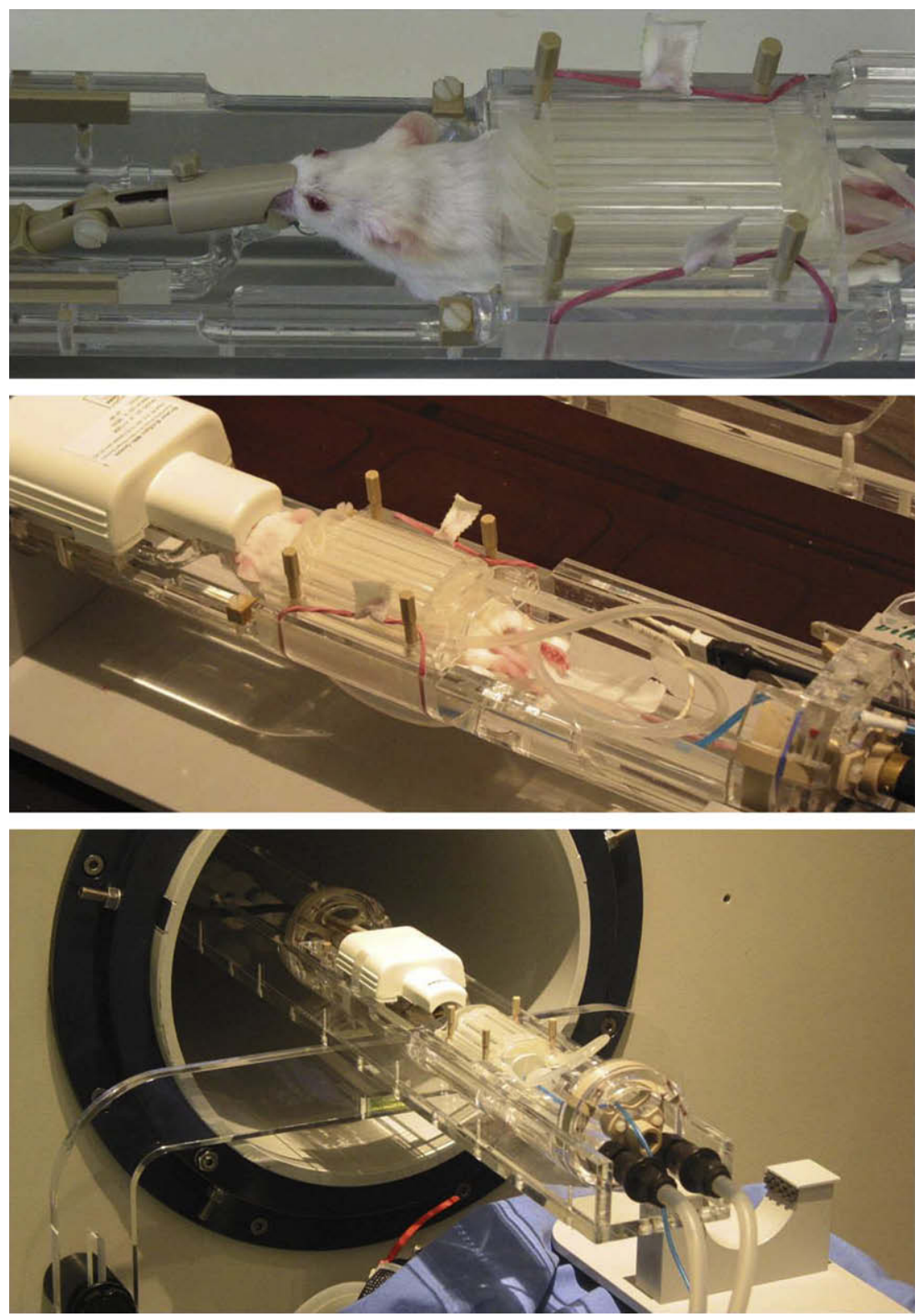

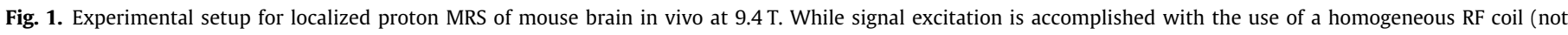

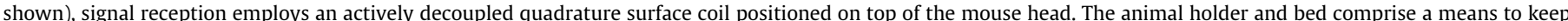

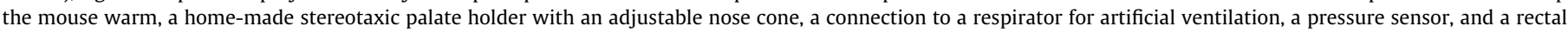
thermometer. Courtesy of Dr. Roland Tammer (rtammer@gwdg.de). 

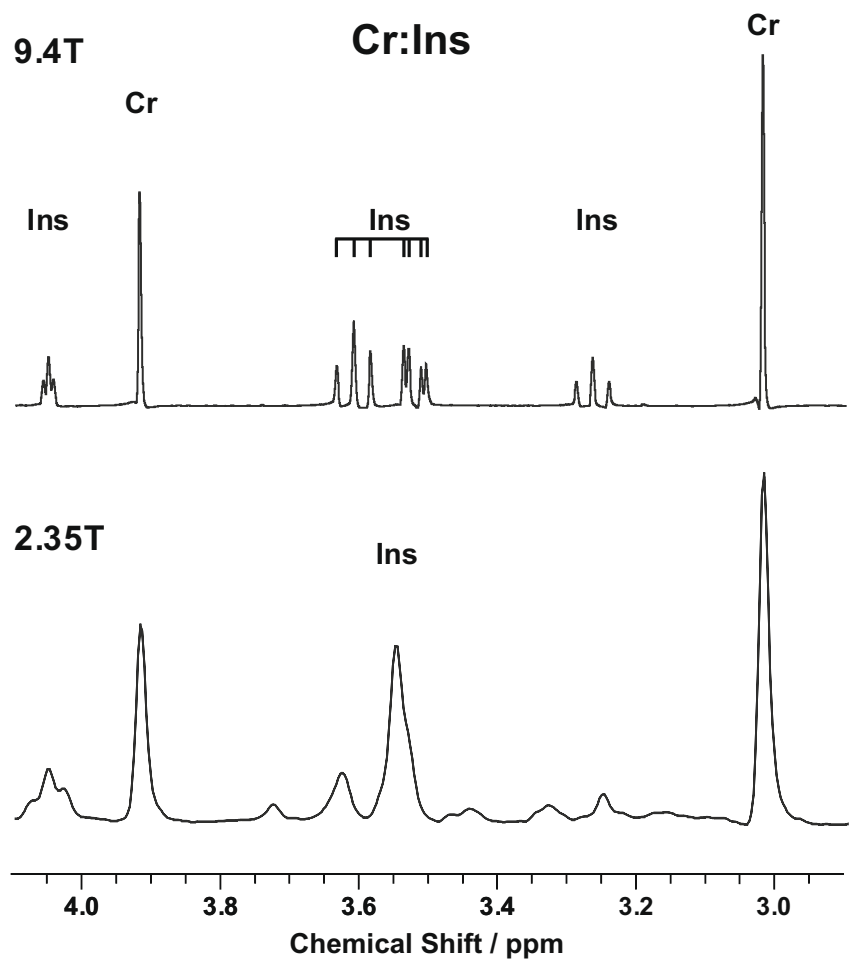

NAA:Glu:GIn

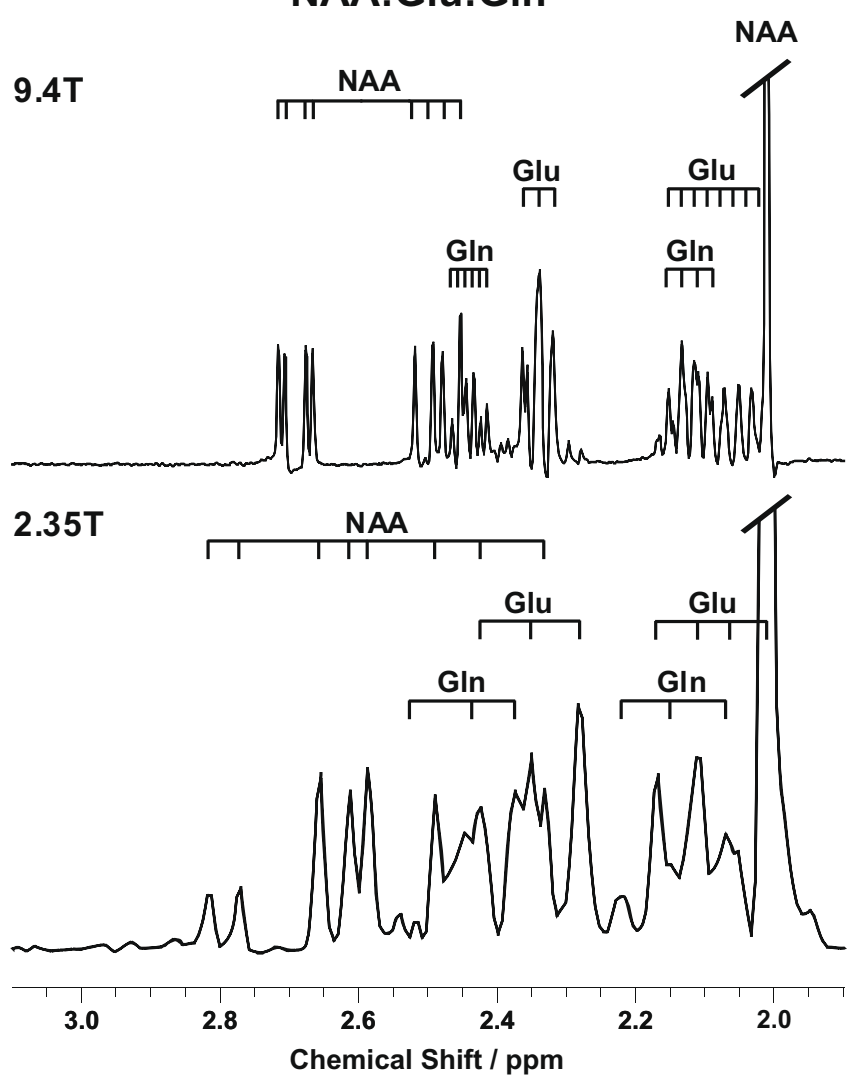

Fig. 2. Localized proton MRS (STEAM) of metabolite solutions at a low field strength $(2.35 \mathrm{~T}, \mathrm{TR} / \mathrm{TE}=10,000 / 10 \mathrm{~ms})$ and a high field strength $(9.4 \mathrm{~T}, \mathrm{TR} /$ $\mathrm{TE}=15,000 / 10 \mathrm{~ms}$ ). (Top) 1:1 mixture of myo-inositol (Ins) and creatine (Cr) and (bottom) 2:2:1 mixture of $N$-acetylaspartate (NAA), glutamate (Glu), and glutamine (Gln). While Ins is easily detectable at low fields due to its apparent singlet resonance, a much better separation of Glu and Gln is achieved at high fields. head. Fig. 1 illustrates the setup used in this laboratory for MRS of mouse brain at 9.4 T. Further advantages in SNR emerge from the use of phased array coils, which are now commercially available for most field strengths/frequencies used for animal research.

Animal MRI systems feature higher magnetic field strengths, smaller bore sizes, and stronger gradient systems than most human MRI systems. The relative merits of high versus low magnetic fields are still a matter of debate, even for localized proton MRS in vivo [181-185]. Fig. 2 demonstrates complementary advantages of a low and high magnetic field strength for the resolution of individual (spin-coupled) metabolite resonances. At $2.35 \mathrm{~T}$, proton spectra of a mixture of myo-inositol (Ins) and creatine $(\mathrm{Cr})$ have a superior peak intensity ratio due to the apparent singlet resonance of Ins which translates into a better relative detectability at low magnetic fields. Conversely, proton spectra of a mixture of $\mathrm{N}$-acetylaspartate (NAA), glutamate (Glu), and glutamine (Gln) demonstrate that the improved separation of the Glu $(2.35 \mathrm{ppm})$ and Gln multiplets $(2.45 \mathrm{ppm})$ at $9.4 \mathrm{~T}$ leads to a better detectability at high magnetic fields. In order to fully exploit the advantage of a larger chemical shift dispersion, it is recommended to use advanced shimming techniques such as FASTMAP [186] in conjunction with sufficiently strong shim currents.

In general, high magnetic field strengths offer a gain in SNR that may be best realized with the use of short echo time MRS acquisitions. This advantage allows for the investigation of small VOIs that are required for cerebral subregions such as the mouse hippocampus. On the other hand, proton MRS of larger animals may successfully be performed at lower fields as demonstrated for nonhuman primates which have mainly been studied in clinical systems at $1.5 \mathrm{~T}$ [106108,110-115,117-119,123-125,127,128] and 3.0 T [116,129].

\subsection{Localization}

The first in vivo MRS studies of animal brain were carried out without spatial localization and therefore suffered from a variety of systematic problems. Typically, surface coils were either placed directly on the brain or skull or even chronically implanted, for example see studies of mice [187-190], rats [191-195], gerbils [196-199], guinea pig [200], rabbits [201-206], cats [207-209], dogs [210-215], sheep [216,217], and swine [218-220]. Because the sensitivity profile of the surface coil alone is not sufficient to properly focus on a particular VOI and to exclude signal contamination from surrounding tissue, such studies remained a historic episode that ended with the advent of single-voxel localized MRS [151-155] and chemical shift imaging [221-223] also termed magnetic resonance spectroscopic imaging (MRSI). In either case, the actual localization of a VOI or reduced field-of-view for spectroscopic imaging is commonly accomplished with the use of a PRESS or STEAM sequence as schematically indicated in Fig. 3. For proton MRS, these sequences are preceded by a water suppression module such as the generic CHESS method [224], that is a water-selective RF excitation pulse followed by a spoiler gradient. Relative advantages and drawbacks of MRS versus MRSI and PRESS versus STEAM have been discussed elsewhere [225-229]. Because all techniques may perform high-quality proton MRS in vivo when properly used, other non-technical issues such as the quantification of metabolite concentrations (rather than the observation of resonance intensity ratios) are more important in view of the achievable neurochemical insight or long-term medical impact.

In general, the aforementioned techniques ensure adequate spatial resolution for studies of regional brain metabolism in anesthetized animals. With regard to field strength, investigations of mice have been remarkably improved by high magnetic fields. For a reasonable SNR and measuring times of $15 \mathrm{~min}$, the minimum VOI for high-field proton MRS is on the order of $1 \times 1 \times 1 \mathrm{~mm}^{3}$ or $1 \mu \mathrm{l}$. Even smaller structures such as pure white 


\section{PRESS}
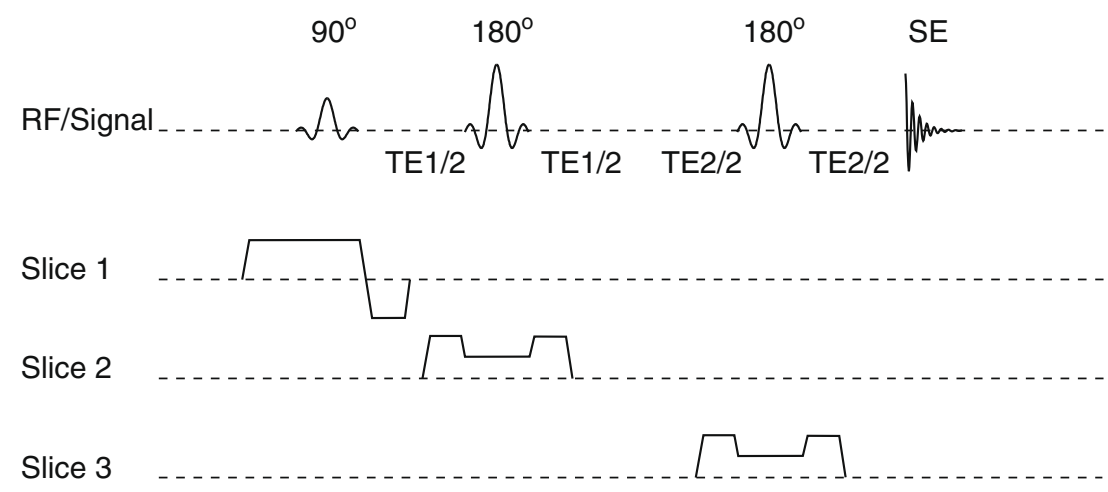

\section{STEAM}
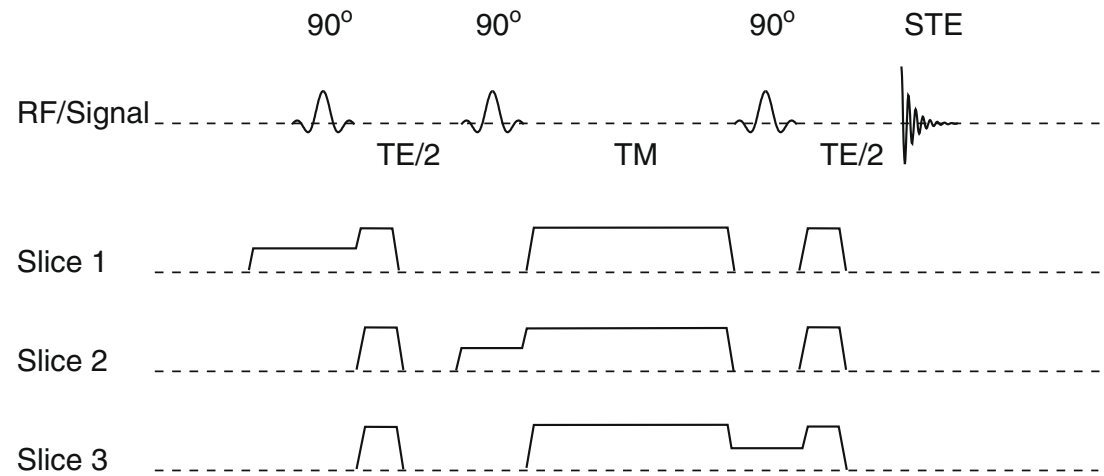

Fig. 3. Generic localization sequences for in vivo proton MRS using spin echoes (PRESS) or stimulated echoes (STEAM).

matter in the mouse corpus callosum would require a VOI of $250 \times 100 \times 500 \mu \mathrm{m}^{3}$ which further attenuates the SNR by a factor of 80 and therefore causes unrealistic measuring times. It is impossible that higher magnetic fields are able to solve this limitation, because current magnets are already close to the technical limit of about $20 \mathrm{~T}$. Moreover, field-dependent increases in $T_{1}$ and decreases in $T_{2}$ relaxation times partly counterbalance the enhanced spin polarization and compromise the achievable gain in SNR per unit time.

\subsection{Metabolites}

A large number of cerebral metabolites has been identified in localized proton MR spectra of animal brain in vivo [230-237]. Under normal physiological conditions the frequency range between 1 and 4 ppm comprises resonances of lactate (Lac), alanine (Ala), acetate, NAA, $\mathrm{N}$-acetylaspartylglutamate (NAAG), $\gamma$-aminobutyric acid (GABA), Glu, Gln, aspartate (Asp), Cr, phosphocreatine ( $\mathrm{PCr}$ ), choline-containing compounds (Cho), taurine (Tau), glucose (Glc), Ins, scyllo-inositol, glycine, glutathione, phosphoethanolamine, vitamin $\mathrm{C}$, and threonine as well as of macromolecules (MM) and (un)-saturated lipids. Under pathological conditions or after drug administration additional metabolites may become detectable including ethanol, methanol, glycerol, acetone, propan-1,2-dyol, guanidinoacetate, pyruvate, and succinate (Suc). The list of detectable metabolites also includes compounds with resonances in the aromatic part of the proton MR spectrum, that is beyond $5 \mathrm{ppm}$.

Often NAA and NAAG (tNAA), $\mathrm{Cr}$ and $\mathrm{PCr}(\mathrm{tCr})$, and Cho are considered as "major" metabolites. This is mainly due to their relatively high concentrations and the singlet nature of their methyl resonances. Together these features lead to a certain ease of detec- tion even at long echo times and/or low SNR. Similar arguments apply to the doublet resonance signal from Lac when its concentration increases above normal physiological levels. Short echo times facilitate the direct observation of additional resonances from Ins, Glu, and Gln, and in some cases also of Glc (e.g., at low fields in rodents and monkey brain) and Tau (e.g., at high fields in mouse brain).

Most of these metabolites are involved in important physiological processes and often represent a specific cell type. Thus, disease-related alterations of respective metabolite levels may reflect both changes in intracellular metabolism and tissue composition. For example, the metabolite pattern may be characteristic for the cerebral energy status, the glial cell population, or the neuroaxonal integrity and function. Briefly, NAA has been demonstrated to be predominantly localized within neurons [238-243] and is commonly considered as a marker for vital neuroaxonal tissue. The energy metabolites $\mathrm{Cr}$ and $\mathrm{PCr}$ are linked to oxidative phosphorylation and mitochondrial function and are constituents of both neuronal and glial cells [240]. A pathological loss of neurons as suggested by reduced NAA therefore causes a similar reduction of $\mathrm{tCr}$ unless compensated for by increased glial cell density (e.g., due to reactive astrogliosis). Elevated concentrations of Lac indicate enhanced nonoxidative glucose consumption, not only in brain cells but also due to the anaerobic metabolism of infiltrating macrophages (e.g., during neurodegeneration). The Cho resonance comprises phosphocholine as a precursor for membrane synthesis as well as glycerophosphocholine as the corresponding membrane degradation product. Accordingly, elevated Cho concentrations may either arise from enhanced membrane turnover (e.g., during development or in brain tumors) or from accumulation of myelin breakdown products (e.g., during active demyelination). A diminished Cho level has been described in Pelizaeus- 
Merzbacher disease due to hypomyelination [244]. Finally, Ins arises from free myo-inositol, which is the most important nonnitrogenous organic osmolyte in the brain with very high concentrations in astrocytes [239]. Thus, elevated Ins concentrations are most often interpreted as increased cellular density of astrocytes (e.g., due to astrocytosis or in glial tumors).

In view of their manifold roles it is not surprising that even the limited set of MRS-detectable metabolites allows for a biochemically relevant and medically important characterization of brain tissue under physiological and pathological conditions. This has been discussed in detail for both humans [156-163] and animals [164-180]. Here, a closer insight into possible metabolic pathways will be confined to the disease models presented in subsequent sections.

\subsection{Quantification}

In order to facilitate a sound interpretation of MRS findings, it is preferable to translate the observation of a spectroscopic alteration into a biochemical quantity such as a metabolite concentration. Thus, a first desirable step is the minimization of $T_{1}$ and $T_{2}$ effects during data acquisition. Similar to relaxation effects in MRI that give rise to pathological contrast, also metabolite relaxation times are usually altered in a disease condition. To avoid time-consuming measurements of the actual relaxation times for corrections of $T_{1}$ and $T_{2}$-weighted spectra, it is therefore advisable to choose suitable acquisition parameters such as long repetition times ( $T R \geqslant 5 \times T_{1}$ ) and short echo times ( $\mathrm{TE} \ll T_{2}$ ). Because long TR values result in excessive measuring times for MRSI, this strategy is only applicable to single-voxel MRS. Spatial mapping of metabolite distributions by MRSI and quantitative evaluations of metabolite concentrations by single-voxel MRS are therefore complementary strategies for investigating brain metabolites.

A second step during data analysis is to avoid the use of relative peak heights or intensities (areas) of individual resonances. Although in some cases the use of metabolite ratios (e.g., relative to $\mathrm{tCr}$ ) might be sufficient to qualitatively identify a neurochemical disturbance, many pathologies involve alterations in cellular density and therefore affect the $\mathrm{tCr}$ level as well. Ratios therefore bear the risk of missing simultaneous concentration changes.

A third important step toward metabolite quantification is an attempt to obtain absolute concentrations with the use of an internal (e.g., brain tissue water) or external reference. In humans, several approaches have been developed to quantify cerebral metabolite concentrations for homogeneous RF coils [245-250]. With appropriate adjustments these methods may also be adapted to surface coils [62] or even phased array coils [251]. Finally, spectral evaluations should be performed in an objective manner, that is fully automatic and without user interference. Available software packages such as LCModel [252,253] supply estimated metabolite concentrations as well as measures of reliability (e.g., Cramer-Rao lower bounds). Some general conditions for MRS quantitation have recently been reviewed for human studies [254].

\subsection{Summary}

State-of-the-art localized proton MRS of animal brain in vivo requires the consideration of a number of technical components: (i) the design of an appropriate experimental setup; (ii) the optimization of a short echo time MRS or MRSI localization technique based on PRESS or STEAM; (iii) a calibration method for quantification of metabolite concentrations; (iv) an objective and reliable spectral evaluation method. In addition, a sound interpretation of MRS findings strongly depends on a profound understanding of the physiological functions of MRS-detectable metabolites.

\section{Mouse models}

The first proton MRS studies of mouse brain in vivo were performed without spatial localization by placing a surface coil on the skull or even directly onto the exposed brain [187-190]. Despite residual contributions from superficial skin, muscle, and fat, this simple approach allowed for investigations of the mouse brain metabolism that paved the way to fully localized acquisition techniques and the analysis of more sophisticated (genetic) mouse models. In fact, the very first study in 1986 already dealt with an inborn error of metabolism by comparing the normal cerebral metabolite profile with that of mutant histidinaemic mice [187]. Further examples refer to a mouse model of scrapie [188], a transgenic mouse overexpressing the human ornithine decarboxylase gene [189], and a mouse model of Duchenne muscular dystrophy [190]. Although these studies demonstrated the unique potential of proton MRS in vivo, the need for technical improvements in small animal MRS as well as the only more recent availability of genetically modified animals hampered the development of mouse brain MRS for about a decade. Fig. 4 shows the results of a feasibility study from 1998 which for the first time offered fully localized proton MRS of the normal and ischemic mouse brain [1].

\subsection{Normal physiology}

Localized proton MR spectra of normal mouse brain are depicted in Fig. 5 for two different field strengths. The list of readily accessible metabolites includes tNAA, $\mathrm{tCr}$, Cho, Ins, Glc, Tau, and Glu. While low fields (here $2.35 \mathrm{~T}$ ) facilitate the detection of Ins and Glc because their strongly spin-coupled multiplets merge into apparent singlet resonances, the identification of Tau and Glu (separated from $\mathrm{Gln}$ ) is more easily achieved at high fields (here 9.4 T) yielding improved spectral resolution due to the enhanced chemical shift dispersion. On the other hand, the increasing linewidths at higher fields are generally larger than most coupling constants and, for example, preclude the resolution of the weakly coupled doublet resonances obtained for Lac ( $7 \mathrm{~Hz}$, centered at $1.33 \mathrm{ppm}$ ) and Ala ( $7 \mathrm{~Hz}$, centered at $1.48 \mathrm{ppm}$ ) which is easily achieved at lower fields. Accordingly, the neurochemically important determination of the Lac concentration may be complicated by competing contri-

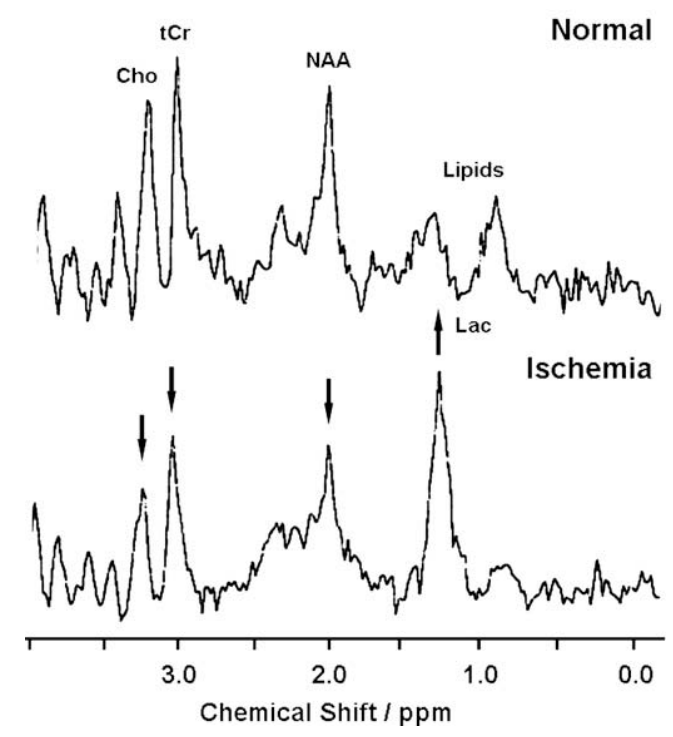

Fig. 4. Feasibility of localized proton MRS of mouse brain in vivo (4.7 T, PRESS, TR/ $\mathrm{TE}=2500 / 20 \mathrm{~ms}, 2 \times 2 \times 2 \mathrm{~mm}^{3}, 128$ accumulations). This early application corresponds to the normal and ischemic hemisphere of a C57BL/6J mouse $3.5 \mathrm{~h}$ after occlusion of the middle cerebral artery. The accumulation of Lac is accompanied by decreases of NAA, tCr, and Cho (arrows). Adapted from Ref. [1] with permission. 

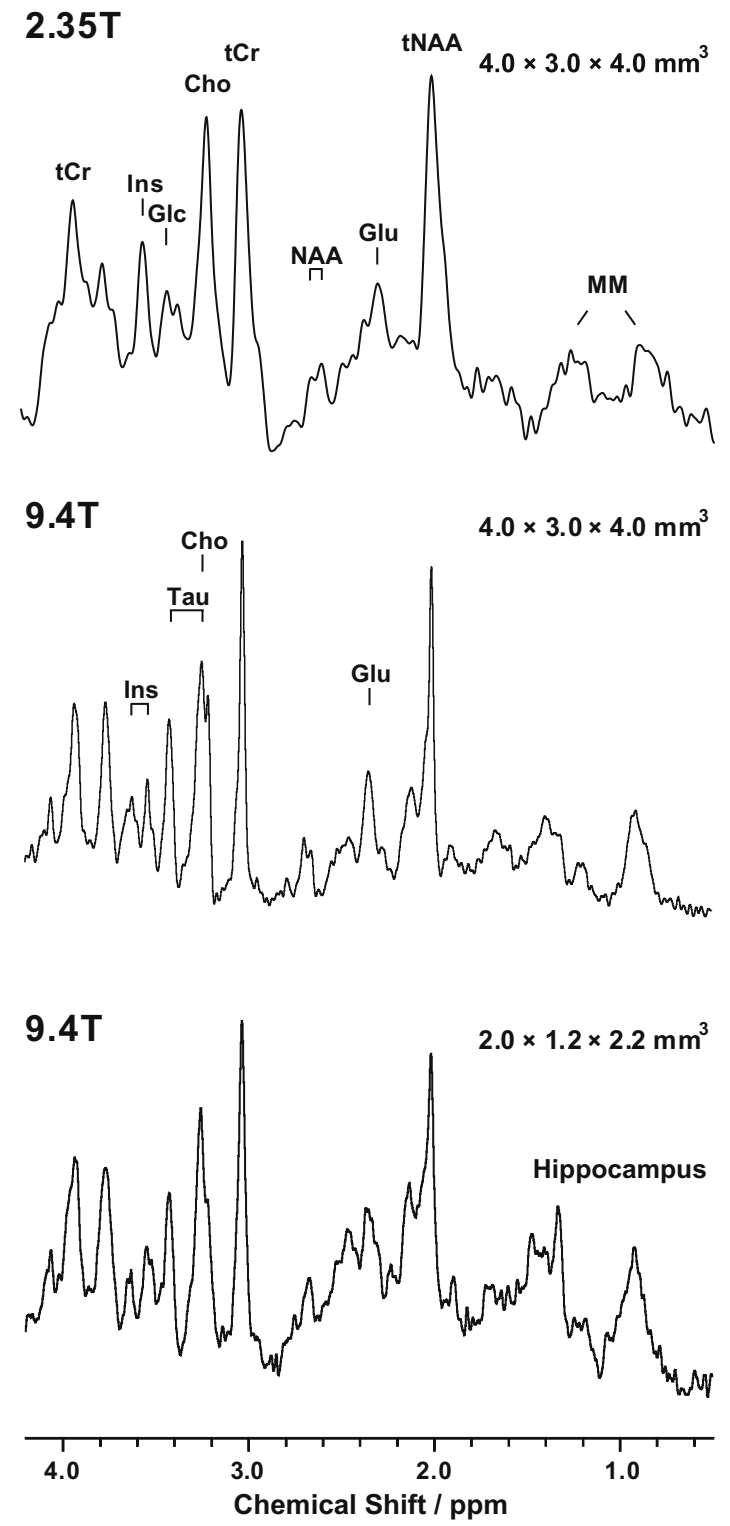

Fig. 5. Localized proton MRS of mouse brain in vivo (NMRI) at different field strengths. In comparison to low field acquisitions $(2.35 \mathrm{~T}$, STEAM, TR/TE $=6000$ / $20 \mathrm{~ms}, 4.0 \times 3.0 \times 4.0 \mathrm{~mm}^{3}, 512$ accumulations) the use of a high field $(9.4 \mathrm{~T}$, STEAM, TR/TE $=6000 / 10 \mathrm{~ms}$ ) allows for either a much lower number of accumulations (32 accumulations) or a much smaller volume $\left(2.0 \times 1.2 \times 2.2 \mathrm{~mm}^{3}\right.$ covering the hippocampus) at still reduced measuring time (128 accumulations). Metabolite resonances refer to tNAA, Glu, tCr, Cho, Ins, Tau, Glc, and MM.

Table 1

Proton MRS linewidths of mouse brain in vivo for different magnetic field strengths (in T) and volumes-of-interest (VOI).

\begin{tabular}{llll}
\hline Field/T & $\mathrm{VOI} / \mathrm{mm}^{3}$ & Linewidth $/ \mathrm{Hz}$ & Reference \\
\hline 2.35 & $4.0 \times 3.0 \times 4.0$ & $7-9$ & {$[8]$} \\
4.7 & $3.4 \times 1.7 \times 1.7$ & 18 & {$[17]$} \\
4.7 & $6.0 \times 3.5 \times 3.0$ & 11 & {$[2]$} \\
7.0 & $2.0 \times 2.0 \times 2.2$ & $13-17$ & {$[29]$} \\
9.4 & $2.0 \times 1.5 \times 2.5$ & $10-14$ & {$[12,28]$} \\
9.4 & $1.5 \times 1.5 \times 1.5$ & $12-20$ & {$[21]$} \\
9.4 & $2.5 \times 2.5 \times 2.5$ & 20 & {$[18]$} \\
\hline
\end{tabular}

butions from the methyl and methylene resonances of mobile lipids and/or macromolecules. Table 1 summarizes the linewidths of water proton resonances that have been reported for mouse brain in vivo in a number of experimental settings. The values range from $7 \mathrm{~Hz}(2.35 \mathrm{~T})$ to $20 \mathrm{~Hz}(9.4 \mathrm{~T})$ depending on field strength

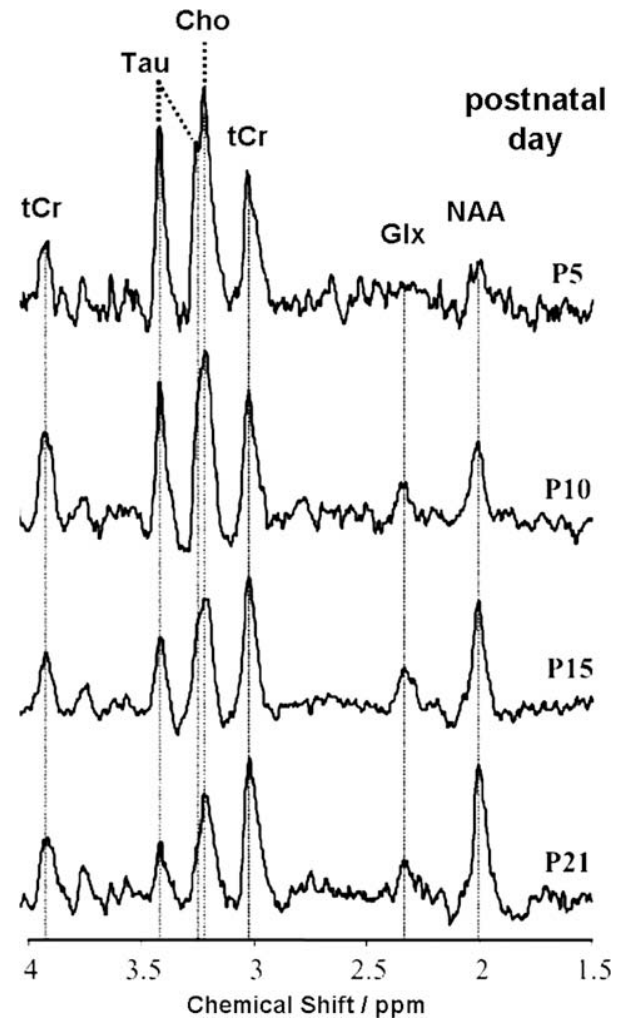

Fig. 6. Mouse brain in vivo (C57BL/6-SJL) during maturation. Localized proton MRS (9.4 T, PRESS, TR/TE $=2000 / 130 \mathrm{~ms}, 2 \times 2 \times 2 \mathrm{~mm}^{3}, 512$ accumulations) of the thalamus as a function of postnatal age (days 5-21) reveals spectral alterations such as an increase of NAA and decrease of Tau. Adapted from Ref. [21] with permission.

and size of the VOI. Further influences are due to regional differences in selected brain areas and may also reflect the investigated mouse strain. In general, the most important advantage of a high field is the enhanced spin polarization which may be translated into a better SNR. This gain provides access to adequately small VOIs that allow for a meaningful metabolic assessment of mouse brain structures such as the hippocampal formation (compare Fig. 5).

Proton MRS has been used to monitor metabolic alterations during brain maturation in the mouse thalamus, olfactory bulb, and cerebellum [21]. Fig. 6 shows serial proton MR spectra from the thalamus for postnatal days 5-21 that reveal increased NAA and Glx signals as well as decreased Cho and Tau resonances as a function of age. After correcting for significantly increased $T_{2}$ relaxation times, the alterations may be assumed to reflect true changes in metabolite concentration. In fact, similar changes of NAA, Cho, Tau, and Glx concentrations during brain maturation were found in rats and humans. Between 4 and 24 months of age the NAA/ $\mathrm{tCr}$ ratio in mouse brain was reported to remain unchanged [17] or to be slightly reduced [18]. In adult mice, regional concentration differences of cerebral metabolites have been reported either in terms of metabolite ratios to $\mathrm{tCr}$ as obtained by proton MRSI $[22,23]$ or, more directly, as absolute metabolite concentrations by quantitative proton MRS [10,12,21]. Localized proton MR spectra of the mouse cerebral cortex, hippocampus, striatum, and cerebellum are compared in Fig. 7 [12]. Qualitatively, the respective metabolite profiles exhibit a close similarity to those observed in other mammals such as rats, monkeys, and humans.

It should be noted that subtle though distinct differences exist between different mouse strains. Several authors compared metabolite levels in NMRI, BALB/c, and C57BL/6 mice [8], CBA, CBA/BL6, and $\mathrm{C} 57 \mathrm{BL} / 6$ mice [12], and $129 / \mathrm{SvJ}, \mathrm{FVB} / \mathrm{N}$, and $\mathrm{C} 57 \mathrm{BL} / 6$ mice [27]. The finding of different metabolic endophenotypes is of partic- 

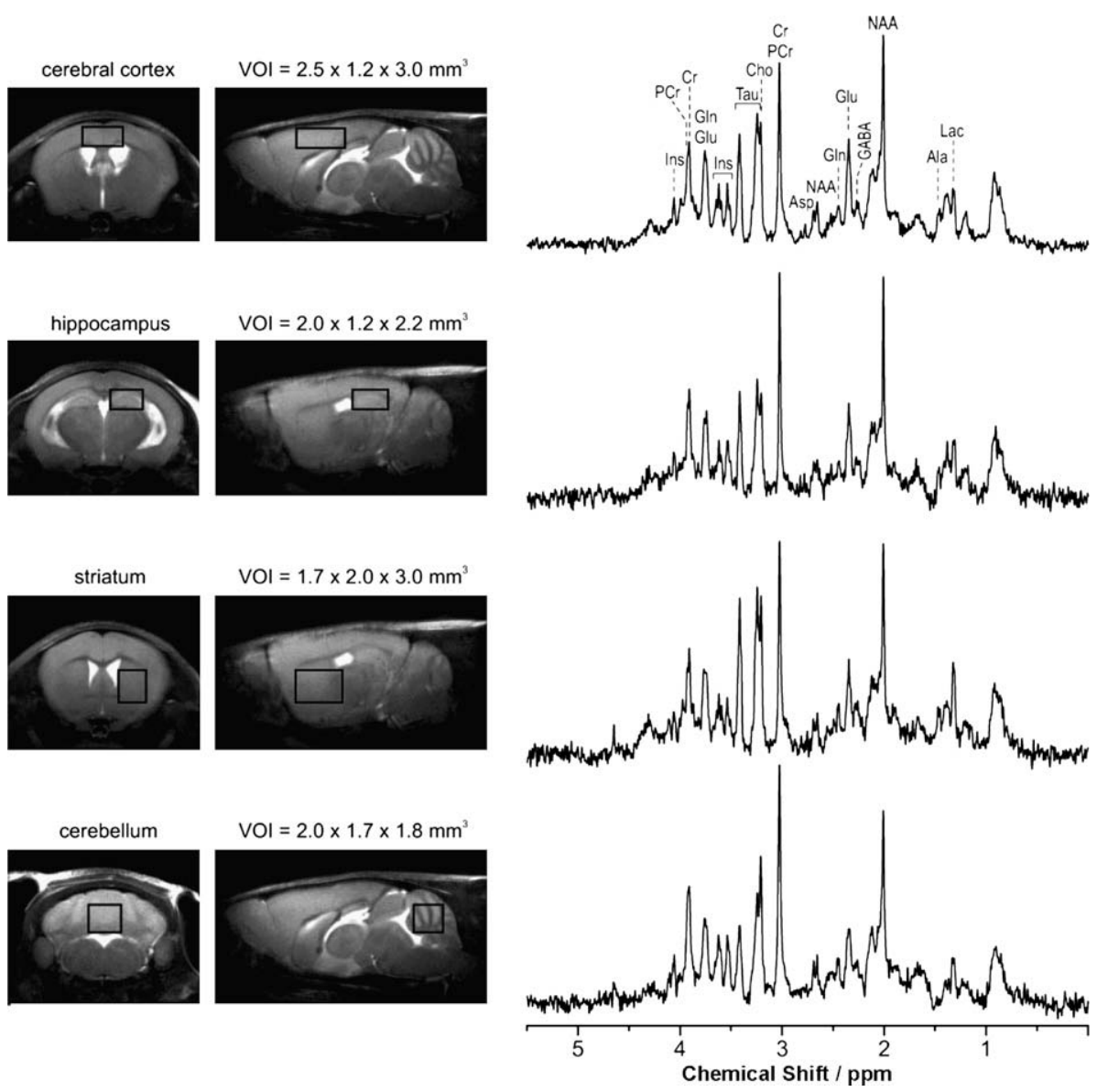

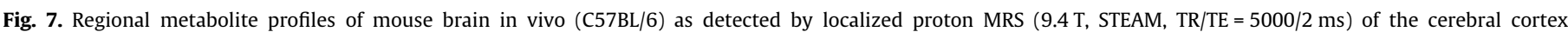

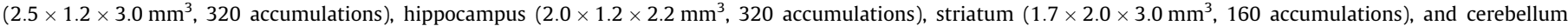
$\left(2.0 \times 1.7 \times 1.8 \mathrm{~mm}^{3}, 320\right.$ accumulations $)$. Adapted from Ref. [12] with permission.

ular importance as the aforementioned strains of inbred mice are popular background strains for the genetic engineering of mouse models. As an example, Fig. 8 compares in vivo and early postmortem proton MR spectra of the brain of NMRI, BALB/c, and C57BL/6 mice [8]. While MRI volumetry of the C57BL/6 strain yielded the largest ventricular spaces, proton MRS resulted in elevated concentrations of tNAA, tCr, Cho, Glc, and Lac relative to BALB/c mice and elevated Glc relative to NMRI mice. Significant morphological and metabolic heterogeneity was also reported for the $129 / \mathrm{SvJ}, \mathrm{FVB} / \mathrm{N}$, and C57BL/6 mouse strains [27]. MRI volumetry not only confirmed the enlarged ventricular volume of the $\mathrm{C} 57 \mathrm{BL} / 6$ strain, but in addition revealed significant alterations in cerebellar and hippocampal volume as well as differences in the thickness of the motor cortex. As far as metabolite levels are concerned, only metabolite ratios to $\mathrm{tCr}$ were reported, but the results are again in line with previous observations [8] yielding the highest $\mathrm{tCr}$ level and lowest $\mathrm{NAA} / \mathrm{tCr}$ ratio in the C57BL/6 strain. In CBA, CBA/BL6, and C57BL/6 mice striatal concentration differences for Lac, NAAG, Glu, Gln, Ins, and phosphoethanolamine were found to be small [12].

In summary, in vivo metabolite concentrations that have been reported for mice as a function of age, brain region, and strain are in good agreement with values determined by in vitro proton NMR spectroscopy of brain tissue extracts [255-258] and qualitatively similar to the metabolite profiles of other mammal brains.

\subsection{Cerebral ischemia}

Cerebral ischemia refers to a condition where the brain or parts of it do not receive sufficient blood flow (i.e., oxygen and glucose) to maintain normal physiological function. Decreased blood flow may be caused by blockage or obstruction of the supplying arterial vessels. If severe or prolonged, brain ischemia results in an acute stroke leading to unconsciousness, tissue damage, or death.

In a C57BL/6 mouse model of focal cerebral ischemia, Fig. 4 demonstrates a pronounced increase of Lac in the affected brain hemisphere and a distinct decrease of NAA $2 \mathrm{~h}$ after occlusion of the middle cerebral artery. The lack of oxygen supply causes a failure of the energy metabolism which involves a switch from oxidative phosphorylation to nonoxidative glucose consumption. This latter process utilizes local glygocen stores and produces Lac. The concomitant spectral reductions of Cho and $\mathrm{tCr}$ may be understood as a dilution of all metabolites due to the developing vasogenic edema which widens the extracellular space by influx of water from the capillary bed [1]. These responses to ischemia are in line with a quantitative study of global ischemia in C57BL/6 mice $1 \mathrm{~h}$ after cardiac arrest as shown in Fig. 8. Noteworthy, apart from the unavoidable changes in Glc and Lac concentrations, no significant reductions of tNAA, $\mathrm{tCr}$, and Cho are observed in BALB/c and NMRI mice [8]. The results support the hypothesis that the enhanced vulnerability of C57BL/6 mice to cerebral ischemia is linked to strain-dependent differences of the cerebral energy metabolism and/or the formation of edema.

In view of the tremendous amount of work on cerebral ischemia using rat models, new insights are required to justify the use of respective mouse models. A novel line of research could possibly arise from transgenic mice that are designed to model specific pathophysiological processes and neurochemical alterations in response to ischemia. 


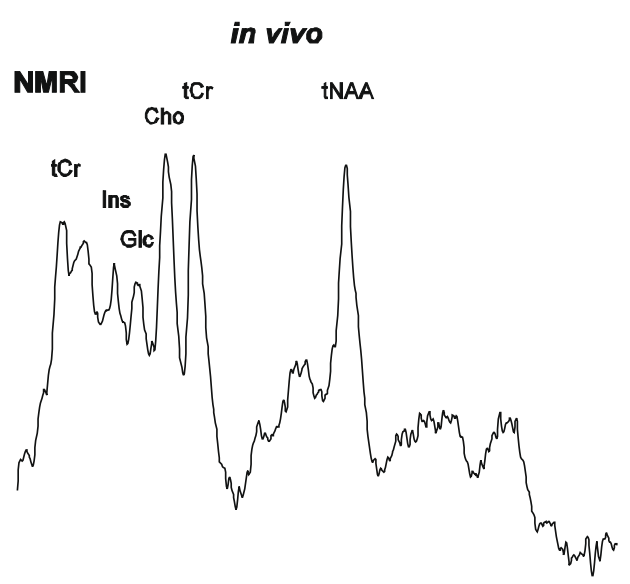

BALB/C
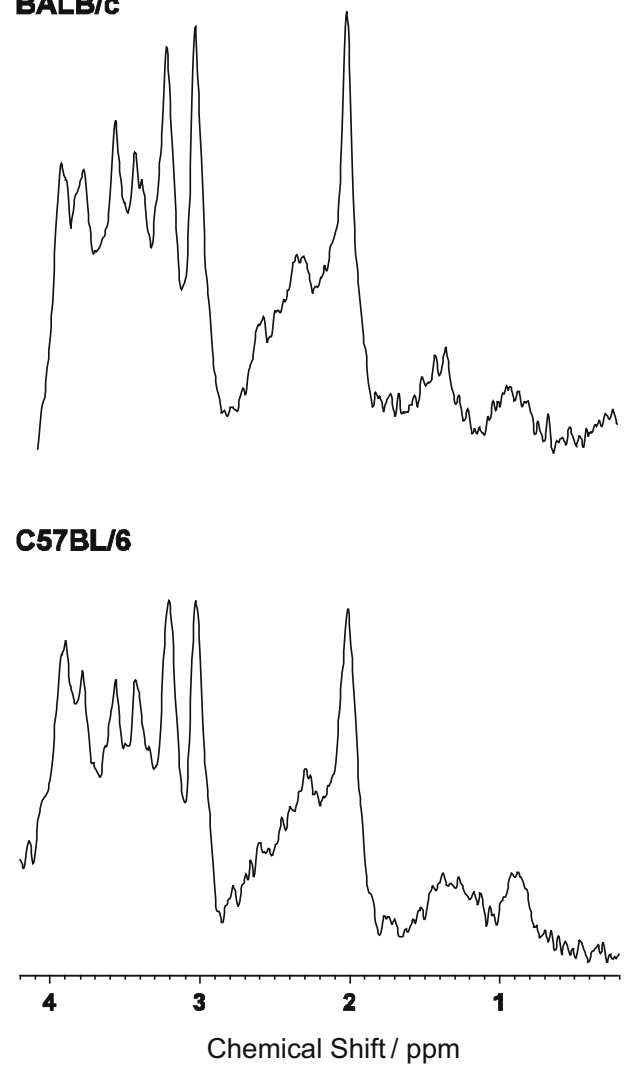

post mortem
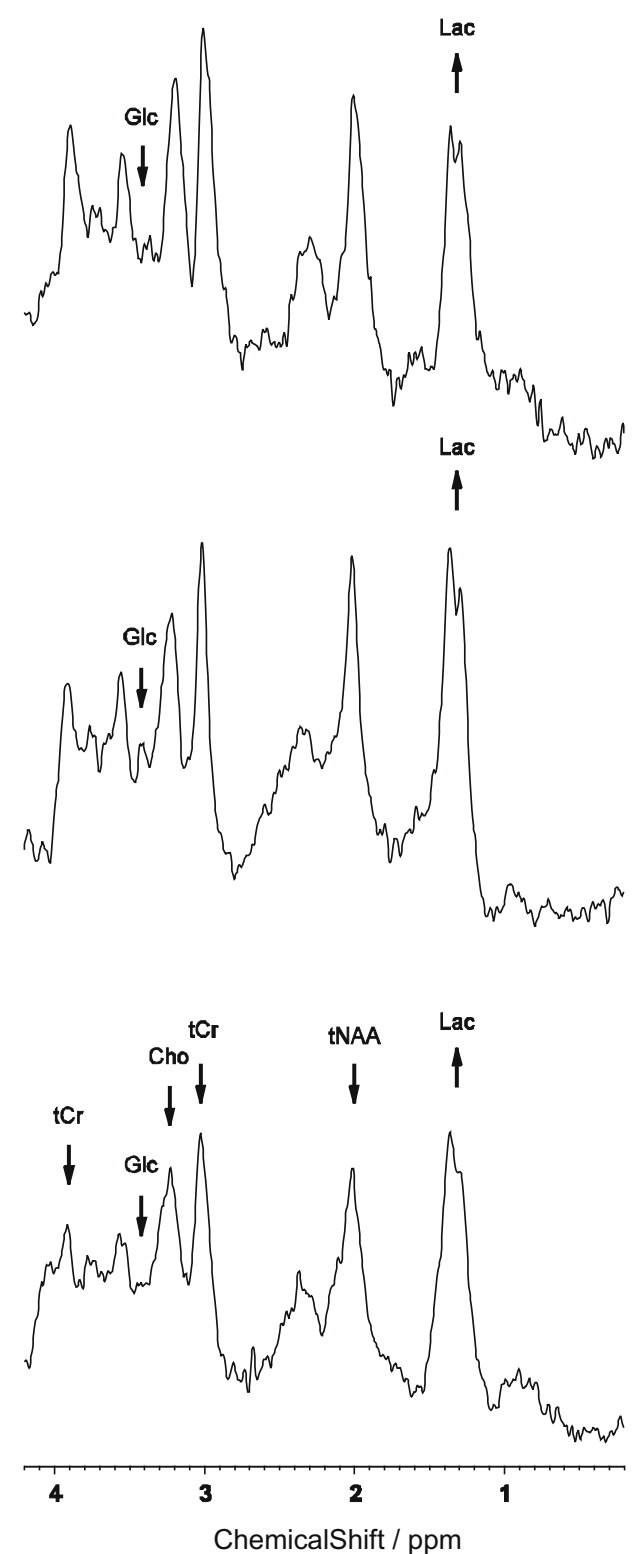

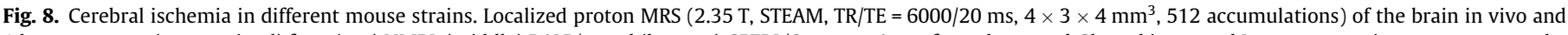

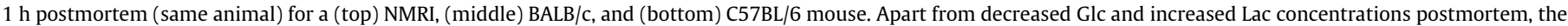

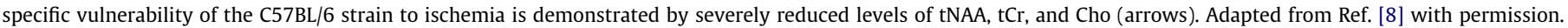

\subsection{Multiple sclerosis}

In humans, proton MRS is widely used to elucidate brain lesions in multiple sclerosis. The pathophysiology of multiple sclerosis is characterized by inflammation, demyelination, and axonal damage. Although the exact etiology is still unknown and subject of ongoing research, a large variety of animal models ranging from monkeys to mice have been developed that mimic the pathologic conditions of multiple sclerosis. The most frequently used animal model of multiple sclerosis is experimental allergic encephalomyelitis (EAE) which in rodents leads to inflammatory demyelination mainly in the spinal cord. Because of a lack of EAE mouse models with robust cerebral involvement, most in vivo studies address morphological alterations using MRI rather than disturbances of tissue metabolism or cellular composition using MRS. To partially overcome this problem Theiler's murine encephalitis virus infec- tion, an established model of demyelinating diseases, has been investigated in C57BL/6J mice [259]. At 3-7 days after intracerebral virus injection serial $T_{1}$-weighted MRI and proton MRS (spectra not shown) revealed periventricular and parahippocampal hypointense lesions with decreasing $\mathrm{NAA} / \mathrm{tCr}$ and $\mathrm{Cho} / \mathrm{tCr}$ ratios. Normalization of the MRI hypointensities 45 days after injection was accompanied by a normalization of the NAA/tCr and Cho/ $\mathrm{tCr}$ ratios, suggesting active regeneration.

In order to further advance our knowledge of the mechanisms regulating disease progression and tissue repair in multiple sclerosis, more correlations of proton MRS in vivo and histopathologic assessments are warranted. Pertinent studies may range from conventional mouse models of reversible demyelination (e.g., after feeding of the toxin cuprizone) to highly specific transgenic models of selected pathophysiologic mechanisms that lead to demyelination and/or axonal damage. 


\subsection{Parkinson's disease}

Parkinson's disease is a chronic motor system disorder which results from a progressive loss of dopamine-producing cells in the substantia nigra. The reduced level or even lack of dopamine leads to a generalized slowness of movements (bradykinesia), muscular rigidity, and tremor which is most noticeable during rest.

Degeneration of nigrostriatal dopaminergic neurons as the pathologic hallmark of Parkinson's disease can be induced by 1methyl-4-phenyl-1,2,3,6-tetrahydropyridine (MPTP) intoxication $[15,24]$. Quantitative proton MRSI in MPTP-treated mice demonstrated a significantly decreased NAA concentration on days 2 and 6 after MPTP injection in the substantia nigra pars compacta and striatum, regions most affected in human disease. More interestingly, MPTP-intoxicated mice that received immune cells (recovered from copaxone-vaccinated animals) presented with similar NAA levels as found in sham-treated animals, whereas adoptive transfer of immune cells from ovalbumin-immunized animals to MPTP-treated mice failed to prevent lower NAA levels and to protect dopaminergic neurons and their projections [15].

Another proton MRS study reported increased striatal $\mathrm{Lac} / \mathrm{tCr}$ ratios as quickly as $2 \mathrm{~h}$ after MPTP injection which returned to basal levels $7 \mathrm{~h}$ after injection [24]. Pre-treatment with deprenyl, a monoamine oxidase B inhibitor, or with GBR-12909, a dopamine uptake inhibitor, almost completely attenuated both the increases in striatal $\mathrm{Lac} / \mathrm{tCr}$ ratios and the subsequent loss of dopaminergic nerve terminals in MPTP-treated mice [24]. These results suggest the potential of proton MRS to detect metabolic alterations in Parkinson's disease and monitor disease progression and treatment.

\subsection{Huntington's disease}

A relatively large number of proton MRS studies has been performed in transgenic mouse models of Huntington's disease. The progressive neurodegenerative disorder is due to a genetic defect of a lengthened cytosine-adenosine-guanosine (CAG) sequence, which codes for an expanded polyglutamine tract in the huntingtin protein. Several transgenic mouse models have been developed that differ in CAG repeat length. For example, N171-82Q mice with 82 CAG repeats exhibit a progressive neurological phenotype at about 3 months of age with a mean death shortly after $[6,19]$. Mice of the R6/1 line with 111-121 CAG repeats show progressive symptoms by 4-5 months of age and therefore serve as an adult-onset model [3]. The more intensively studied R6/2 mice with 150 CAG repeats develop first behavioral symptoms at about 1-2 months and are considered to model juvenile-onset Huntington's disease [2,13,19,28]. In all studies, proton MRS is employed to assess the neurochemical profile of the striatum during disease progression.

Longitudinal measurements of relative metabolite ratios in the juvenile R6/2 mouse model revealed a pronounced nonlinear drop of striatal NAA levels starting at about 6 weeks of age coincident with the onset of symptoms. Histopathology after natural death demonstrated that the in vivo $\mathrm{NAA} / \mathrm{tCr}$ reduction did not reflect neuronal death but neuronal dysfunction [2]. Decreased striatal NAA levels were also found in other proton MRS studies, while Cho and/or $\mathrm{tCr}$ levels were not altered in R6/1 mice [3] and elevated in R6/2 mice $[13,28]$. As demonstrated in Fig. 9, the severity of the NAA reduction strongly correlated with the CAG repeat length as well as with the levels of gene expression and protein context [19].

Behavioral testing and proton MRS have been used to assess therapeutic effects of various drugs in transgenic mouse models of Huntington's disease. Thus, daily administration of CGS21680, an $A_{2 A}$ adenosine receptor-selective agonist, improved the motor performance, prevented a reduction of brain weight, and normalized elevated blood glucose levels in the R6/2 mouse. It also significantly reduced the increased Cho levels in the striatum, but failed

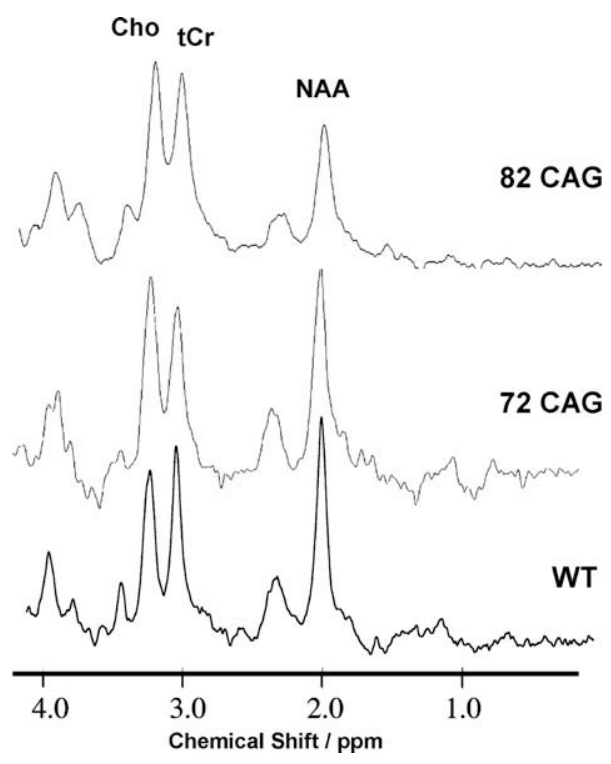

Fig. 9. Transgenic mouse model of Huntington's disease. Localized proton MRS (4.7 T, PRESS, TR/TE $=2000 / 136 \mathrm{~ms}, 6.0 \times 3.5 \times 3.0 \mathrm{~mm}^{3}, 256$ accumulations) of the striatum of a N171-82Q mouse with 82 cytosine-adenosine-guanosine (CAG) repeats, a YAC72 mouse with 72 CAG repeats (low expression level), and a wildtype (WT) YAC mouse. The NAA/tCr ratio decreases with increasing length of CAG repeats. Adapted from Ref. [19] with permission.

to prevent the decrease of the NAA/tCr ratio [13]. Neuroprotective effects of creatine were observed in N171-82Q and R6/2 animals. Dietary creatine supplementation not only significantly increased brain $\mathrm{tCr}$ concentrations and delayed decreases in NAA, but also improved survival, slowed down the development of brain atrophy, reduced the formation of intranuclear inclusions, and delayed the development of hyperglycemia. These results suggest a metabolic dysfunction in Huntington's disease which may benefit from therapeutic strategies that strengthen the energy metabolism in order to delay the pathologic process [6].

It has been noted that the neurochemical profile in the striatum of $6 / 2$ mice is rather distinct from those found in non-transgenic animal models of Huntington's disease [28]. For example, differences exist in comparison to the quinolinic acid rat model [73] and the 3-nitropropionic (3NP) acid monkey model [115]. A clarification of these findings requires further studies in different species but may open additional insights into progression and treatment of Huntington's disease.

\subsection{Alzheimer's disease}

Alzheimer's disease is an age-dependent neurodegenerative disorder that leads to a progressive decline of cognitive functions. Neuropathological hallmarks of Alzheimer's disease are amyloid plaques and neurofibrillary tangles in the central nervous system. So far, an unambiguous diagnosis is only possible postmortem. Because the increased life span is expected to dramatically enhance the number of affected patients, there is an urgent need for a surrogate marker that allows for an in vivo diagnosis of Alzheimer's disease. Even more importantly, such a marker would be a valuable tool in the preclinical evaluation of new drugs and, subsequently, for the assessment of treatment efficacy in individual patients. The neurochemical abnormalities of Alzheimer's disease have been studied by proton MRS in different transgenic mouse models $[11,17,18]$.

A first study [11] employed transgenic mice which express mutant forms of human amyloid precursor protein $\left(\mathrm{APP}_{\mathrm{Tg} 2576}\right)$. APP mice develop $\beta$-amyloid plaques throughout the cortex starting at 10 months of age. Though statistically not significant, proton 
MRS in vivo revealed alterations of the NAA/tCr, Cho/tCr, Glx/tCr, and $\mathrm{Tau} / \mathrm{tCr}$ intensity ratios at 19 months. In comparison to wildtype mice, in vitro NMR spectroscopy of APP mice demonstrated significant decreases of the $\mathrm{NAA} / \mathrm{tCr}$ and $\mathrm{Glu} / \mathrm{tCr}$ ratios and an increase of the $\mathrm{Tau} / \mathrm{tCr}$ ratio, while the Ins/ $\mathrm{tCr}$ ratio remained normal. Although elevation of Ins has been proposed as an early indicator of Alzheimer's disease in humans, this finding could not be confirmed.

In a second model of Alzheimer's disease [17] mice express mutant forms of human presenilin 2 (PS2) and APP (PS2APP). PS2APP mice develop severe amyloidosis in the neocortex including the hippocampus at 8 months of age. Serial proton MRS throughout the life span revealed stable $\mathrm{NAA} / \mathrm{tCr}$ and $\mathrm{Glu} / \mathrm{tCr}$ ratios during the first 12 months of age, but significantly decreased $\mathrm{NAA} / \mathrm{tCr}$ and $\mathrm{Glu} / \mathrm{tCr}$ ratios in 24-month-old animals. In line with the aforementioned study of Alzheimer's disease [11], differences of the Ins/ $\mathrm{tCr}$ ratio were not detected.

A third study [18] used mice which coexpress mutant human presenilin 1 (PS1) and amyloid- $\beta$ precursor protein (APP-PS1). Amyloid plaques start to appear at 3 months of age. Again, proton MRS of APP-PS1 mice at 16-23 months revealed reduced NAA/tCr and $\mathrm{Glu} / \mathrm{tCr}$ ratios with advanced age. In contrast to the former studies [11,17], this model also caused a strong increase of the Ins/tCr ratio as shown in Fig. 10. Because APP-PS1 mice develop plaques at a faster rate than APP mice, it cannot be excluded that APP mice with the same plaque load as found in 20-month-old APP-PS1 mice would also lead to elevated Ins/tCr ratios. Further research is needed to determine whether plaque load or genotype are responsible for an increased Ins/tCr ratio.

Interestingly, age-dependent changes of the cerebral metabolite profile observed in APP-PS1 mice closely resemble proton MRS results obtained in patients with probable Alzheimer's disease, e.g., see [260]. Although still a matter of controversy, the transgenic APP-PS1 mouse model seems to best match the neurochemical profile found in humans.

\subsection{Deficiencies of energy metabolism}

In vivo MRS studies of transgenic mouse models with altered high-energy phosphoryl transfer metabolism have recently been reviewed [180]. A prominent example is a knockout mouse model of guanidinoacetate methyltransferase (GAMT) deficiency. This phenotype had originally been discovered as "creatine deficiency" by in vivo proton MRS of a human patient $[261,262]$. As demon-
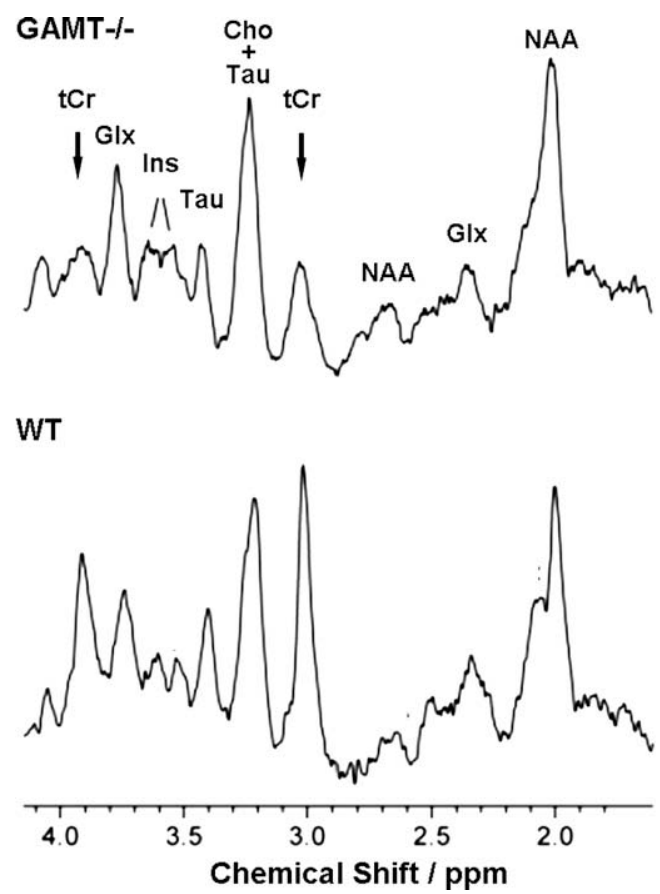

Fig. 11. Transgenic mouse model of guanidinoacetate methyltransferase (GAMT) deficiency. Localized proton MRS (7.0 T, STEAM, TR/TE $=5000 / 10 \mathrm{~ms}$, $3 \times 3 \times 3 \mathrm{~mm}^{3}, 64$ accumulations) of the brain of a guanidinoacetate methyltransferase-deficient (GAMT-/-) mouse demonstrates a dramatic loss in $\mathrm{tCr}$ (arrows) relative to a wild-type (WT) animal. Adapted from Ref. [9] with permission.

strated in Fig. 11, GAMT-deficient mice indeed suffer from markedly reduced brain $\mathrm{tCr}$ levels [9]. By combining in vivo and in vitro phosphorus and proton MRS of brain and muscle tissue it could be demonstrated that GAMT-deficient mice present with similar abnormalities as those found in human GAMT deficiency patients. The model therefore emerges as a valid tool for further investigations of the biosynthesis and intracellular transport of creatine. For example, a longitudinal study of creatine supplementation in GAMT-deficient mice indicated that creatine uptake is faster in skeletal muscle than in brain [29].

Another important enzyme for oxidative phosphorylation is creatine kinase $(\mathrm{CK})$. Transgenic mice that lack either the cytosolic isoenzyme (B-CK-l-) or the mitochondrial ubiquitous isoenzyme

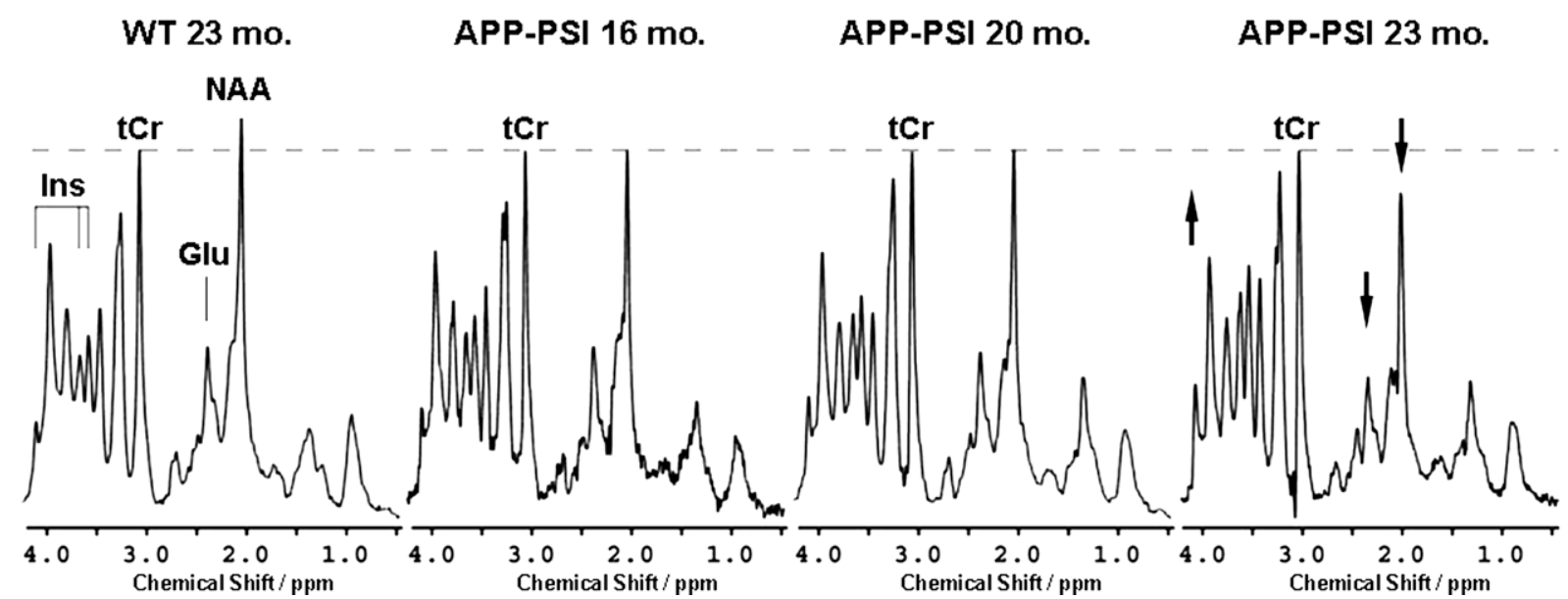

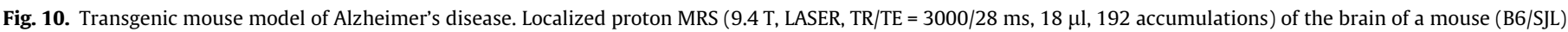

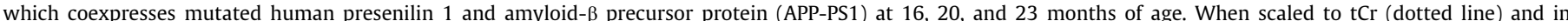

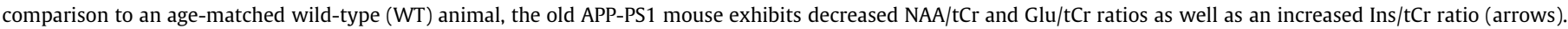
Adapted from Ref. [18] with permission. 
(UbCKmit-/-) have normal brain levels of PCr and adenosine triphosphate (ATP) as well as $\mathrm{tCr}$ and NAA as revealed by phosphorus and proton MRS, respectively [10]. In contrast, however, double knockouts $(\mathrm{CK}-/-)$ presented with extremely low $\mathrm{PCr}$ concentrations below detectability but otherwise normal high-energy phosphates [10]. Proton MRS of these animals detected a $20-30 \%$ decrease of $\mathrm{tCr}$ and a similar increase of NAA in all brain regions investigated. Both alterations are unexpected and raise new questions about physiological roles of $\mathrm{tCr}$ other than a mere function in energy metabolism. Similar arguments hold true for NAA. While elevated NAA levels may reflect alterations of its concentration in neurons and/or differences in the relative neuronal volume due to changes in cell size and/or cell type distribution, it has also been suggested that a concomitant NAA increase and $\mathrm{tCr}$ decrease may reflect a redistribution of cerebral osmolites [10]. These studies clearly point to the powerful role of mice in unravelling the genetic control of basic (and disturbed) in vivo physiology.

\subsection{Transgenic models of other diseases}

Amytrophic lateral sclerosis (ALS) is a severe neurodegenerative disease characterized by motor neuron loss. Transgenic mice with the G93A human superoxide dismutase mutation were proposed as an animal model of familial ALS. G93A mice develop progressive motor weakness starting at about 100 days of age. Rapid disease progression results in premature death after about 1 month. Proton MRS revealed increased Glx/tCr ratios in G93A mice brain at 80 and 115 days of age [7]. However, alterations of the NAA/tCr and Cho/ tCr ratios were statistically not significant. Creatine supplementation, starting at 4 weeks of age, significantly increased longevity and motor performance and attenuated the increases of the Glx/ $\mathrm{tCr}$ ratio at 80 days of age, but had no effect at 115 days of age [7]. The results are consistent with impaired Glu transport in the brain of G93A mice.

Rett syndrome is an X-linked neurologic disorder in which most patients carry a mutation in the gene encoding the methyl-CpGbinding protein 2 (MECP2). Proton MRS in Mecp2-/y mice with a complete absence of the Mecp2 gene product in all cells revealed decreased ratios of Glx and Ins with the sum of all other metabolite resonance areas as well as an increased NAA/sum ratio [26]. These ratios are not generally accepted and may mask a disturbance depending on other changes of individual metabolites. In fact, visual inspection of the spectra shown in Fig. 12 does not support the conclusion of a significant change in the $\mathrm{NAA} / \mathrm{tCr}$ and $\mathrm{Glx} / \mathrm{tCr}$ ratio. A proton MRS study of 9 girls with Rett syndrome in the age range 2-21 years reported a mild decrease of absolute NAA levels with increasing age but revealed no other abnormalities [263].

Canavan disease is another rare neurological disorder, classified as leukodystrophy, where clinical symptoms such as mental retardation, abnormal muscle tone, and abnormal head size appear in early infancy and progress rapidly. The underlying genetic defect is an aspartoacyclase deficiency which normally breaks down NAA. Loss of the enzyme increases the cellular concentration of NAA as shown by proton MRS of affected children [264] and impairs the normal function of the nervous system. A proton MRS study of a respective knockout mouse revealed a dramatic increase of the NAA/tCr ratio in the thalamus of homozygous mice relative to wild-type and heterozygous animals [5]. These results were confirmed by high-resolution proton NMR spectroscopy of brain extracts and suggest the successful creation of a mouse model of Canavan disease for further evaluation.

The segmental trisomy Ts65Dn mouse serves as a model of Down syndrome which is a genetic disorder caused by abnormal cell division during development. In humans, Down syndrome or trisomy 21 is characterized by three (instead of two) copies of chromosome 21 and leads to mental retardation and other prob-
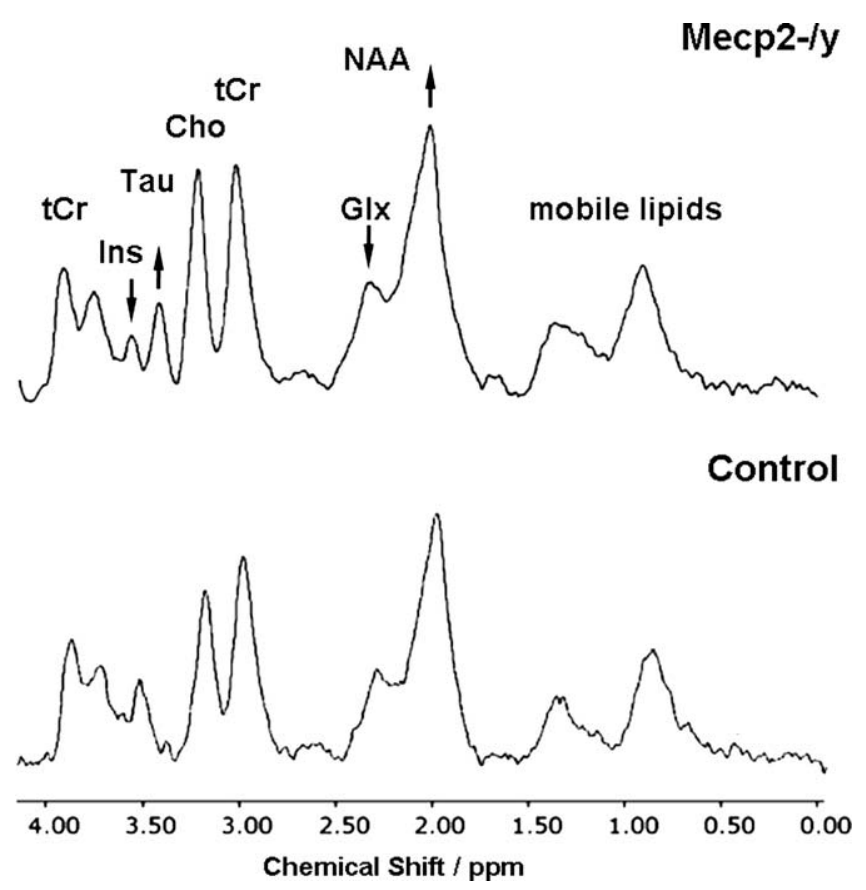

Fig. 12. Transgenic mouse model of Rett syndrome. Localized proton MRS (4.7 T, PRESS, TR/TE $=1500 / 16 \mathrm{~ms}, 3.5 \times 3.5 \times 3.5 \mathrm{~mm}^{3}, 256$ accumulations) of the brain of a Mecp2-/y mouse shows decreased Ins and increased Tau resonances (arrows) relative to a control. Metabolite ratios with the sum of all metabolite signals reveal increased NAA/sum and decreased Glx/sum and Ins/sum ratios in Mecp2-/y mice (arrows). Adapted from Ref. [26] with permission.

lems with largely variable severity. A proton MRS study reported decreased $\mathrm{NAA} / \mathrm{tCr}$ and elevated $\mathrm{Ins} / \mathrm{tCr}$ ratios in Ts65Dn mice [4]. Although this finding is in line with results reported in patients [265], the achieved spectral quality shown in Fig. 13 precludes a reliable evaluation of the Ins resonance. Despite this difficulty the study reported a decreased $\mathrm{Ins} / \mathrm{tCr}$ ratio for the combined group of controls and Ts65Dn mice after 30 days of lithium treatment, while the $\mathrm{NAA} / \mathrm{tCr}$ and $\mathrm{Cho} / \mathrm{tCr}$ ratios remained unaltered [4]. Further investigations are needed to confirm these preliminary results.

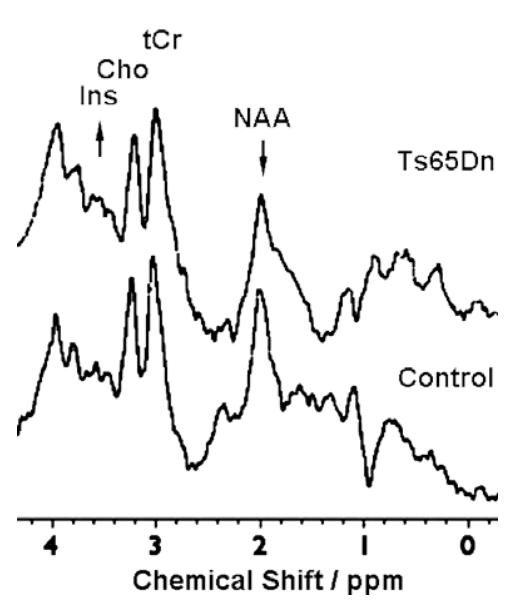

Fig. 13. Transgenic mouse model of Down syndrome. Localized proton MRS (4.7 T, STEAM, TR/TE $=1500 / 30 \mathrm{~ms}, 5 \times 3 \times 5 \mathrm{~mm}^{3}, 512$ accumulations) of the brain of a Ts65Dn mouse reveals a decreased NAA/tCr and increased Ins/tCr ratio (arrows) in comparison to a control. Adapted from Ref. [4] with permission. 


\subsection{HIV encephalitis}

The human immunodeficiency virus (HIV) attacks specific white blood cells that form an important part of the immune system. After about a decade of progressively reducing the effectiveness of the immune system, HIV infections lead to the acquired immune deficiency syndrome (AIDS) which leaves individuals susceptible to a large variety of opportunistic infections and tumors. In order to generate a mouse model of HIV-1 encephalitis, human HIV-infected monocyte-derived macrophages were unilaterally injected into the subcortex of immunodeficient mice. The procedure yields focal giant cell encephalitis, reactive astrocytes, microgliosis, and neuronal dropout 7 days after injection as confirmed by histology [16]. In comparison with unmanipulated and sham-operated animals proton MRS of HIV-1 encephalitis mice exhibited a significant NAA reduction in both the injected and contralateral hemisphere as well as in subregions such as the hippocampus, where neuropathology was limited or absent. A group average of all spectra from all animals revealed a statistically significant, global decrease of the NAA concentration. Because concomitant global alterations of the Cho and $\mathrm{tCr}$ concentrations were not observed, the NAA reduction may not be explained by edema or enlarged cerebrospinal fluid (CSF) spaces. The data suggest that a highly focal encephalitis can produce global deficits in neuronal function and metabolism [16].

\subsection{Prion diseases}

The infectious agent in a prion disease is a protein, usually a normal cell membrane protein with an atypical three-dimensional configuration. Prion diseases such as the human Creutzfeldt-Jakob disease, scrapie in sheep and goats, and the bovine spongiform encephalopathy (BSE) or "mad cow disease" are usually referred to as transmissible spongiform encephalopathies. They lead to extensive vacuole formation in the central nervous system, develop progressively, and are all fatal. Proton MRS of mouse models of prion diseases discovered alterations of cerebral metabolite levels already in early preclinical stages [25]. Adult C57BL/6 mice were inoculated intracerebrally with either the mouse-adapted BSE strain 6 PB1 or the mouse C506M3 scrapie strain and followed up to 180 days post infection. Interestingly, in BSE-infected mice the increase of the Ins/ $\mathrm{tCr}$ ratio preceded clinical signs such as ataxia by 20 days and was followed by a decrease of the NAA/tCr ratio at advanced stages. In scrapie-infected mice, changes of the NAA/ $\mathrm{tCr}$ and $\mathrm{Ins} / \mathrm{tCr}$ ratios were detected at the beginning of the symptomatic phase. Because the incubation period was shorter in the scrapie model and because the first MRS examination was performed too late to detect preclinical alterations, an early increase of the Ins/tCr might have been missed due to study design [25]. However, in either case decreased NAA/tCr ratios are in line with observations in a further murine ME7 model that support the view that $\mathrm{NAA} / \mathrm{tCr}$ reductions precede clinical signs and occur concomitant with early behavioral deficits [30]. These findings could allow for an early investigation of pathological alterations in prion diseases using in vivo MRS.

\section{Rat models}

Rats are common laboratory animals in preclinical brain research offering a broad variety of disease models. Rats were also the first animals in 1983 to be investigated by (nonlocalized) proton MRS in vivo [191-195]. These early studies dealt with technical feasibilities but also addressed normal and pathological brain metabolism in vivo and in utero. To date, rats are still the most frequently used animals for localized proton MRS of brain metabolism. Because the large number of studies precludes a comprehensive survey, this section will focus on a selection of important in vivo applications.

\subsection{Normal physiology}

Initial applications of localized proton MRS to normal rat brain identified metabolite resonances at short echo times and studied their alterations shortly after death [31]. As depicted in Fig. 14 such studies for the first time demonstrated access to cerebral glucose (Glc) concentrations in vivo [32]. At $2.35 \mathrm{~T}$ the strongly coupled Glc resonances merge into two apparent singlets at 3.43 and $3.8 \mathrm{ppm}$ that overlap with the multiplet resonances of Tau and the $\alpha-\mathrm{CH}$ resonances from Glu and Gln, respectively. After death Glc vanishes due to temporary nonoxidative glucose consumption (from free Glc as well as brain glycogen stores) and causes a concomitant accumulation of Lac in the absence of blood flow.

While early rat brain studies relied on metabolite ratios to $\mathrm{tCr}$, the adaptation of user-independent quantification methods to surface coil studies led to numerous reports of absolute metabolite concentrations. For example, using ultra-short echo times of $\mathrm{TE}=1-2 \mathrm{~ms}$, quantification of high-field MRS acquisitions involved
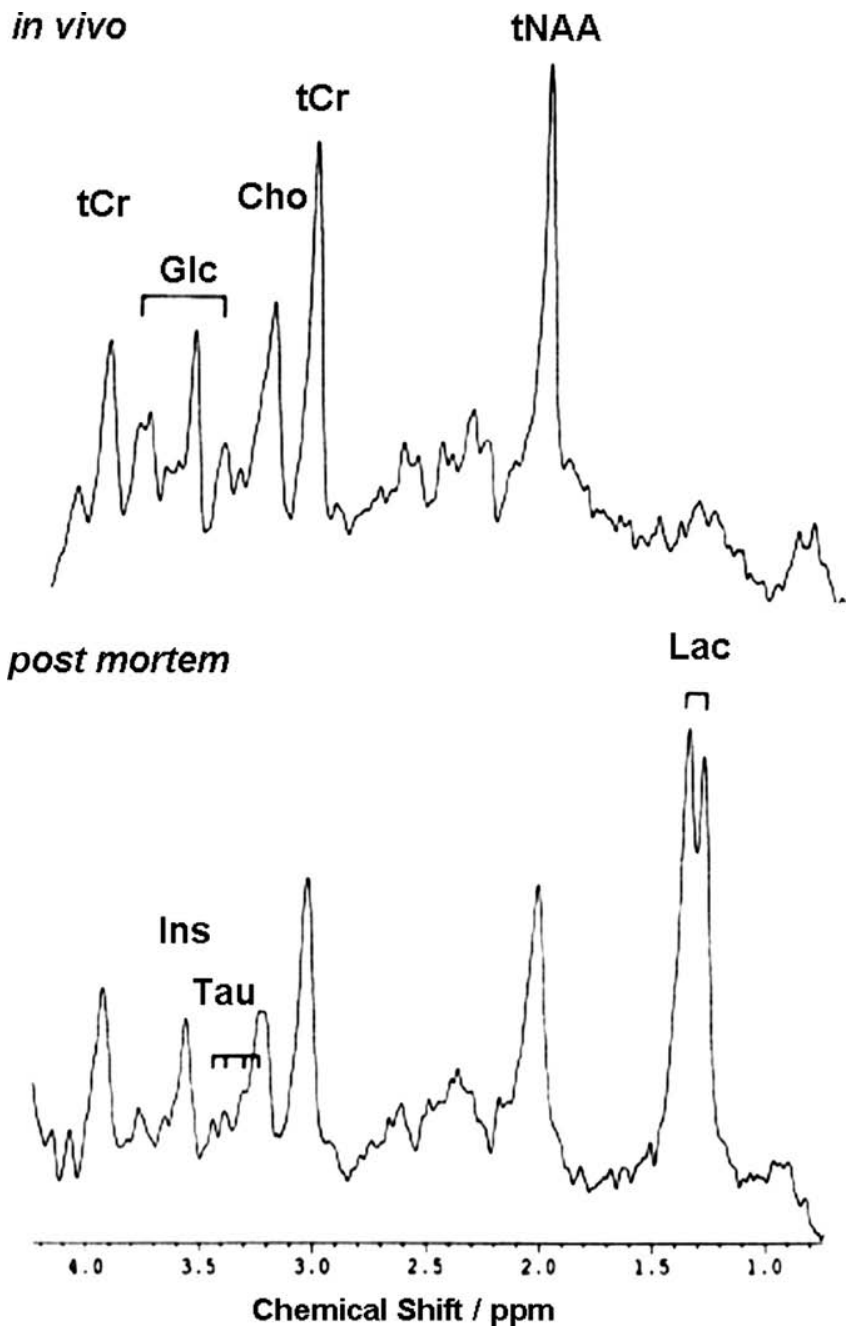

Fig. 14. Identification of glucose in rat brain in vivo. Localized proton MRS (2.35 T, STEAM, TR/TE $=3000 / 20 \mathrm{~ms}, 5 \times 5 \times 5 \mathrm{~mm}^{3}, 128$ accumulations) of rat brain in vivo and $25 \mathrm{~min}$ postmortem allow for the assignment of the strongly coupled resonances at $3.43 \mathrm{ppm}$ (overlap with Tau) and $3.8 \mathrm{ppm}$ (overlap with $\alpha-\mathrm{CH}$ resonances of Glx) to Glc. The in vivo resonances vanish due to nonoxidative glucose consumption during early postmortem phases, while the weakly coupled doublet resonances at $1.33 \mathrm{ppm}$ indicate the resulting accumulation of Lac. Adapted from Ref. [32] with permission. 
up to 18 metabolites [60,61]. Regional differences in the neurochemical profiles of the hippocampus, striatum, and cortex are most pronounced for NAA, Cho, Tau, and Ins [79]. A comparison of low-field versus high-field proton MRS of rat brain as shown in Fig. 15 confirms the findings reported for mice: because the achievable resonance linewidths are smaller at low fields (about $7 \mathrm{~Hz}$ [31]) than at high fields (about $12 \mathrm{~Hz}$ [60]), the full realization of the high-field advantages strongly depends on the ability to improve the local magnetic field homogeneity. $T_{1}$ and $T_{2}$ relaxation times of major metabolites in rat brain have been determined at 4.0, 9.4, and $11.7 \mathrm{~T}$ [97].

When studied as a function of postnatal age, proton MRS of rat brain revealed marked changes in cerebral metabolite composition in the hippocampus, striatum, and cortex during early development [79]. This particularly applies to increases of NAA, Glu, tCr, and Ins as well as to decreases of Tau and Cho in all investigated brain regions. The effects are clearly visible in Fig. 16 for the hippocampus. In general, the in vivo metabolite concentrations for different ages and/or brain regions are in agreement with values obtained by in vitro proton NMR spectroscopy of tissue extracts [266-268].

Cerebral metabolite changes in response to functional brain activation have been studied by proton MRS of $\alpha$-chloralose-anesthetized rats [96] as demonstrated in Fig. 17. During forepaw stim- ulation and concomitant focal activation of the primary somatosensory cortex, the main observation was a decrease of the $\mathrm{PCr} / \mathrm{Cr}$ ratio (resolved in high-field proton MR spectra), but no elevation of Lac - the latter finding is in line with similar observations in cats [136]. These results suggest that increased energy consumption due to focal brain activation causes a shift in the creatine kinase reaction towards the direction of ATP production, that is at the expense of reduced $\mathrm{PCr}$ and correspondingly elevated $\mathrm{Cr}$ [96]. At the same time, the enhanced energy demand does not lead to a significant increase in the glycolytic lactate production under physiological conditions.

\subsection{Cerebral ischemia and hypoxia}

During the past two decades rats have served as key animals for studies of global or focal cerebral ischemia, for reviews see $[169,173,175,176]$. Apart from histological correlations, proton MRS in vivo is often combined with other techniques such as diffusion-weighted MRI or electrophysiological recordings of transient cell depolarization $[36,39]$. For quantitative assessments of metabolite concentrations it is important to note that in the ischemic region $T_{1}$ and $T_{2}$ relaxation times of the metabolites NAA, tCr, and Cho were found to remain unchanged during the first few hours of ischemia but altered after $24 \mathrm{~h}$ [40].

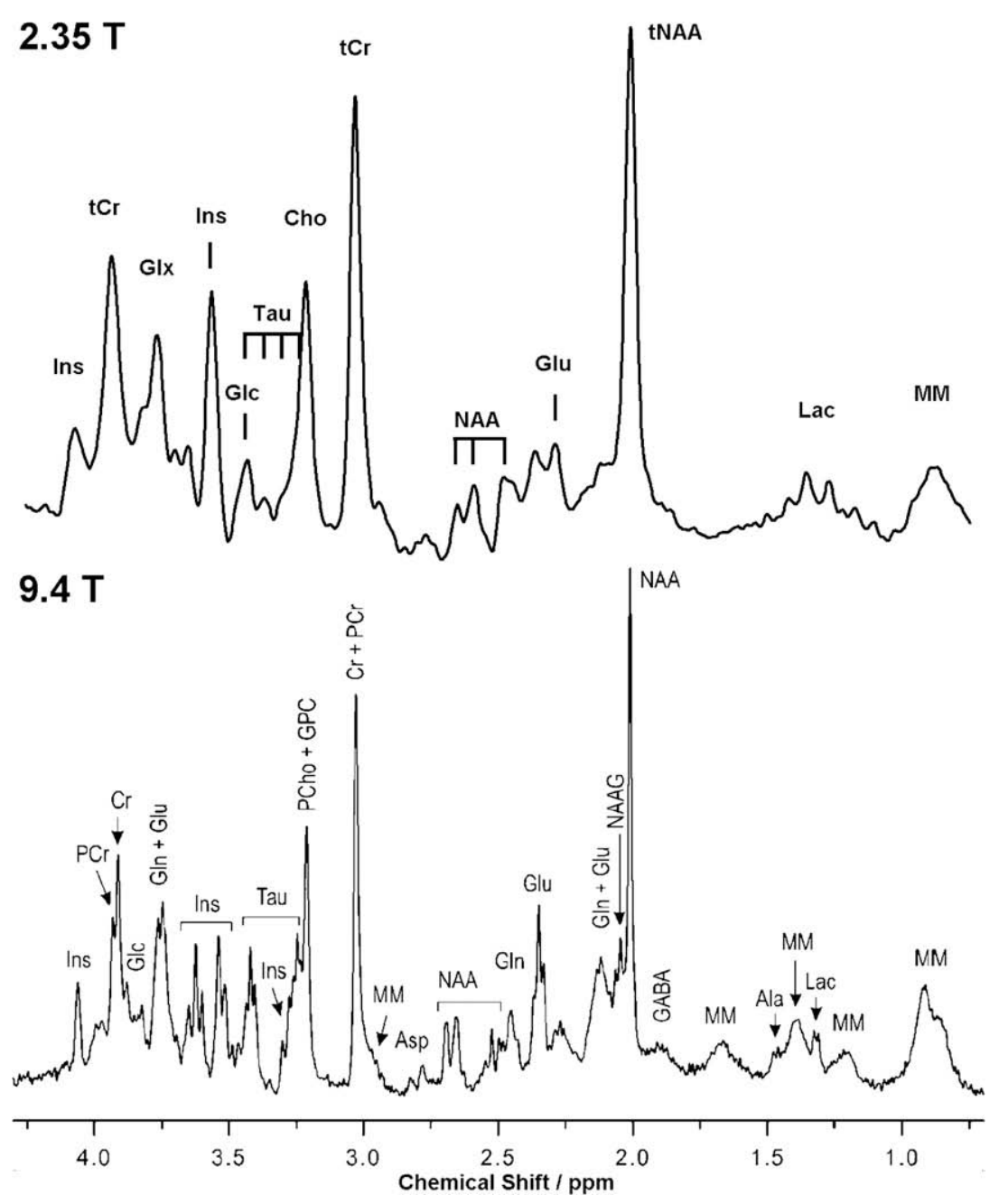

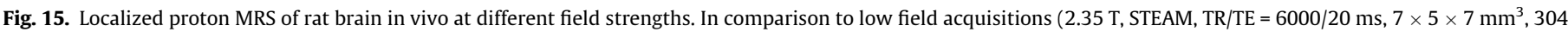

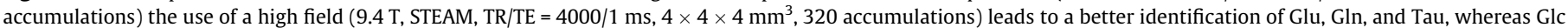

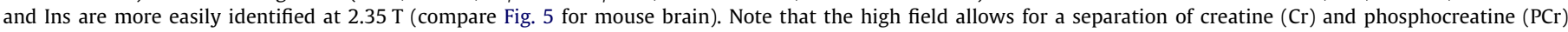

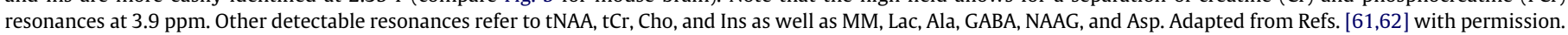




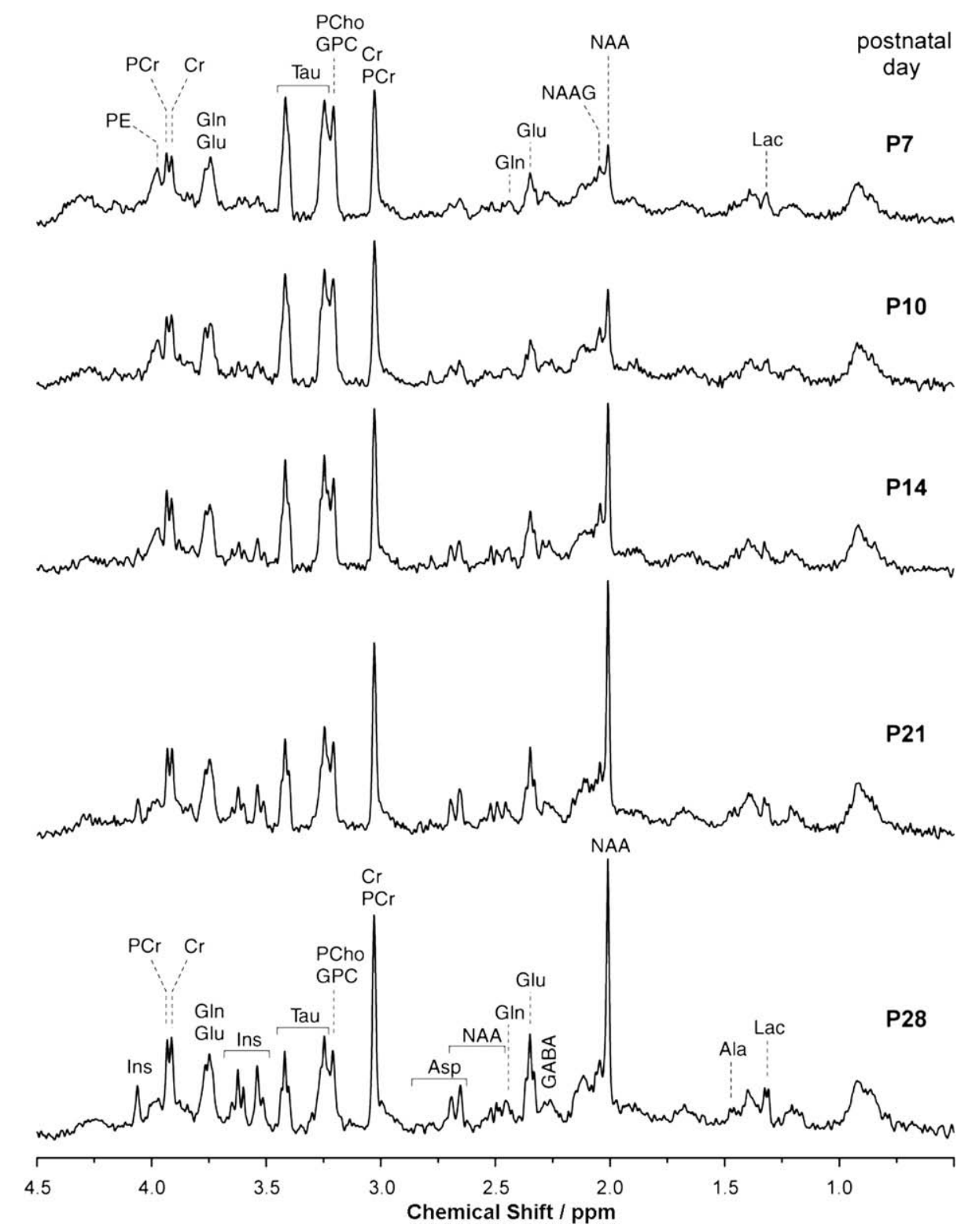

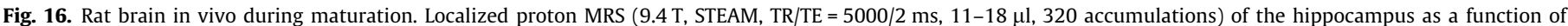

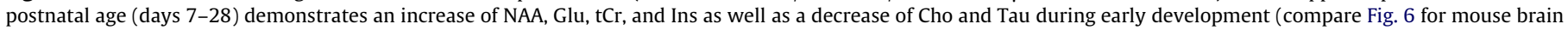
maturation). Adapted from Ref. [79] with permission.

Dynamic monitoring of cerebral metabolites during and after 10 min of transient global ischemia in rats revealed a rapid decline of brain Glc and a corresponding increase of Lac [41]. During reperfusion Lac clearance was characterized by a first-order rate constant of $0.03 / \mathrm{min}$. The recovery of Glc above basal concentrations within $1 \mathrm{~h}$ after the end of ischemia suggests a transient mismatch of Glc uptake and consumption during the early post-ischemic phase. Moreover, while NAA, $\mathrm{tCr}$, Cho, and Ins concentrations remained constant during early reperfusion, NAA and $\mathrm{tCr}$ levels decreased several hours later. After $24 \mathrm{~h}$ of reperfusion most metabolite concentrations were found to be severely reduced [51]. In models of focal cerebral ischemia that involve a permanent occlusion of the middle cerebral artery, a continuous decrease of NAA was seen starting after the onset of ischemia $[39,42,56]$.

Oral supplementation of creatine has been proposed to possess neuroprotective potential. In rats dietary creatine resulted in elevated cerebral concentrations of $\mathrm{tCr}$ and Ins as determined in vitro, while in vivo proton MRS revealed only trends for elevated
$\mathrm{tCr}$, Ins, and Glc [62]. The concomitant observation of a statistically significant decrease of cerebral Lac in creatine-fed rats indicated a strengthening of the oxidative metabolism relative to nonoxidative glycolysis. However, when comparing creatine-fed rats and controls during ischemia and early reperfusion, Fig. 18 demonstrates no differences with respect to Lac accumulation and clearance as well as Glc depletion and recovery. To further assess the therapeutic potential of creatine supplementation, mean time courses of the trace of the brain water apparent diffusion coefficients (ADC) were acquired [63]. During ischemia the observed decrease of the ADC trace in three stages paralleled the sequential pathophysiological events of energy depletion, development of a cytotoxic edema, and brain cooling. But again, less severe and mildly delayed diffusion changes in creatine-fed rats during ischemia and similar beneficial trends during early reperfusion did not reach statistical significance [63].

Other studies investigated therapeutic options at later stages of ischemia. For example, proton MRS was used to demonstrate that 


\section{Stimulated}

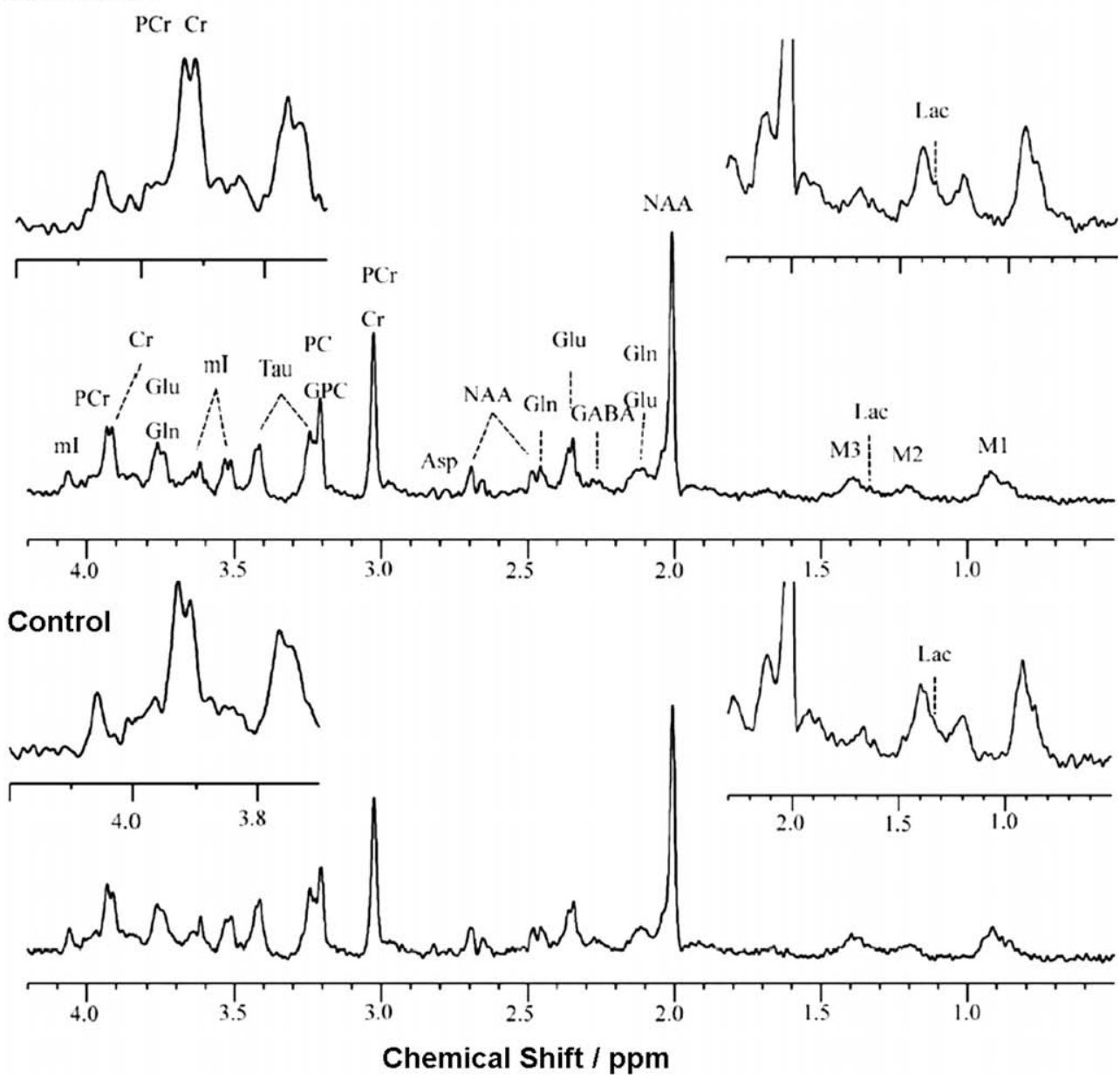

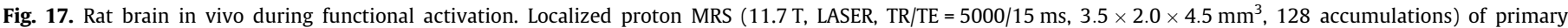

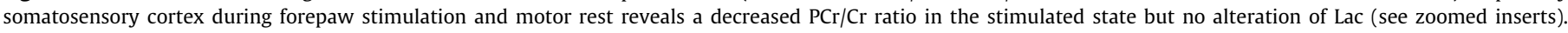
Adapted from Ref. [96] with permission.

intravenous infusion of immortalized human mesenchymal stem cells protect against ischemic injury [98]. About one week after focal ischemia untreated rats revealed the expected focal NAA decreases and Lac increases in the lesion, whereas rats treated $12 \mathrm{~h}$ after ischemia exhibited a normal NAA/tCr ratio and low Lac levels. These findings suggest at least a partial preservation of brain tissue in response to stem cell transplantation [98].

Diffusion-weighted MRI provides a sensitive tool for imaging affected tissue during acute stroke. Complementary, diffusionweighted MRS [166] has been used to monitor alterations of intracellular metabolite diffusion in rat brain during transient global ischemia and reperfusion [43] as well as during focal ischemia $[49,71]$. The ADCs of NAA, tCr, Cho, and Ins decrease during ischemia. As shown in Fig. 19 the corresponding increase of the diffusion-weighted MRS signal intensity is more pronounced for the glial marker Ins than for the neuronal marker NAA, indicating distinct glial responses to ischemia. These results are contradictory to the naive assumption that an increased intracellular volume due to the development of cytotoxic edema should increase rather than decrease the ADC of metabolites. In fact, neither changes of the metabolite concentrations [41] nor metabolite $T_{2}$ relaxation times [55] were observed during and shortly after transient global ischemia which excludes changes in intracellular viscosity. Reduced metabolite ADCs are more likely to reflect the failure of ATPdependent transport processes that contribute to the intracellular streaming under normal physiological conditions. While further studies are warranted, the approach provides a novel basis for the assessment of circulatory and metabolic compromise during ischemia and reperfusion.

In contrast to ischemia, cerebral hypoxia refers to a deficiency of oxygen supply to the brain in the presence of adequate blood flow. In humans, this may be caused by drowning, strangling, suffocation, carbon monoxide poisoning, and complications of general anesthesia. The effects of chronic hypoxia on the developing brain have been studied by proton MRS in a rat model of continuous hypoxia from postnatal days P3 to P28 [94]. Although the age-dependent metabolite profiles found in the hippocampus of affected rats were qualitatively similar to those seen in normoxic animals, several metabolites did not reach normal concentrations. The observation of an increased $\mathrm{PCr} / \mathrm{Cr}$ ratio was proposed to be consistent with a decreased energy consumption in the brain. The elevated GABA level was taken as an indicator of suppressed excitatory neurotransmission in an energy-limited environment, while decreased NAA was suggested to reflect reduced neuronal integrity.

\subsection{Multiple sclerosis}

A rat model of experimental demyelination employed intracerebral injections of lysophosphatidylcholine (LPC) to induce focal brain lesions [76]. Histology demonstrated demyelination around the site of injection with surrounding edema and prominent infiltration of inflammatory cells in the early phase. After about 2 

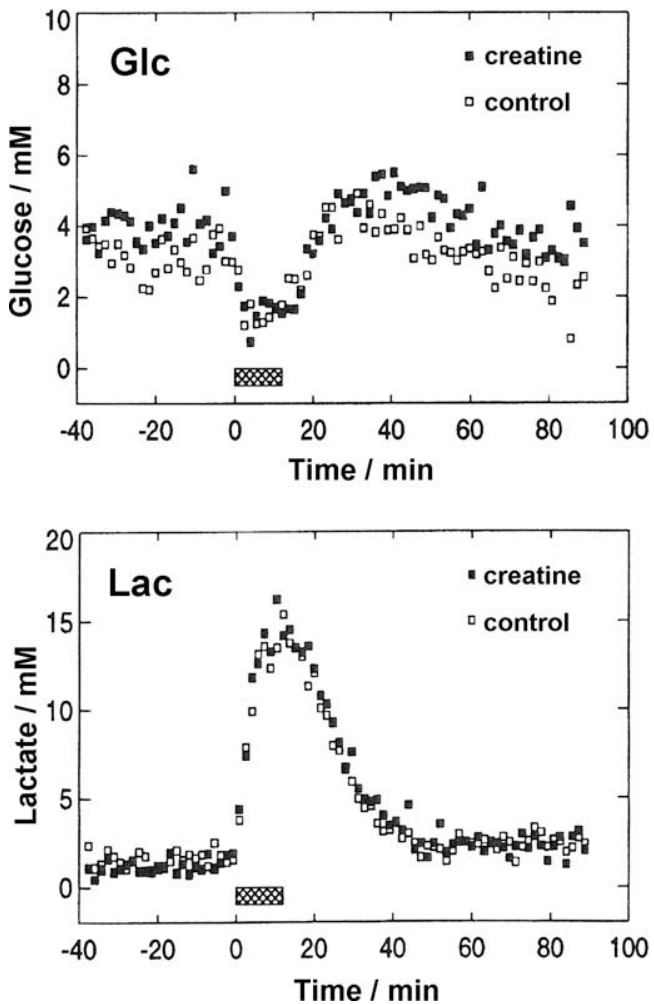

Fig. 18. Rat model of transient global cerebral ischemia (hashed bar) yielding mean time courses of Lac and Glc concentrations (in $\mathrm{mM}$ ) for creatine-fed rats ( $n=6$, closed squares) and controls ( $n=7$, open squares). Localized proton MRS ( $2.35 \mathrm{~T}$, STEAM, TR $/ \mathrm{TE}=6000 / 20 \mathrm{~ms}, 7 \times 5 \times 7 \mathrm{~mm}^{3}, 16$ accumulations) at a temporal resolution of $96 \mathrm{~s}$ reveals Glc depletion and recovery as well as Lac accumulation and clearance, but no differences between groups. Adapted from Ref. [62] with permission.

weeks of lesion progression remyelination was observed. In contrast to EAE models of multiple sclerosis that predominantly cause spinal cord lesions, LPC-induced lesions have a precise location and therefore offer sequential follow-up proton MRS studies even prior to full lesion development. In fact, early demyelination was characterized by decreased $\mathrm{NAA} / \mathrm{tCr}$ ratios, increased $\mathrm{Cho} / \mathrm{tCr}$ ratios, and elevated lipid and/or macromolecular signals in the internal capsule [76]. With the onset of remyelination, these alterations were reversed and the metabolite ratios recovered to normal values. Further correlative studies with histology are needed to establish more specific markers than a metabolite ratio that may serve for a better differentiation of acute and chronic lesions as well as of demyelination versus remyelination.

\subsection{Parkinson's disease}

Only a few proton MRS studies have addressed Parkinson's disease in rats. As for mice, intoxication of brain tissue after intrastriatal injections of MPTP led to acute and focal increases of Lac with normal levels of NAA [46]. One week after the injection Lac levels returned to baseline and NAA decreased. A further decline of NAA was observed up to 3 months post injection. The results are in line with similar observations in mice [15,24] and monkeys [114].

\subsection{Huntington's disease}

Several proton MRS studies of rat brain revealed metabolic alterations in different models of Huntington's disease. Intrastriatal injections of the $N$-methyl-D-aspartate (NMDA) agonist quinolinic acid [52,73] or systemic administrations of the
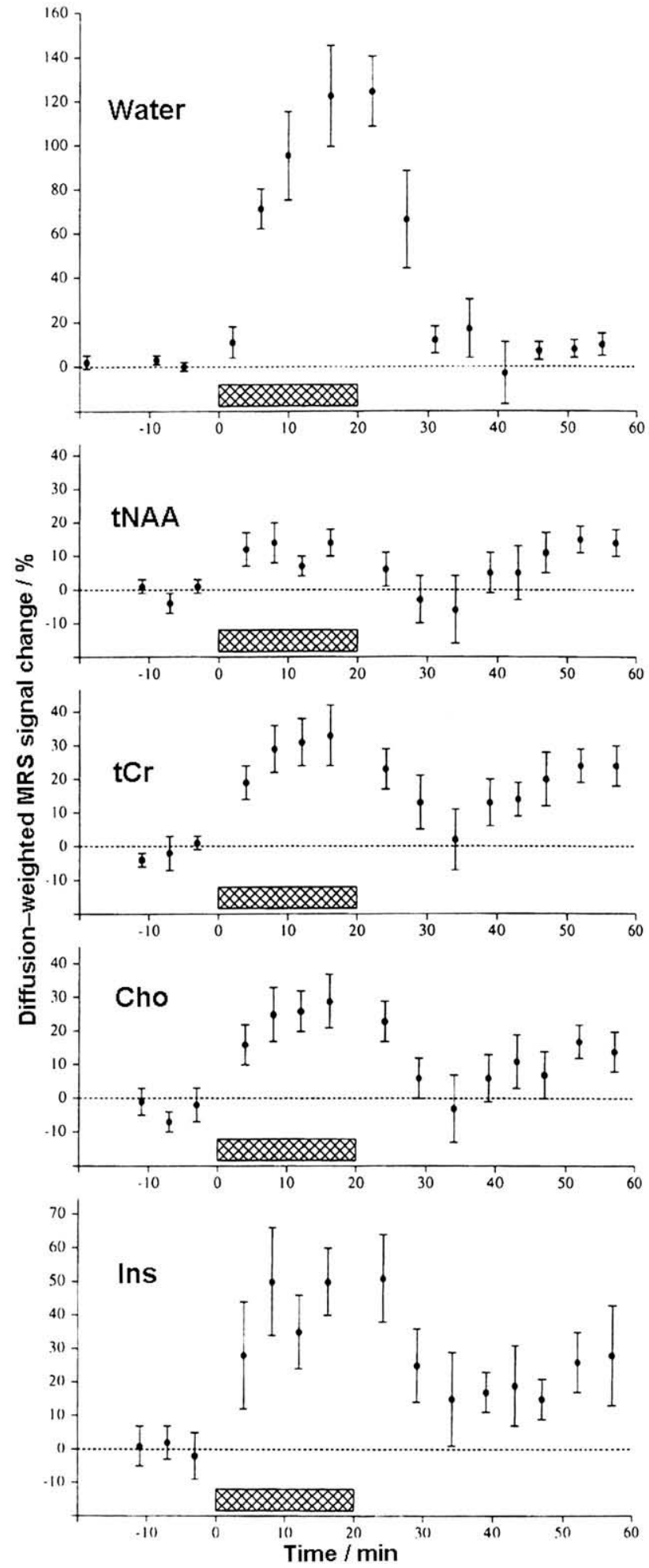

Fig. 19. Rat model of transient global cerebral ischemia (hashed bar) yielding mean time courses of diffusion-weighted MRS signal intensity changes of water and metabolite resonances $(n=8)$. Localized proton MRS $(2.35$ T, STEAM, TR $\geqslant 3000 \mathrm{~ms}$ respiratory triggered, $\mathrm{TE}=120 \mathrm{~ms}, 7.5 \times 5.0 \times 7.5 \mathrm{~mm}^{3}, 64$ accumulations) was performed with diffusion gradients in both TE/2 intervals $(\Delta=\delta=25 \mathrm{~ms}$ ) yielding $b=2960 \mathrm{~s} \mathrm{~mm}^{-2}$. Signal increases correspond to a decrease of the apparent diffusion coefficient. Adapted from Ref. [43] with permission.

mitochondrial toxin 3NP $[46,57,66,67,90,116]$ were used to induce selective striatal lesions. The axon-sparing excitotoxic quinolinic acid causes neuronal damage by overstimulation of glutamate 
receptors which can lead to mitochondrial dysfunction and formation of nitric oxide and other free radicals. The model produces behavioral and neuroanatomical effects which closely mimic some of the characteristics of Huntington's disease. Proton MRSI revealed dose-dependent decreases of NAA, tCr, and Cho two weeks after injection of quinolinic acid, consistent with a generalized loss of viable cells in the striatum [52]. Five days after a relatively low dose of quinolinic acid, quantitative proton MRS revealed striatal increases of Gln in conjunction with decreased NAA, Glu, Tau, and $\mathrm{tCr}$ [73]. At higher doses, quinolinic acid resulted in more pronounced changes consistent with necrosis.

The primary effect of 3NP is the partial blockade of mitochondrial complex II including the inhibition of succinate dehydrogenase. Acute metabolic changes after 3NP administration were reported to be time-dependent and partly reversible. In particular, $3 \mathrm{~h}$ after a single $3 \mathrm{NP}$ administration, proton MRS demonstrated a simultaneous increase of the ratios of Suc/tCr and acetate/tCr. These changes were followed by elevated Lac and later also reduced NAA. After depletion of NAA, acetate decreased to baseline levels suggesting hydrolysis [66]. It is of general interest for the interpretation of NAA changes that the reversible reduction of NAA in the acute phase indicates reversible mitochondrial dysfunction rather than neuronal loss $[90,116]$. In final stages, however, neuronal cell death was observed if 3NP administration was continued. Accordingly, studies of symptomatic rats at 4 weeks and 4 months after administration showed no Suc and Lac but increased $\mathrm{Cho} / \mathrm{tCr}$ and decreased $\mathrm{NAA} / \mathrm{tCr}$ ratios [90].

The efficacy of neuroprotective interventions in rats after 3NPinduced striatal lesioning was investigated using creatine and cyclocreatine [57] as well as lamotrigine and dizocilpine maleate (MK801 ) [67]. Oral supplementation of creatine but not of cyclocreatine protected against 3NP neurotoxicity as indicated by smaller lesion volumes and reduced Lac/NAA ratios in the acute phase [57]. Creatine supplementation increased cerebral $\mathrm{PCr}$ concentrations and therefore alleviates the 3NP-induced depletion of the high-energy phosphate metabolites $\mathrm{PCr}$ and ATP. Alternative treatment strategies addressed the excitotoxic brain injury in 3NP-treated animals. Because it involves the activation of excitatory glutamate receptors, excessive influx of calcium ions, and overproduction of reactive oxygen species which together lead to cell death by apoptosis and necrosis, NMDA receptor antagonists such as MK-801 were considered as a therapeutic option [67]. In addition, application of the anticonvulsant lamotrigine which modulates voltagegated calcium channels was proposed to counterbalance an overload of calcium ions in neurons [67]. As demonstrated in Fig. 20, pre-treatment with either MK-801 or lamotrigine indeed precluded the common increase of striatal Suc and Lac levels after 3NP-induced lesioning and mostly prevented decreases of the $\mathrm{NAA} / \mathrm{tCr}$ and $\mathrm{Cho} / \mathrm{tCr}$ ratios [67]. These results suggest considerable potential of localized proton MRS for monitoring therapeutic interventions in Huntington's disease.

\subsection{Hydrocephalus and head trauma}

Hydrocephalus arises from abnormal accumulation of CSF in the ventricles of the brain. It causes increased intracranial pressure and progressive enlargement of the head, convulsion, and mental disability. The condition may result from an overproduction of CSF, from a congenital malformation blocking normal CSF outflow, or from complications of head injuries or infections. The use of localized proton MRS for an evaluation of cerebral metabolism in hydrocephalus has recently been reviewed [171]. Rat studies have been combined with $T_{2}$-weighted MRI, diffusion-weighted MRI, and phosphorus MRS [54,59,65].

Rat models of hydrocephalus involve injection of kaolin into the cisterna magna. As shown in Fig. $21 \mathrm{~T}_{2}$-weighted MRI revealed
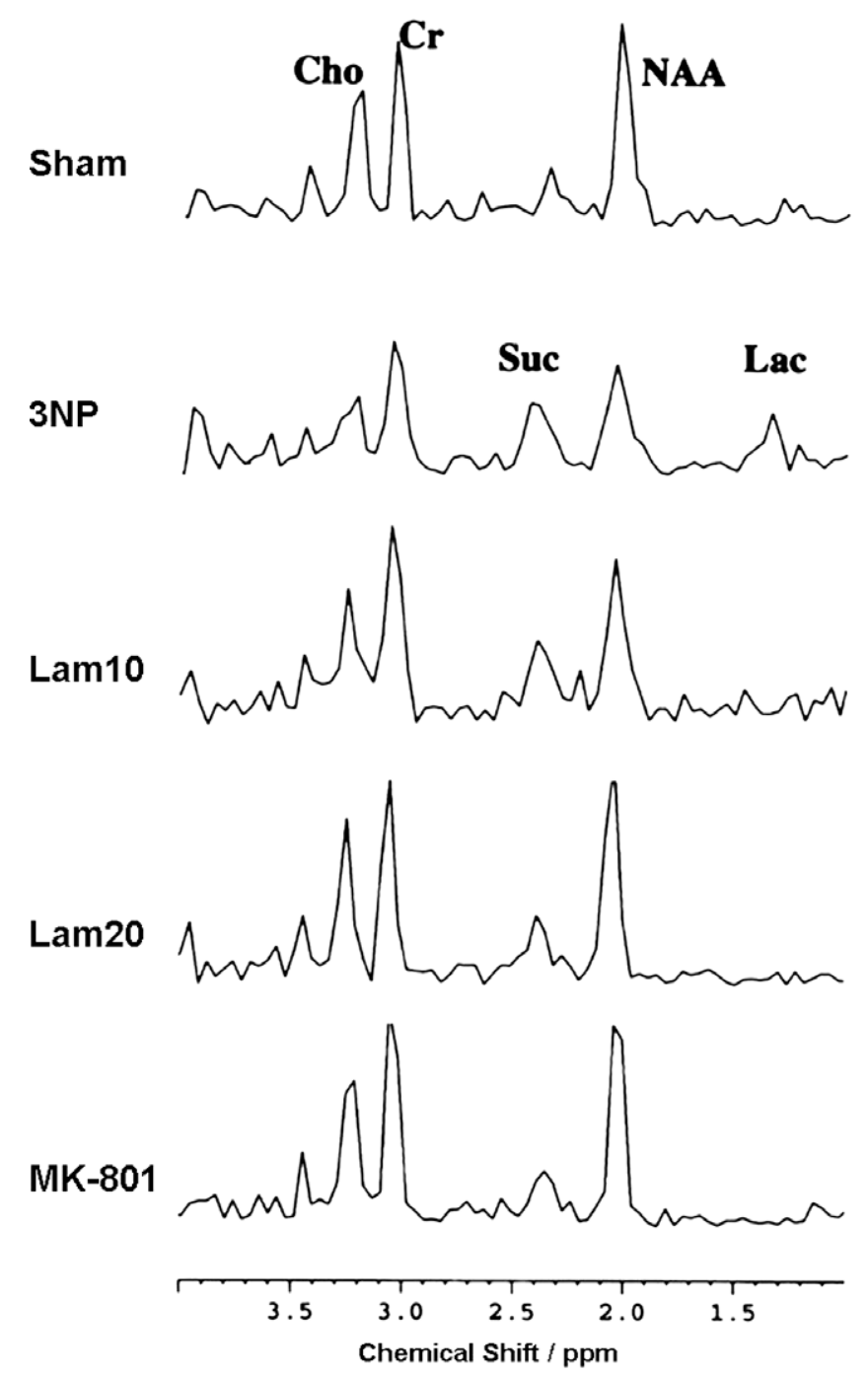

Fig. 20. Rat model of Huntington's disease. Localized proton MRS (4.7 T, PRESS, TR/ $\mathrm{TE}=2000 / 135 \mathrm{~ms}, 5 \times 5 \times 5 \mathrm{~mm}^{3}, 256$ accumulations) of rat striatum after $3 \mathrm{NP}$ intoxication shows increased Lac and succinate (Suc) relative to sham-operated animals. These alterations were markedly reduced after pre-treatment with lamotrigine at a dose of 10 (Lam10) or $20 \mathrm{mg} / \mathrm{kg} / \mathrm{day}$ (Lam20) or with MK-801. Adapted from Ref. [67] with permission.

strongly enlarged ventricles 16 weeks after intoxication. Proton MRS of a relatively large VOI detected elevated Lac at all time points investigated, while MRSI identified Lac to be mainly present in CSF [59]. The observation of decreased NAA/Cho and Cho/ $\mathrm{tCr}$ ratios was suggested to implicate neuronal loss/dysfunction or changes in membrane phospholipid metabolism [65].

In humans, concussion is the most common and least serious type of traumatic brain injury. However, a head trauma can also lead to epidural and subdural hematoma, subarachnoid hemorrhage, cerebral contusion, and diffuse axonal injury. In many cases, these alterations are accompanied by increased intracranial pressure which then becomes the main goal of treatment. In a rat model of experimental traumatic brain contusion metabolic changes were followed for up to 4 weeks by proton MRS and histology [83]. Immediately after lesioning pericontusional concentrations of NAA, $\mathrm{tCr}$, and Glu decreased due to neuronal cell disintegration and other secondary perturbations unraveled by histology. Metabolite concentrations partially recovered at day 7 in parallel to immunohistochemical indications of repair, but without regaining control levels at day 28 . Though initially decreased, the concentra- 


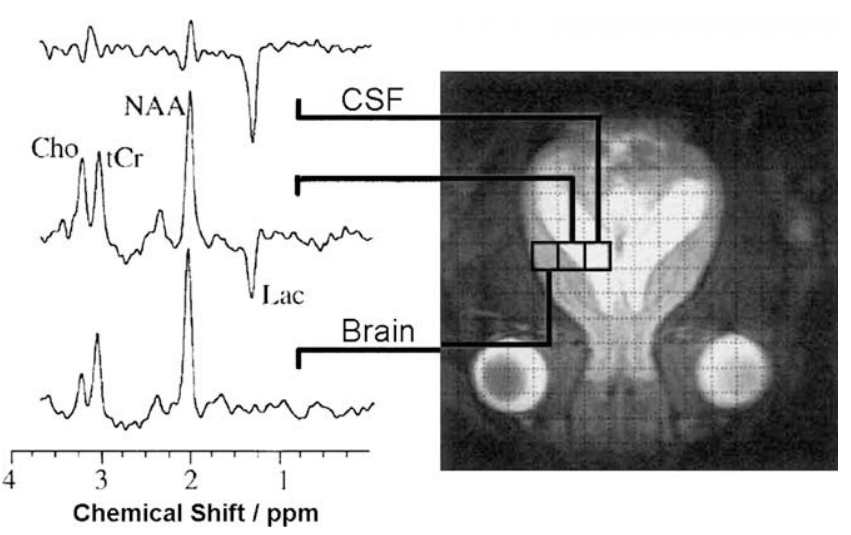

Fig. 21. Rat model of hydrocephalus. Localized proton MRSI (4.7 T, PRESS, TR/ $\mathrm{TE}=2500 / 244 \mathrm{~ms}, 2 \times 2 \times 4 \mathrm{~mm}^{3}, 16 \times 16$ acquisition matrix) of the brain 8 weeks after kaolin injection reveals elevated Lac predominantly in CSF. Adapted from Ref. [59] with permission.

tions of Cho and Ins increased above normal values at day 7, indicating glial activation and proliferation. Increased levels of Lac and lipids were detected at all time points [83].

Another rat study examined whether proton MRS is capable of measuring S100B proteins which are released by astrocytes after lateral fluid-percussion injury and thought to correlate with outcome [93]. The in vitro identification of a S100B resonance at $4.5 \mathrm{ppm}$ was based on a positive correlation between different S100B concentrations and the resonance integral as well as by an increased resonance in rat brain in vivo after 5 days of continuous intraventricular infusion of S100B [93]. It should be mentioned, however, that the unambiguous analysis of a resonance close to that of brain water is extremely difficult under in vivo conditions, mainly because of the distorted lineshape of the residual watersuppressed signal.

\subsection{Primary brain tumors}

The growth of intracranial tumors is caused by the uncontrolled proliferation of cells. Brain neoplasms are subdivided into primary tumors that originate from glia such as astrocytes (astrocytomas), oligodendrocytes (oligodendrogliomas), or ependymal cells (ependymoma) and secondary tumors that represent metastatic forms. Proton MRS was performed to enhance the diagnostic specificity of MRI procedures and, in animals, to study tumor metabolism for a better understanding and optimization of therapeutic interventions. For a review about tumor metabolomics in animal models of human cancer see [179]. The studies discussed here employed intracerebral gliomas grown after in vivo implantation of C6 cells [38,72,81], F98 cells [33], RT2 cells [37], 9L cells [44], or BT4C cells transfected with a viral herpes simplex virus thymidine kinase (HSV-tk) gene $[64,80]$.

In comparison to normal contralateral brain tissue and notwithstanding technical differences such as echo times and VOI sizes, proton MRS studies of gliomas generally yield (i) strongly increased Lac and/or lipids, (ii) reduced or even depleted NAA, decreased $\mathrm{tCr}$, strongly increased Cho, and elevated Ins with potential contributions from glycine. Fig. 22 illustrates the high degree of interindividual variability found in F98 gliomas which hampers the establishment of a consistent relationship between proton MRS observations and tumor development [33]. Part of the variability can be explained by the heterogeneity of the tumor tissue which is also supported by proton MRSI of C6 gliomas demonstrating differences in the spatial distribution of metabolites [38,72,81]. Moreover, it has been shown that mobile lipids are only detectable
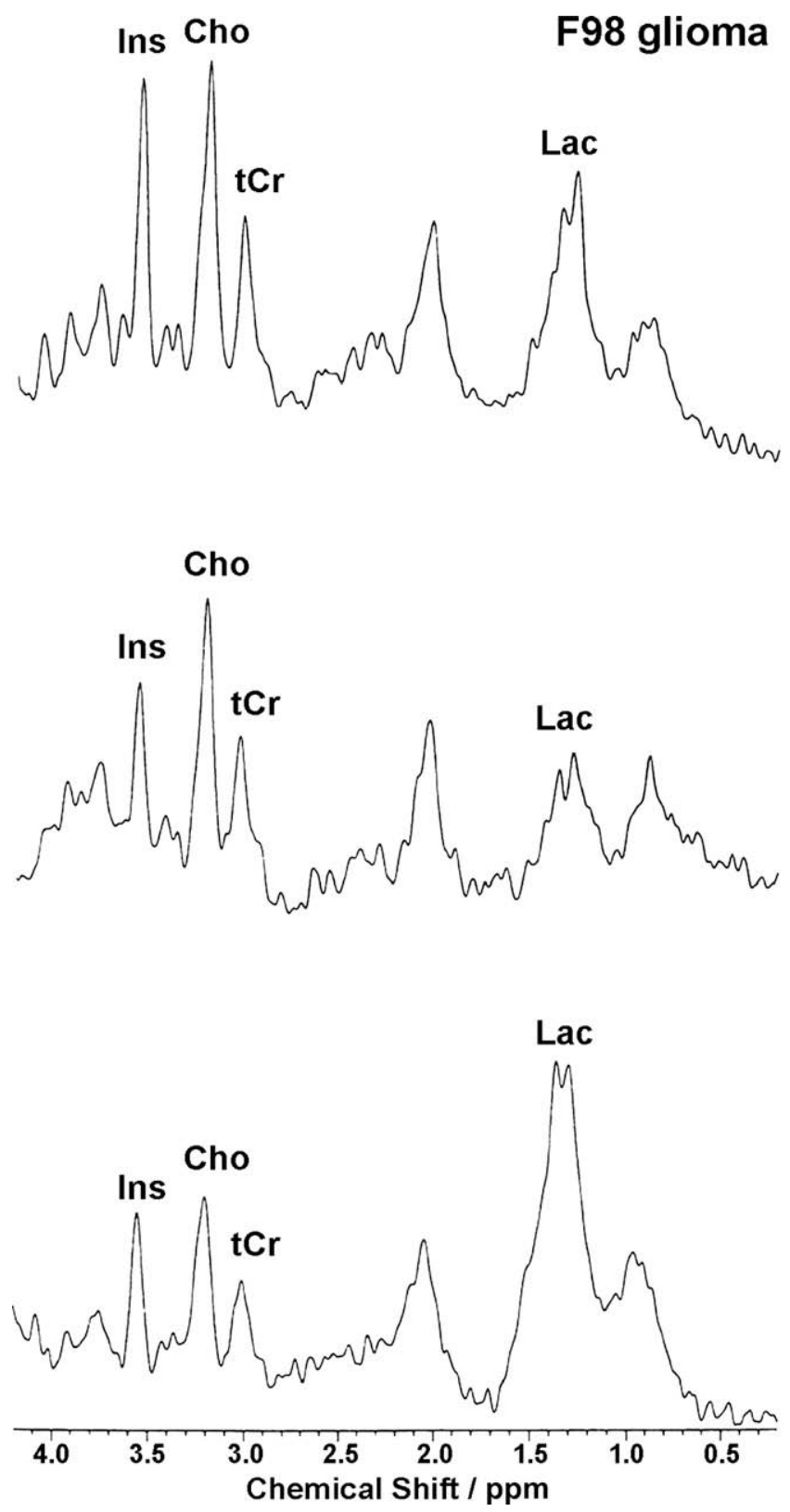

Fig. 22. Rat model of brain tumor. Localized proton MRS (2.35 T, STEAM, TR/ $\mathrm{TE}=3000 / 20 \mathrm{~ms}, 4 \times 4 \times 4 \mathrm{~mm}^{3}, 256$ accumulations) of three different animals 2 weeks after inoculation of F98 glioma cells into the right caudate nucleus demonstrates pronounced interindividual variability of the growing tumors. This particularly applies to the concentrations of Lac and mobile lipids $(0.9,1.3$, and $2.05 \mathrm{ppm}$ ). Adapted from Ref. [33] with permission.

at later stages of tumor development and mainly arise from lipid droplets in necrotic areas [81]. After the infusion of 2-imidazole1-yl-3-ethoxycarbonylpropionic acid (IEPA) into the right jugular vein, IEPA resonances were detected only in the glioma and enabled the calculation of a mean extracellular $\mathrm{pH}$ of 7.08 from the chemical shift of the $\mathrm{pH}$-dependent $\mathrm{H} 2$ resonance [72]. NAA and Lac levels were found to correlate negatively with MRS-detected IEPA level, as expected for a glioma surrounded by normal tissue. However, the unexpected lack of a negative correlation of Lac with extracellular $\mathrm{pH}$ led to the conclusion that Lac production is greatest in well-perfused parts of gliomas from which proton equivalents are rapidly cleared [72].

In a rat model of intracranial 9L glioma, proton MRS was applied to assess the efficacy of gene therapy [44]. The treatment involved 
a recombinant adenoviral vector to transfer the HSV-tk gene to the tumor and a subsequent systemic administration of the antiherpetic agent ganciclovir. MRI of treated rats revealed a significant reduction of the doubling time for tumor volume, but with a large variation in antitumor activity of individual animals. Proton MRS of untreated gliomas exhibited reduced NAA and $\mathrm{tCr}$ levels but no other changes as compared to normal tissue in the contralateral hemisphere. In contrast, treated tumors exhibited dramatic increases of resonances in the $0.9-1.3 \mathrm{ppm}$ range from mobile lipids and/or Lac. The results suggest that specific changes of the tumor metabolite profile may be predictive of the effectiveness of the applied therapeutic regimen [44].

Other studies used BT4C glioma cells that were transfected with the viral HSV-tk gene and implanted into the corpus callosum $[64,80]$. In contrast to the aforementioned work [44], proton MRS of the solid tumor was dominated by resonances from saturated lipids ( $1.3 \mathrm{ppm}$ ) and polyunsaturated fatty acids (5.4 ppm). Alterations of these lipids as well as of tCr, Glx, Cho, Tau, and Ins (plus glycine) were quantified during days $0-8$ of ganciclovir treatment. The histologically determined decrease of tumor cell density with treatment was paralleled by decreases of $\mathrm{tCr}$, Tau, and Ins (glycine) as well as by increases of saturated and unsaturated lipids. The authors concluded that increases of saturated and unsaturated lipids can be used as a marker for tumor growth arrest and early detection of tumor eradication in vivo.

\subsection{Epilepsy}

Epilepsy is a chronic neurological disorder characterized by recurrent unprovoked seizures due to abnormal, excessive or synchronous neuronal activity in the brain. In humans, temporal lobe epilepsy is the most common variant in adults with involvement of the hippocampus. Although still an open question whether or not it is a cause or an effect of seizures, hippocampal sclerosis seems to represent a common pathological pathway to partial epilepsy from a number of different causes.

Proton MRS studies of the hippocampus have assessed the metabolite profiles during and after seizures. In most cases status epilepticus was induced by systemic administration of kainate acid $[53,58]$ or pilocarpine $[82,91]$. The data constitute a rather consistent picture of hippocampal alterations in epileptic rats. As demonstrated in Fig. 23, elevated Lac is usually detected as early as $1 \mathrm{~h}$ after seizure onset $[53,91]$ and persists for up to 7 days while slowly decreasing toward normal levels [53]. Moreover, and apart from a report about transient increases of the NAA/tCr ratio in the acute phase [53], the NAA/tCr ratio is generally characterized by a progressive reduction starting several hours after kainate administration [53] or pilocarpine injection [82,91]. The $\mathrm{Cho} / \mathrm{tCr}$ ratio in these studies was either not altered [53,82] or decreased [91].

Pre-treatment with cycloheximide, a protein synthesis inhibitor, prevented increases of the $\mathrm{Lac} / \mathrm{tCr}$ ratio during and one day after kainate-induced seizure onset [58]. Similar to an earlier study [53], a transient increase of the NAA/tCr ratios was observed $1 \mathrm{~h}$ after seizures which was not affected by the treatment [58]. However, one day after seizure onset, the NAA/tCr ratio in the hippocampus was higher in cycloheximide-treated animals than in untreated rats. This indication of enhanced neuronal survival was histologically confirmed by the absence of a significant cell loss in both CA3 and hilar areas [58]. A separate study reported the use of oral creatine to prevent the decrease of hippocampal NAA 28 days after pilocarpine injection [82]. Surprisingly, proton MRS yielded normal NAA concentrations in creatine-fed epileptic rats, whereas histology revealed an even more pronounced loss of pyramidal neurons than in untreated epileptic rats [82]. A plausible explanation for the observation of normal NAA in the presence of massive neuronal loss is still lacking.

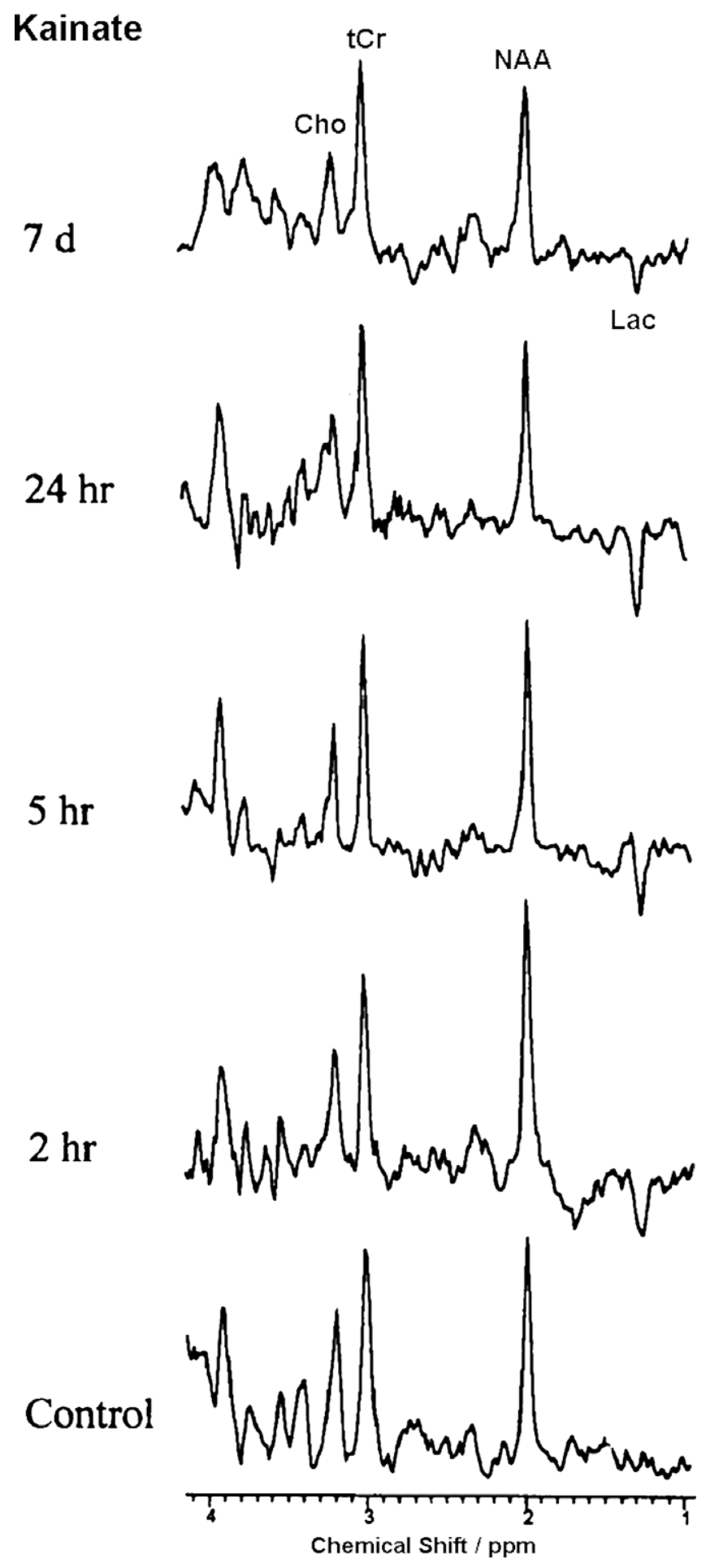

Fig. 23. Rat model of epilepsy. Localized proton MRS (4.7 T, PRESS, TR/TE $=2500$ ) $135 \mathrm{~ms}, 10 \times 3.4 \times 3.6 \mathrm{~mm}^{3}, 768$ accumulations) of rat hippocampus after kainic acid-induced seizures shows increased Lac in the acute phase and decreased NAA at later stages. Adapted from Ref. [53] with permission.

\subsection{Schizophrenia and depression}

Schizophrenia denotes a complex syndrome of still relatively unknown causes. Neurobiological investigations have demonstrated an impaired function of the prefrontal cortex. In a rat model of excitotoxic lesioning of the prefrontal cortex, proton MRS revealed a persistent reduction of NAA in both prefrontal cortex 


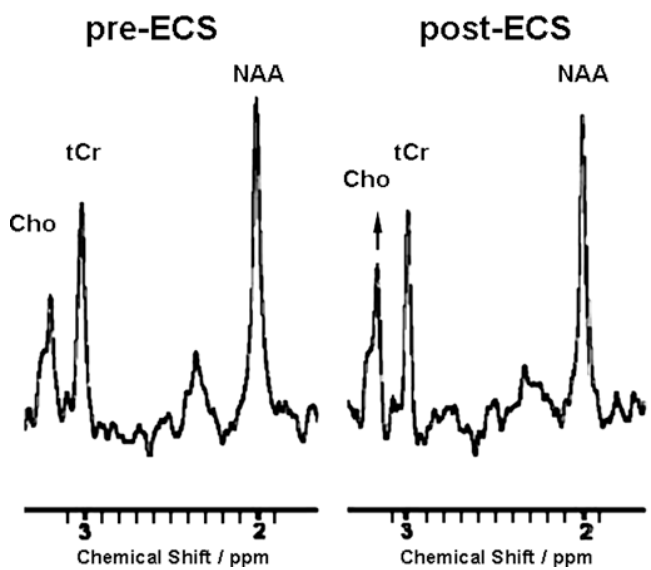

Fig. 24. Rat brain after electroconvulsive shock (ECS) treatment. Localized proton MRS (4.7 T, PRESS, TR/TE $=2500 / 144 \mathrm{~ms}, 1.6 \times 2.6 \times 2.5 \mathrm{~mm}^{3}, 256$ accumulations) of the hippocampus reveals an increased $\mathrm{Cho} / \mathrm{tCr}$ ratio in response to treatment (arrow). Adapted from Ref. [85] with permission.

and striatum indicating local and downstream alterations in neuronal integrity [70]. Similarly decreased NAA levels were observed in the prefrontal cortex of young adult rats after neonatal excitotoxic lesioning of the ventral hippocampus. The authors concluded that early hippocampal lesions produce developmental neuronal pathology in the prefrontal cortex that is associated with dysregulation of dopamine behaviors and reminiscent of the temporal profile of schizophrenia [77]. The effects of the antipsychotic drugs haloperidol, clozapine, and olanzapine on metabolite ratios were determined in normal rat brain and found to be negligible or absent [69]. In turn, these results suggest that the metabolite alterations observed in treated schizophrenics reflect disease-related disturbances rather than short-term effects of medication.

Major depressive disorder or simply depression is a mental disorder characterized by a pervasive low mood and diminished ability to experience pleasure. While there is no single known cause of depression, it likely results from a combination of genetic, biochemical, environmental, and psychological factors. Several proton MRS studies evaluated the potential of electroconvulsive shock (ECS) treatment in learned helplessness rats as an animal model of depression $[85,86]$. As shown in Fig. 24, daily ECS treatment led to elevated $\mathrm{Cho} / \mathrm{tCr}$ and Cho/NAA ratios in the hippocampus of normal rats, while the $\mathrm{NAA} / \mathrm{tCr}$ ratio remained constant [85]. Thus, ECS-induced seizures seem to cause a different metabolic profile than observed after kainate administration, where normal Cho and reduced NAA levels have been reported. A concurrent study demonstrated increased $\mathrm{Cho} / \mathrm{tCr}$ ratios in both learned and non-learned helplessness rats after ECS treatment [86] which therefore seems to reflect a non-specific effect. In a further study the involvement of the prefrontal cortex in major depressive disorder was investigated in rats exposed to the forced swimming test [100]. Relative to controls, rats with a depressed mental status exhibited increased $\mathrm{Cho} / \mathrm{tCr}$ and Cho/NAA ratios. Unfortunately, most proton MRS studies of rat models of depression are hampered by the use of metabolite ratios. The results remain vague and demand quantitative MRS studies of metabolite concentrations similar to those performed in tree shrews to clarify which cerebral metabolites are truly altered and subject to treatment.

\subsection{Ethanol intoxication}

A relatively large number of rat studies addressed the consequences of acute and chronic ethanol exposure onto the brain metabolism. Because human studies are usually hampered by many poorly controllable variables and confounds including differ- ences in alcohol consumption, nutritional status, and anamnesis, animal studies of ethanol intoxication are more suited for systematic investigations of the pathophysiology underlying alcohol-related brain damage.

Proton MRS studies of acute ethanol administration led to the conclusion that ethanol diffuses freely with water, so that its concentration should be proportional to the water content of a given brain area. Nevertheless, early MRS reports of brain ethanol concentrations largely differed, so that impaired MRS visibility of brain ethanol due to motional restrictions was put forward as an explanation [48]. However, a more recent quantitative study of ethanol kinetics in rat brain indicated concentrations based on cerebral MRS and blood alcohol levels to be in good agreement with the administered dose [99], suggesting experimental differences in previous work.

Chronic ethanol exposure is expected to alter cerebral metabolism. Thus, 8 weeks of ethanol consumption resulted in a significant decrease of the $\mathrm{Ins} / \mathrm{tCr}$ ratio in rat brain, consistent with perturbances in astrocytes [68]. However, NAA/tCr and Cho/tCr ratios remained normal at this stage. A longitudinal study of rats chronically exposed to ethanol revealed a decrease in the NAA/ Cho ratio at about 16 weeks, followed by an increase above normal values after 44 weeks [84]. While alterations of the NAA/tCr ratio were not observed, the persistently elevated NAA/Cho ratio for up to 60 weeks after the start of alcohol intoxication was suggested to mainly reflect reduced Cho, that is lower levels of glycerophosphocholine and phosphocholine.

In the context of alcohol intoxication and abuse, proton MRS studies also determined neurochemical alterations in the thiamine-deficient rat brain $[34,45,75]$. In humans, thiamine (vitamin $\mathrm{B}_{1}$ ) deficiency is a frequent nutritional complication in alcoholics which can cause brain damage associated with Wernicke-Korsakoff syndrome. In rats a combination of a thiamine-deficient diet with daily intraperitonal injections of the thiamine antagonist pyrithiamine was employed to induce neurological symptoms similar to Wernicke's encephalopathy [45]. In line with observations after chronic ethanol intoxication, longitudinal studies of up to 26 days after the initiation of thiamine deficiency confirmed a reduction of the brain Cho level as deducible from an increased $\mathrm{NAA} / \mathrm{Cho}$ ratio but unchanged $\mathrm{NAA} / \mathrm{tCr}$ ratio. Interestingly, a dose-dependent recovery of the NAA/Cho ratio was observed within $2 \mathrm{~h}$ after thiamine administration [45], while injections of a choline solution exerted only minor effects on the Cho resonance [75]. A satisfactory explanation for this observation is lacking and needs further investigation.

In order to investigate why administration of glucose precipitated Wernicke's encephalopathy in some patients with subclinical thiamine deficiency, the brain metabolites of thiamine-deficient rats were assessed under glucose load [34]. Proton MRS yielded dramatic increases of Lac, while animals presented with advanced neurological signs. These results were found to be consistent with a metabolic block at the reaction catalyzed by the thiamine-dependent enzyme $\alpha$-ketoglutarate dehydrogenase soon after the onset of neurologic symptoms, and a further block at the pyruvate dehydrogenase arising late in the course of thiamine deficiency [34]. Because this latter block precludes the further metabolism of pyruvate in the tricarboxylic cycle, it effectively eliminates the use of oxidative glucose consumption, so that glycolysis accumulates Lac.

\subsection{Diabetes and other disease models}

Diabetes mellitus is a complex metabolic disorder characterized by elevated blood glucose (hyperglycemia). It can lead to longterm complications in both the peripheral and the central nervous system. Type 1 diabetes is caused by insulin deficiency due to a 


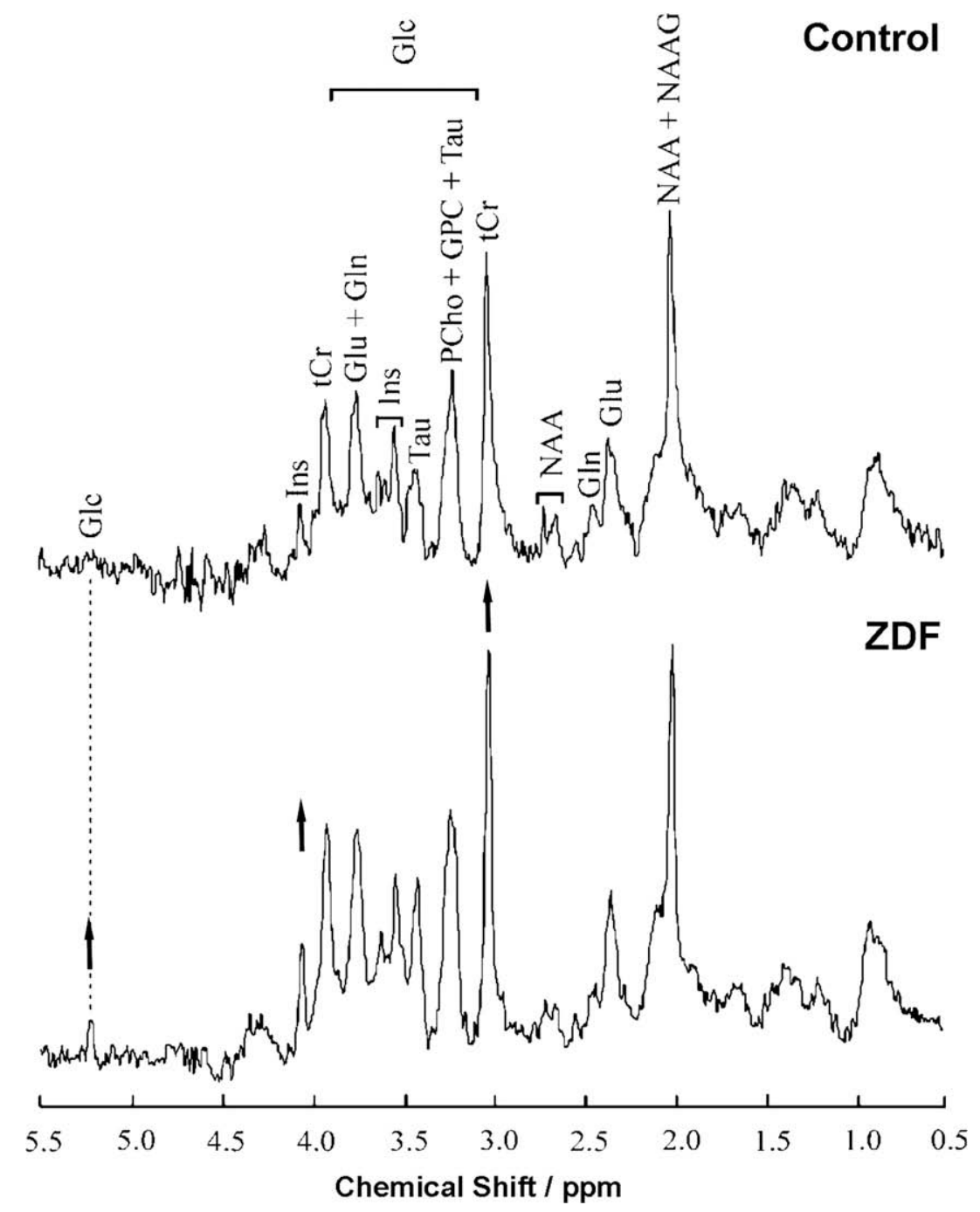

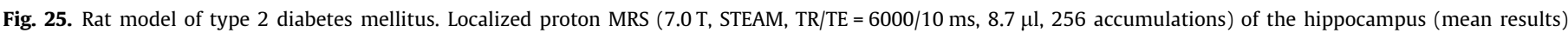

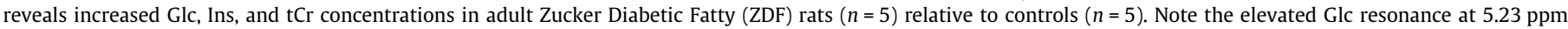
(arrows). Adapted from Ref. [92] with permission.

malfunction of the insulin-producing cells in the pancreas, while type 2 diabetes refers to insulin resistance of the body cells.

Proton MRS of streptozotocin-induced diabetic rats 2 weeks as well as 4 and 8 months after diabetes induction showed decreased $\mathrm{NAA} / \mathrm{tCr}$ ratios at all time points investigated [74]. The results were interpreted as a relative reduction of NAA possibly indicating early metabolic or functional abnormalities in neurons. A more recent quantitative proton MRS study focused on possible changes in the hippocampus of adult Zucker Diabetic Fatty (ZDF) rats [92]. The ZDF rat is a widely used animal model for type 2 diabetes mellitus. At about 10 weeks of age, ZDF rats become mildly hyperglycemic and thereafter develop overt diabetes. Quantitative analyses of the spectra shown in Fig. 25 revealed statistically significant increases for the hippocampal concentrations of Glc, Ins, and $\mathrm{tCr}$, while other metabolites including NAA and Cho remained normal between 20 and 28 weeks of age [92]. These findings are in line with observations in human patients and suggest the ZDF rat to present a reliable animal model for studying the effects of diabetes on brain metabolism. Noteworthy, the determination of absolute metabolite concentrations was instrumental in this study as the use of metabolite ratios (with $\mathrm{tCr}$ ) would have masked the increase of Glc and Ins.

Excitotoxicity has been suggested to play a key role in the pathogenesis of several cerebral disorders such as ischemia, Huntington's disease, trauma, and epilepsy. Two studies addressed the susceptibility of immature rat brain to the neurotoxicity of NMDA [49] and ouabain [87]. A modest accumulation of Lac was observed in the first $6 \mathrm{~h}$ after NMDA administration, followed by an overall decrease of all cerebral metabolites after $24 \mathrm{~h}$. Treatment with the NMDA antagonist MK-801 given up to 90 min after NMDA injection reversed these metabolite changes in the entire ipsilateral hemisphere [49]. However, with reference to NMDA, it has been argued that the use of ouabain, a $\mathrm{Na}^{+} / \mathrm{K}^{+}$-ATPase inhibitor, elicits more glutamate receptor overstimulation, so that ouabain-induced excitotoxicity might be better suited to monitor neuroprotective strategies [87].

Other proton MRS studies of rat brain investigated metabolite concentrations under hyponatremic conditions [50], in a hyperserotonemic model of autism [78], after repetitive low-frequency transcranial magnetic stimulation [88], in the developing hippocampus after perinatal iron deficiency [89], in pinelectomized rat brains to assess a putative protective role of melatonin [95], and after exposure to methylphenidate (Ritalin) [101].

\section{Nonhuman primates}

As pointed out earlier proton MRS studies of nonhuman primates offer anatomical, immunological, and functional similarities to 
humans that may be indispensable when addressing pathophysiological mechanisms of or novel therapeutic strategies against specific human brain disorders. So far, most studies used Old World monkeys such as rhesus monkeys or baboons and covered a broad range of disease models. Surprisingly, much less effort has been made to investigate New World monkeys such as common marmoset monkeys (Callithrix jacchus) which, because of their smaller body size than macaques, have considerable practical advantages as, for example, the applicability of dedicated small-bore animal magnets. While the taxonomic status of the diurnal-active tree shrews (Tupaia belangeri) is controversial, they are regarded as an intermediate between insectivores and primates and placed in the separate order Scandentia. Here tree shrews are included in this section, because their brain anatomy and metabolism has more in common with nonhuman primates than with rodents and because tree shrews have become a valuable model for studies of psychosocial stress [269,270].

\subsection{Normal physiology}

The first application of localized proton MRS to monkey brain relied on a long echo time and therefore revealed only resonances from NAA, tCr, and Cho [105]. Fig. 26 shows data from a state-ofthe-art proton MRS study of the brain of rhesus monkey (Macaca mulatta) [121]. With the use of a STEAM sequence and LCModel data analysis up to 16 metabolites could be identified in anesthetized animals. As for rodents, the metabolite assignments and concentrations are in general agreement with in vitro proton NMR studies of intact tissues and extracts from macaque brains [271273]. With respect to spectroscopic resolution at 7.0 T, the reduction of macroscopic susceptibility variations by decreasing the VOI from $3.14 \mathrm{ml}$ to $50 \mu$ l yielded linewidths of 14.2 and $7.6 \mathrm{~Hz}$, respectively [122]. As summarized in Table 2 linewidths of about $5 \mathrm{~Hz}$ were reported for rhesus monkey brain at $1.5 \mathrm{~T}$ [107] and $3.0 \mathrm{~T}$ [129] in agreement with linewidths of $6.3 \pm 0.9 \mathrm{~Hz}(n=15$, unpublished results) obtained at $2.35 \mathrm{~T}$ in the brain of tree shrews.

MRSI at a nominal spatial resolution of about $4 \mu$ lallowed for a segregation of gray and white matter in the visual cortex of rhesus monkeys by sorting individual spectra according to their different
Table 2

Proton MRS linewidths of rhesus monkey brain in vivo for different magnetic field strengths (in T) and volumes-of-interest (VOI).

\begin{tabular}{llll}
\hline Field/T & VOI/mm ${ }^{3}$ & Linewidth/Hz & Reference \\
\hline 1.5 & $25 \times 25 \times 12$ & $4-6$ & {$[107]$} \\
2.35 & $5 \times 3 \times 5$ & $4-5$ & Marmoset $^{\mathrm{a}}$ \\
2.35 & $7 \times 5 \times 7$ & 6 & Tree shrew $^{\mathrm{a}}$ \\
3.0 & $18 \times 18 \times 18$ & 5 & {$[129]$} \\
4.7 & $15 \times 15 \times 15$ & 16 & {$[109]$} \\
7.0 & $5 \times 5 \times 5$ & $8-11$ & {$[121,122]$} \\
\hline
\end{tabular}

a This lab, unpublished results.

metabolite levels [126]. Regional differences in the neurochemical profiles of common marmoset monkeys are demonstrated in Fig. 27. At the low field of $2.35 \mathrm{~T}$ excellent linewidths of about 3.7, 4.1, and $4.6 \mathrm{~Hz}$ were achieved for predominantly white matter, gray matter, and thalamus, respectively. In line with quantitative results obtained in macaque monkeys [122] and humans [245], higher tNAA concentrations were found in the gray matter of marmoset monkeys than in white matter. In comparison to other investigated brain regions elevated Cho concentrations were observed in the thalamus.

An interesting observation is reported in Fig. 28 which demonstrates increased Lac in the brain of macaque monkeys (Macaca fascicularis) under isoflurane anesthesia in a dose-dependent manner [129]. The midsagittal volume in frontoparietal cortex comprised contributions from gray matter, white matter, and CSF. With the use of diffusion-weighted localized proton MRS, the authors also found larger ADCs (corresponding to enhanced mobility) for all intracellular metabolites when increasing the isoflurane dose from $1 \%$ to $2 \%$ (opposite to the ADC decreases observed during ischemia). The results are explained by an increased membrane permeability at high levels of isoflurane which facilitates the exchange of metabolites between subcellular structures. Because a strict mitochondrial and cytosolic compartmentation is essential for efficient mitochondrial function, this could also explain why isoflurane has been suggested to inhibit oxidative metabolism [274].

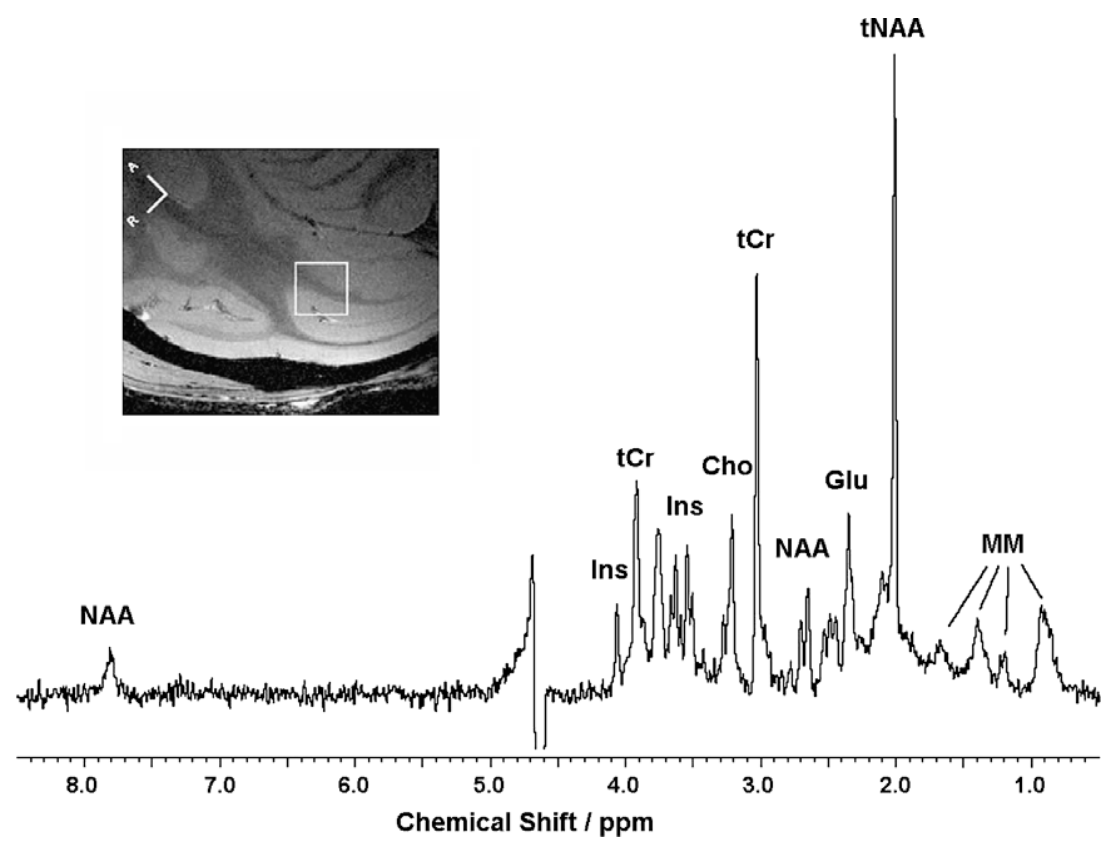

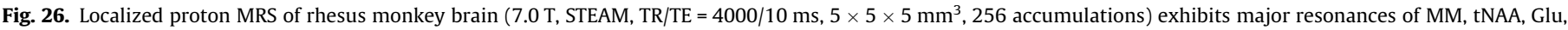
$\mathrm{tCr}$, Cho, and Ins. The use of LCModel allows for the reliable detection of about 16 metabolites. Adapted from Ref. [121] with permission. 

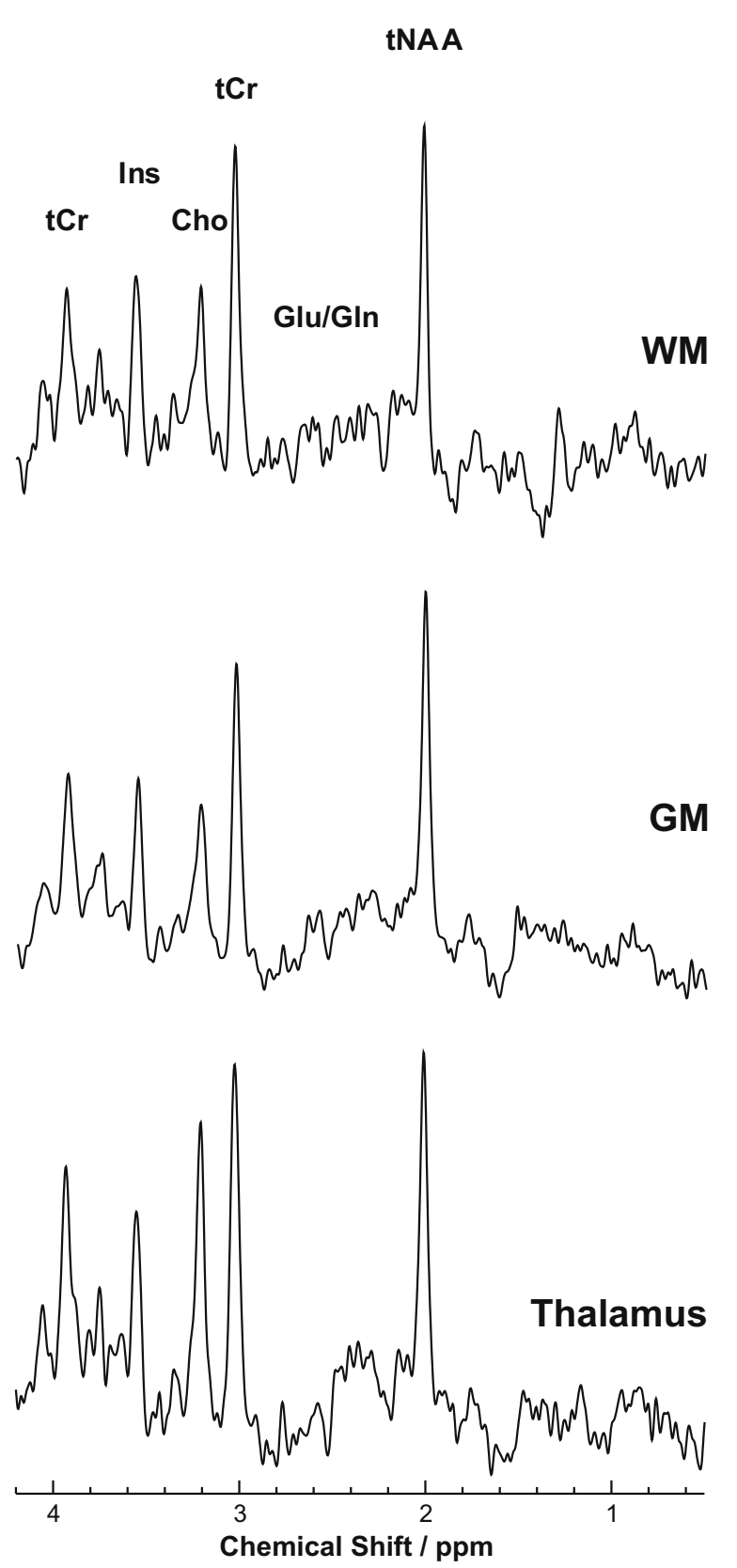

Fig. 27. Localized proton MRS of marmoset monkey brain (2.35 T, STEAM, TR/ $\mathrm{TE}=6000 / 20 \mathrm{~ms}, 128$ accumulations) reveals different neurochemical profiles for predominantly white matter $\left(\mathrm{WM}, 4.5 \times 3.0 \times 4.5 \mathrm{~mm}^{3}\right)$, gray matter (GM, $\left.5.0 \times 3.0 \times 5.0 \mathrm{~mm}^{3}\right)$, and thalamus $\left(6.0 \times 5.0 \times 6.0 \mathrm{~mm}^{3}\right)$. For example, while tNAA concentrations are highest in gray matter, Cho concentrations are highest in thalamus.

In humans, studies of the aging brain are commonly hampered by a large number of unknown variables and the need for unrealistically large groups of subjects. To overcome these drawbacks, putative influences of gender on aging, and separately on chronic cortisol treatment, were investigated in the tree shrew brain [102]. Physiological processes underlying brain aging are characterized by an increasing imbalance among the various neurotransmitters and neuromodulators resulting in significant structural and biochemical changes. In particular, dysregulation of the hypothalamus-pituitary-adrenal (HPA) axis appears to be a common phenomenon in aged mammals including humans. Therefore, excess availability of the adrenocortical glucocorticoid hormones cortisol and corticosterone may play an important role in aging. Moreover,
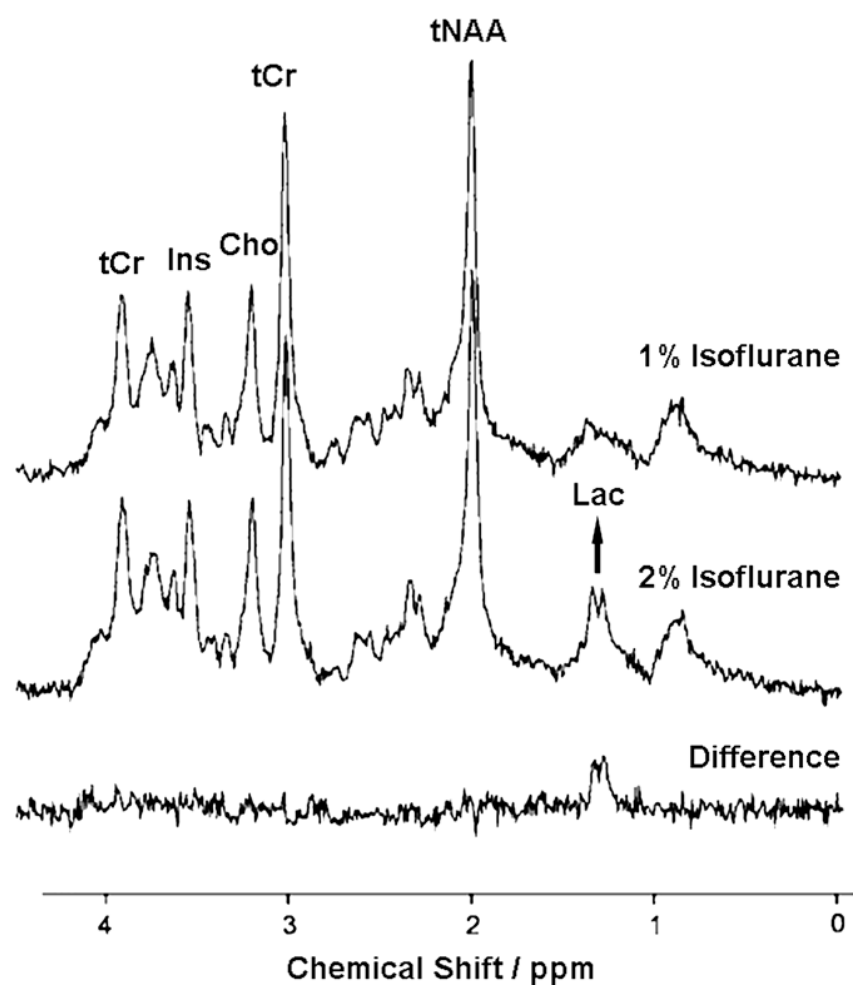

Fig. 28. Rhesus monkey brain under different doses of isoflurane anesthesia. Localized proton MRS (3.0 T, STEAM, TR/TE $=2100 / 21 \mathrm{~ms}, 18 \times 18 \times 18 \mathrm{~mm}^{3}, 32$ accumulations) under $1 \%$ and $2 \%$ isoflurane demonstrates increased Lac concentrations at the higher dose (see difference spectrum). Adapted from Ref. [129] with permission.

gender should be considered as another factor because, for example, the much higher secretion of plasma concentrations of corticosteroid hormones in females suggests sexual dimorphism in the regulation of the HPA axis activity. As demonstrated in Fig. 29, proton MRS of aged tree shrews indeed revealed lower concentrations of tNAA and $\mathrm{tCr}$ in line with the occurrence of neuronal loss. In contrast, however, aged females exhibited increased concentrations of Cho which, together with a tendency for increased $\mathrm{tCr}$ and Ins, indicates glial proliferation [102]. After administration of cortisol, male but not female tree shrews showed a specific reduction of Cho. The observed gender differences with age are likely to result from differences in the regulation of stress-related hormones which is further supported by the gender-specific responses to cortisol.

In nonhuman primates age-related changes of brain metabolites have been reported for juvenile macaques within the first 1000 days of life [117], and also for aged rhesus monkeys [113]. Similar to observations in humans, increasing NAA/tCr ratios during adolescence were interpreted as ongoing neuronal development [117], while aged rhesus monkeys presented with unchanged $\mathrm{NAA} / \mathrm{tCr}$ and $\mathrm{Cho} / \mathrm{tCr}$ ratios but a remarkable increase of the Ins/tCr ratio [113]. Because the latter study did not distinguish between males and females and also relied on metabolite ratios, the findings must be considered preliminary. For example, a simultaneous decrease of tNAA and $\mathrm{tCr}$, as typical for neuronal loss and observed in aged male tree shrews [102], would have been masked by the use of metabolite ratios.

\subsection{Cerebral ischemia}

So far, proton MRS studies of the ischemic monkey brain have confirmed the well-known increases of Lac and decreases of NAA 

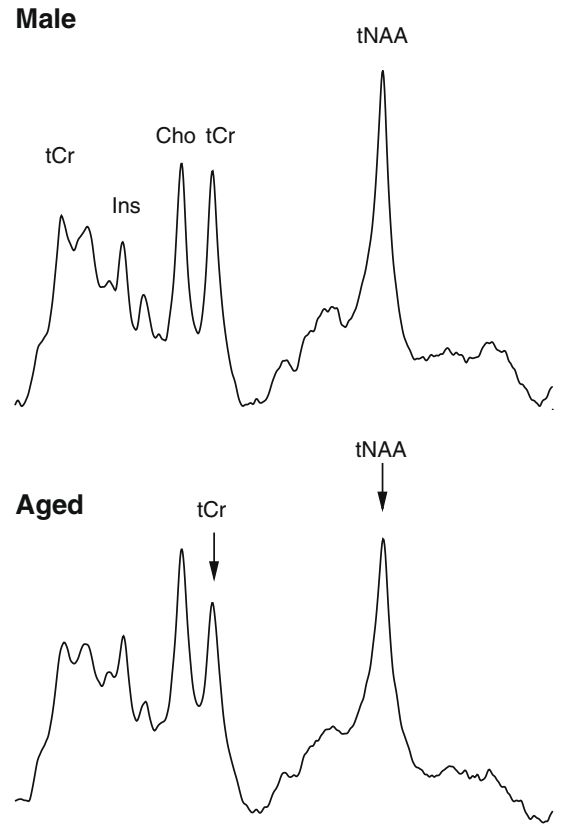

Cortisol

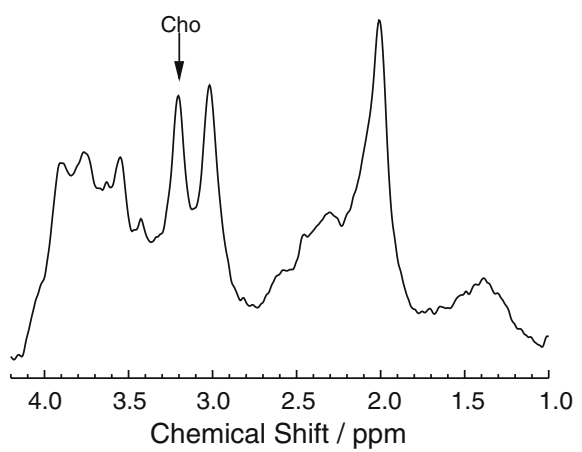

Female
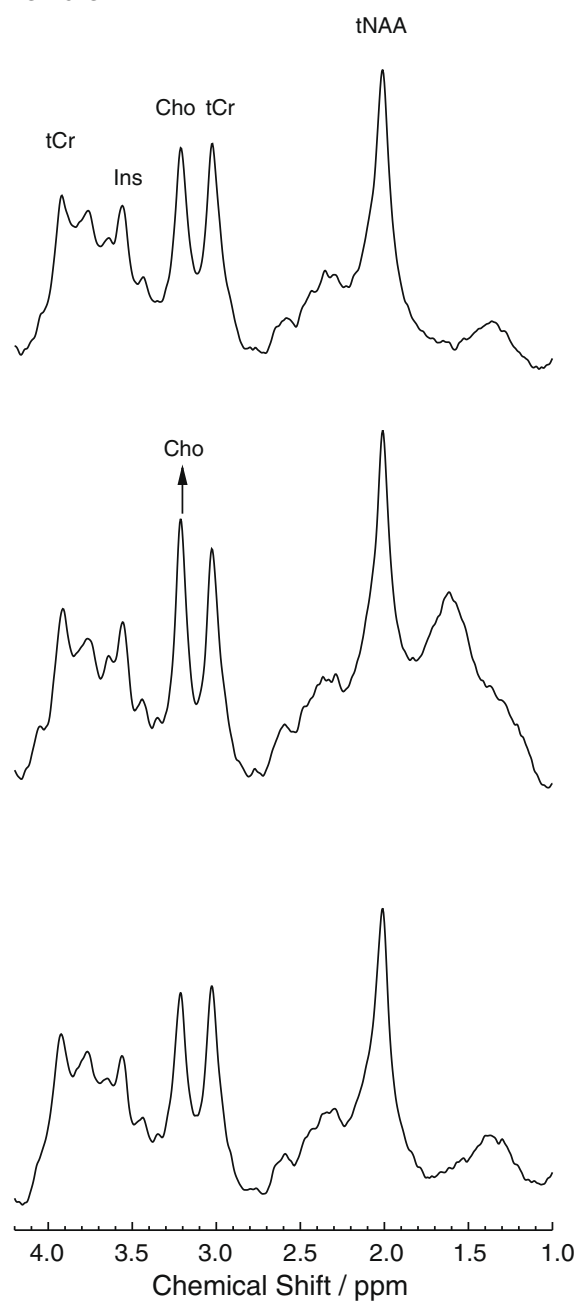

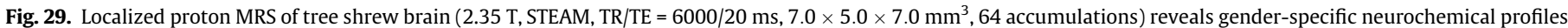

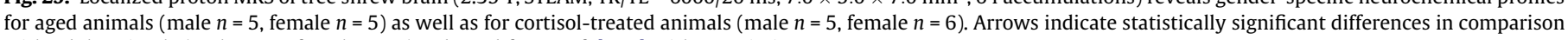
with adult animals (male $n=5$, female $n=6$ ). Adapted from Ref. [102] with permission.

several hours [106], days [110,127], or months [110,119] after the event. No scientific advances were made beyond the findings in rodents. However, future proton MRS of focal cerebral ischemia in monkeys may become important for the optimization of novel treatment options including drug efficiency and duration of the therapeutic window. This also involves the long-time monitoring of metabolite alterations in tissue at risk, that is in the penumbra adjacent to the core ischemic region.

\subsection{Multiple sclerosis}

In combination with $T_{2}$-weighted MRI and histology, localized proton MRS has been performed in macaques ( $M$. fascicularis) with EAE [109]. Acutely fatal EAE lesions were large and showed increased Cho concentrations at disease onset. Chronic EAE lesions were preceded by multiple inflammatory attacks and exhibited consistently low levels of NAA after the initial attack. The combination and temporal correlation of MRI lesion activity and MRS-determined metabolite concentrations was found to be useful for predicting the histologic lesion type and subsequent disease course. In general, the use of nonhuman primates for research on multiple sclerosis benefits from an immunological system comparable to that of humans. On the other hand, these similarities may cause a corresponding degree of heterogeneity as observed in human patients with multiple sclerosis which complicates study design and lowers statistical power in therapeutic trials.

\subsection{Parkinson's disease}

Long-term neurodegenerative changes have been studied in a primate model (M. fascicularis) of Parkinson's disease using multiple administrations of the mitochondrial complex-1 inhibitor MPTP [114]. For up to 10 months after MPTP proton MRS revealed dramatic increases of Lac and macromolecules in the striatum. By 2 years after MPTP, Lac and macromolecule levels had returned to normal values, while striatal tissue exhibited increased $\mathrm{Cho} / \mathrm{tCr}$ and decreased NAA/tCr ratios [114]. In a MPTP model of marmoset monkeys studied before and 3.5 weeks after intoxication, a daily oral dose of the vigilance enhancer modafinil demonstrated neuroprotective potential as indicated by a preserved $\mathrm{NAA} / \mathrm{tCr}$ ratio [130].

Exposure to high levels of manganese is known to produce a complex neurological syndrome with psychiatric disturbances, cognitive impairments, and Parkinsonian features. After chronic manganese exposure proton MRS of macaques ( $M$. fascicularis) yielded a decreased $\mathrm{NAA} / \mathrm{tCr}$ ratio in the parietal cortex [128]. Although the exact reason for the manganese-induced pathology 
is currently unknown, the findings may indicate ongoing neuronal dysfunction.

\subsection{Huntington's disease}

After chronic and systemic administration of the mitochondrial toxin 3NP quantitative proton MRS of baboons demonstrated a progressive and region-specific decrease of striatal NAA, $\mathrm{tCr}$, and Cho that occurred already 3 weeks before the first detection of Lac. Because these metabolic disturbances were not observed in an occipital control region as shown in Fig. 30, the NAA decrease does not appear to simply reflect the degree of mitochondrial impairment but indicates a preferential vulnerability of the striatum to 3NP-induced toxicity [115] similar to observations in rats. Further work demonstrated that early NAA depletion in this model corresponds to a reversible state of neuronal dysfunction preceding ultimate cell degeneration and death. Such findings suggest that in vivo NAA concentrations may become a valuable tool for the assessment of early neuronal dysfunction and a putative marker for the success of neuroprotective therapies [116].

\subsection{HIV encephalitis}

HIV infections that lead to AIDS are associated with abnormalities in the immune system that may cause neurological disorders known as neuroAIDS. The clinical syndromes include sensory neuropathy, myelopathy, HIV dementia, and cognitive/motor disorder. Rather than infecting neurons themselves, neuronal injury is thought to arise by indirect mechanisms. The virus infects perivascular macrophages and microglia within the CNS, and it is believed that substances including cytokines and viral products generated by these cells ultimately result in neuronal injury. Nonhuman primates infected with the simian immunodeficiency virus (SIV) are essential models in the development of novel treatment strategies such as highly active antiretroviral therapy.

A prospective longitudinal proton MRS study of the SIV macaque model examined SIVmac251-infected animals to terminal AIDS or an endpoint of 2 years [123]. During acute infection cerebral metabolites were characterized by a dominant increase of the $\mathrm{Cho} / \mathrm{tCr}$ ratio in frontal cortex. Subsequently, brain metabolite profiles diverged between individual animals and metabolite ratios were not significantly different from baseline at any time point after 2 weeks post inoculation. The increases of $\mathrm{Cho} / \mathrm{tCr}$ and Ins/ $\mathrm{tCr}$ ratios 11 days post inoculation were confirmed in another study using a larger number of animals [124]. Although these find- ings suggest brain injury and repair during acute SIV infection, Ins/ $\mathrm{tCr}$ ratios remained elevated at day 25 , while $\mathrm{Cho} / \mathrm{tCr}$ ratios decreased below normal values, as shown in Fig. 31 [123]. In a further study SIV infection and CD8 lymphocyte depletion resulted in rapid neuronal injury as indicated by a pronounced decrease of the $\mathrm{NAA} / \mathrm{tCr}$ ratio during the first 10 weeks [125]. This finding is in line with MRS studies of respective mouse models. Animals which underwent an antiretroviral combination therapy immediately

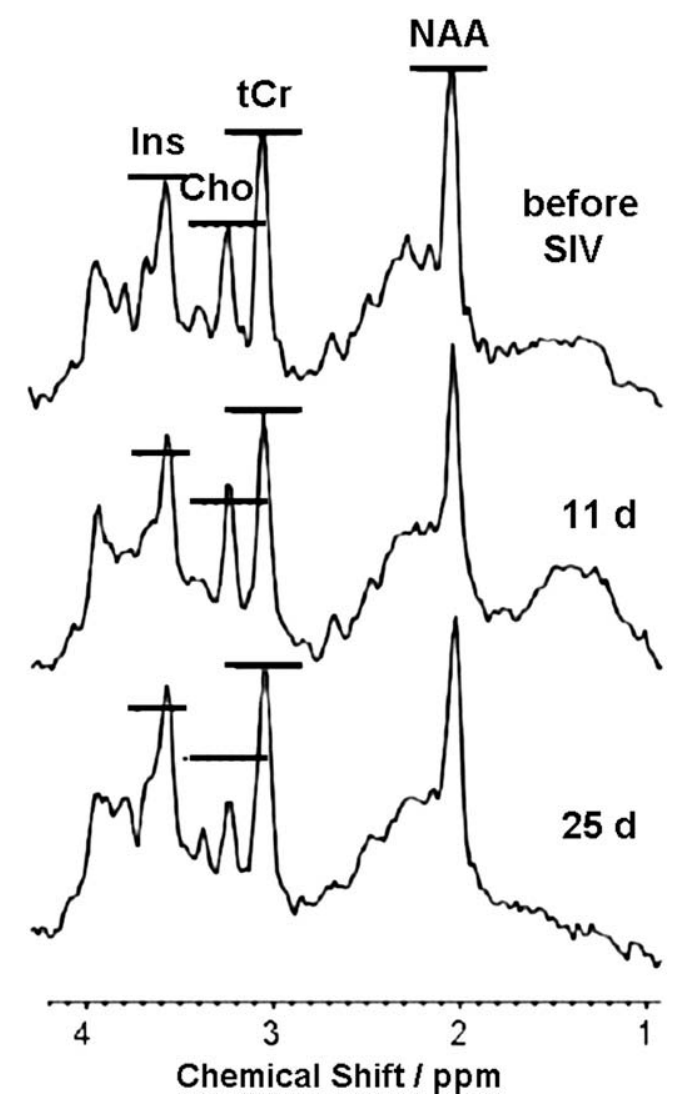

Fig. 31. Rhesus monkey model of SIV infection. Localized proton MRS (1.5 T, PRESS $\mathrm{TR} / \mathrm{TE}=3000 / 35 \mathrm{~ms}, 15 \times 15 \times 15 \mathrm{~mm}^{3}, 128$ accumulations) of the frontal lobe before as well as 11 and 25 days after i.v. inoculation with SIVmac251 reveals alterations of $\mathrm{Cho} / \mathrm{tCr}$ and $\mathrm{Ins} / \mathrm{tCr}$ ratios (as indicated by respective bars). Adapted from Ref. [124] with permission.
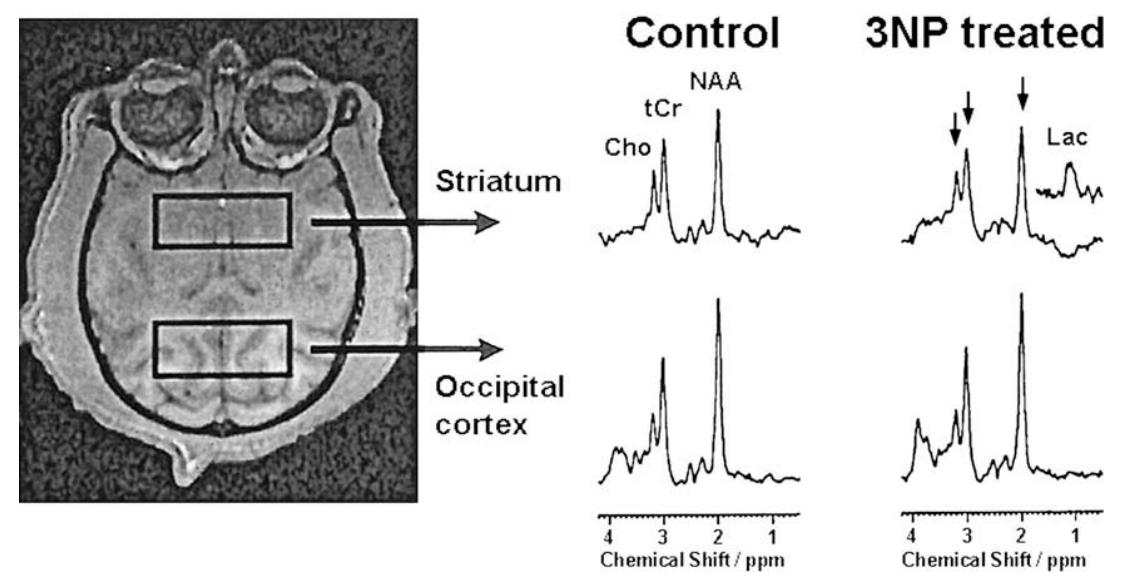

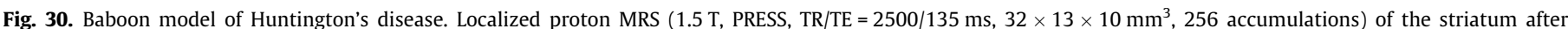

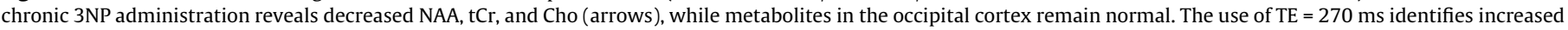
Lac (insert). Adapted from Ref. [115] with permission. 
after the observation of a significant NAA/tCr decrease, showed a rapid recovery of the $\mathrm{NAA} / \mathrm{tCr}$ ratio after 2 weeks of treatment reaching almost pre-infection levels after 4 weeks [125]. Although preliminary and based on metabolite ratios, these studies demonstrate the ability of in vivo MRS to monitor therapeutic approaches in an advanced animal model of neuroAIDS.

\subsection{Psychosocial stress and depression}

Chronic stress causes neurochemical, hormonal, and physiologic changes and acts as a potent trigger of major depressive disorder. In recent years, adult male tree shrews have been developed as a valuable animal model for depression based on chronic psychosocial stress [269,270], that is daily exposure to a dominant male for several weeks. Using quantitative proton MRS of absolute metabolite concentrations, the brains of stressed tree shrews exhibited significantly decreased in vivo concentrations of tNAA, $\mathrm{tCr}$, and Cho $[103,104]$. Although the concomitant reductions are clearly visible in the upper part of Fig. 32, they would have escaped detection when using metabolite ratios (with $\mathrm{tCr}$ ), a finding which may explain the conflicting results of clinical MRS studies of depressed subjects. The observed tNAA reduction reflects a lower neural cell density and/or neuronal dysfunction. Accordingly, alterations of the Cho level may result from disturbances in the formation and degradation of cell membranes or, because Cho is highly concentrated in oligodendrocytes [240], a respective reduction of cell density. Interestingly, a low number of oligodendrocytes was reported postmortem in patients with major depressive disorder [275]. A reduced cellular density of neurons and/or oligodendrocytes is in line with the lowered concentration of $\mathrm{tCr}$ as a constituent of all cells. Moreover, the unchanged concentration of the marker compound Ins indicates a preservation of astrocytes.

Medication in depression attempts to normalize the concentrations of neurotransmitters, notably serotonin and norepinephrine, but also dopamine. To mimic a realistic situation of antidepressant medication in an animal model, tree shrews were subjected to a period of psychosocial stress to elicit stress-induced endocrine and central nervous alterations before the onset of daily oral administration of the drugs. Psychosocial stress was continued during treatment. As demonstrated in the lower parts of Fig. 32, the stress-induced decreases of $\mathrm{tNAA}, \mathrm{tCr}$, and Cho were prevented by antidepressant treatment with tianeptine [103], clomipramine [104], and the neurokinin $1\left(\mathrm{NK}_{1}\right)$ receptor antagonist L-760,735 [104]. The latter two drugs had an even more enhancing effect on brain metabolites than tianeptine and also led to elevated Ins concentrations [104]. Similar treatment results were obtained for the novel $\mathrm{NK}_{1}$ receptor antagonist SLV-323 [276]. Taken together, the proton MRS results confirm a direct neurobiologic effect of chronic stress and suggest a similar protective effect for different classes of antidepressants. Moreover, it may be speculated that the used antidepressants preserved or even stimulated oligodendritic activity, and consequently counteracted neural resilience.

\subsection{Developmental disturbances}

Similar to the results in rat brain, proton MRS of macaque brain revealed normal NAA, tCr, and Cho levels after acute ethanol administration [107]. In contrast, however, adult monkeys (Macaca nemestrina) at 2 and 4 years of age but with a prenatal history of ethanol exposure exhibited increased $\mathrm{Cho} / \mathrm{tCr}$ ratios [108]. These alterations occurred in the absence of gross structural brain abnormalities and were correlated with ethanol-related cognitive and behavioral dysfunction. The study clearly demonstrated that fetal brain development is influenced by ethanol and that long-lasting metabolic effects persisting to adulthood are detectable by proton MRS in vivo.
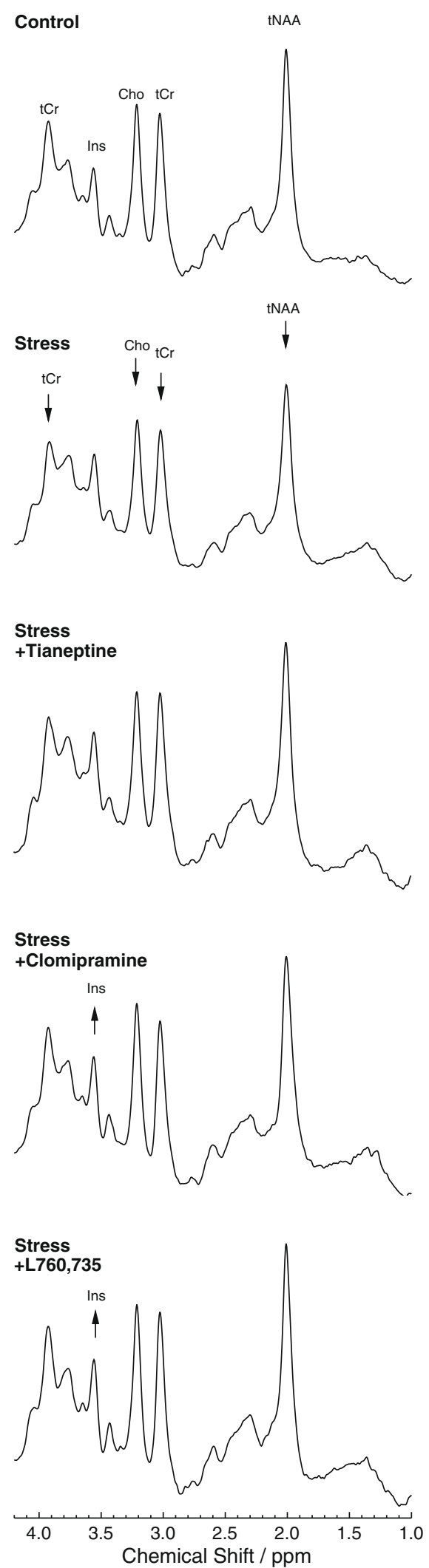

Fig. 32. Tree shrew model of psychosocial stress and antidepressant treatment. Localized proton MRS $\left(2.35 \mathrm{~T}\right.$, STEAM, TR/TE $=6000 / 20 \mathrm{~ms}, 7.0 \times 5.0 \times 7.0 \mathrm{~mm}^{3}, 64$ accumulations) of the brain (mean results) reveals stress-induced decreases of tNAA, tCr, and Cho $(n=11)$ which are prevented by antidepressant treatment with tianeptine $(n=6)$, clomipramine $(n=5)$, and the neurokinin-1 receptor antagonist L-760,735 $(n=5)$. Arrows indicate statistically significant differences in comparison with controls $(n=9)$. Adapted from Refs. [103,104] with permission. 
Developmental alterations were also found in adult nonhuman primates exposed to early-life stressors. For a few months, Bonnet macaque (Macaca radiata) mother-infant dyads were exposed to uncertain requirements for food procurement, that is variable foraging demand. Ten years later, these animals displayed significantly decreased $\mathrm{NAA} / \mathrm{tCr}$ and increased $\mathrm{Glx} / \mathrm{tCr}$ ratios in the anterior cingulate cortex [118]. In the medial temporal lobe, the $\mathrm{Cho} / \mathrm{tCr}$ ratio was increased. These findings indicate that adverse early rearing in primates has an enduring impact on adult metabolite concentrations that are considered to reflect neuronal integrity, membrane structure, and glial function [118]. Interestingly, the observed metabolite alterations occurred in the same brain regions implicated in trauma-related psychiatric disorders.

Another proton MRS study investigated the long-term effects of early mesial temporolimbic lesions on neurons of the prefrontal cortex [112]. A reduction of the NAA/tCr ratio in the prefrontal cortex was exclusively observed in rhesus monkeys lesioned neonatally, that is within 3 weeks of birth, but not in animals lesioned at adulthood. The authors concluded that, apart from developmental aspects, this finding may have implications for similarly reduced NAA levels in the hippocampus and prefrontal cortex of patients with schizophrenia.

\subsection{Radiation effects}

The neurochemical consequences of radiation therapy on normal brain tissue were assessed in monkeys (Macaca fuscata) using sequential proton MRS after interstitial brachytherapy [111]. The hemisphere with the sealed radioactive source showed significantly decreased $\mathrm{NAA} / \mathrm{tCr}$ and $\mathrm{Cho} / \mathrm{tCr}$ ratios one week after implantation, while the contralateral side exhibited a trend toward decreased metabolite ratios. Lac was not detected. The results suggest the use of proton MRS for a differentiation of radiation necrosis from residual and/or recurrent glioblastomas with the use of contralateral comparisons after radiation therapy [111].

\section{Other animal models}

\subsection{Gerbils, squirrels, guinea pigs, and rabbits}

The Mongolian gerbil (Meriones unguiculatus) has been used as a popular model for cerebral ischemia [131,196-198]. The cere- bral vasculature of the gerbil is characterized by an incomplete circle of Willis, so that animals lack a collateral supply of arterial blood to the forebrain and hindbrain circulations from both the vertebral and carotid arteries. Although this might be of advantage for experimental purposes, it has been stated that the neuroanatomy of the gerbil is unfavorable for proton MRS [199]. However, studies of global ischemia achieved sufficient spectral resolution to detect increased Lac/NAA ratios [196,197] as well as decreased $\mathrm{Cho} / \mathrm{tCr}$ ratios and increased $T_{2}$ values of Cho [198]. In a quantitative proton MRS study during and after ischemia altered NAA concentrations could be correlated with graded hippocampal damage and stereologically determined neuronal density [131].

Hibernation is a state of inactivity and metabolic depression in animals to conserve energy during winter. It is characterized by a lower body temperature, slower breathing, and lower metabolic rate. The effects of near-freezing temperatures $\left(7^{\circ} \mathrm{C}\right)$ on brain energy metabolism and neurotransmission were studied in hibernating 13-lined ground squirrels (Spermophilus tridecemlineatus) [132]. As demonstrated in Fig. 33, the $\mathrm{PCr} / \mathrm{Cr}$ ratio determined at 9.4 T was increased during torpor indicating enhanced stores of high-energy phosphates. The ratio remained increased, albeit to a lesser degree, during interbout arousal (IBA), but returned to a normal level in the spring. The decreased Glu and Gln concentrations during torpor suggest that the generally lowered metabolism in hibernation is accompanied by a reduction of the excitatory neurotransmitter levels [132]. Localized proton MRS of hibernating mammals may become helpful in the search for novel neuroprotective strategies after stroke.

In a model of multiple sclerosis Dunkin-Hartley guinea pigs were followed sequentially 6 weeks post EAE inoculation by nonlocalized proton MRS [200]. The detection of an increased Cho/ $\mathrm{tCr}$ ratio in vivo was associated with an increase of choline, betaine, and phosphocholine as revealed by in vitro NMR spectroscopy of PCA extracts of respective brain tissue.

New Zealand white rabbits were intensively studied to monitor cerebral Lac elevation (and recovery) during hypoxemia [201], hyper- and hypocarbia [202], bicuculline-induced seizures [203], and cortical electroshock [204,205]. A further study reported a good agreement between cerebral and blood ethanol concentrations at all times after intraarterial or intragastric ethanol administration [206].

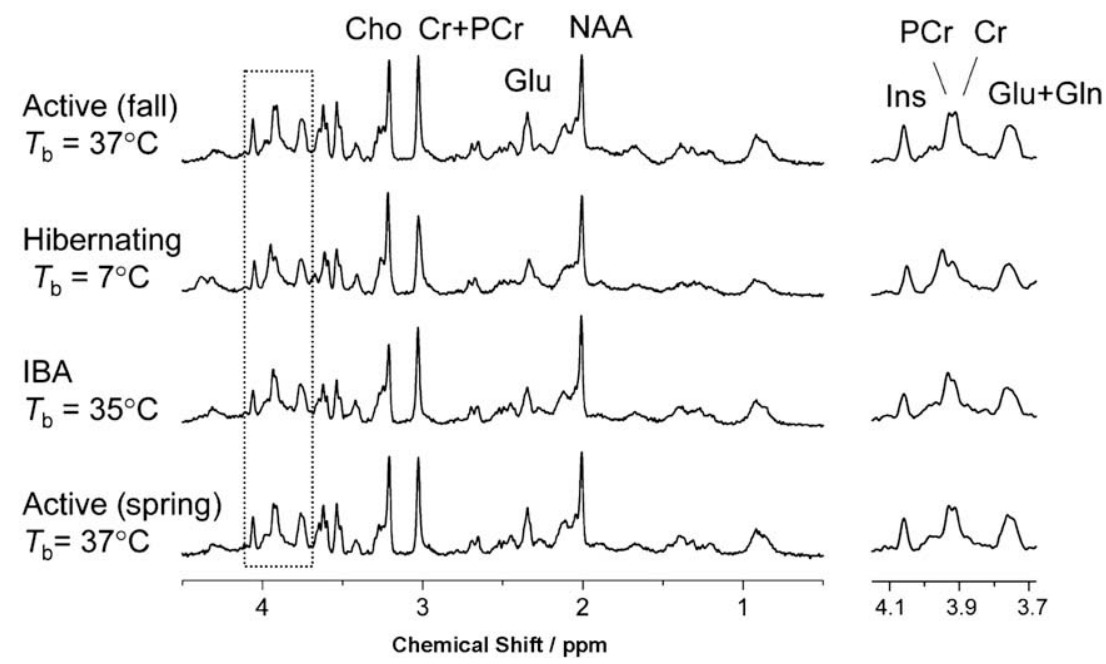

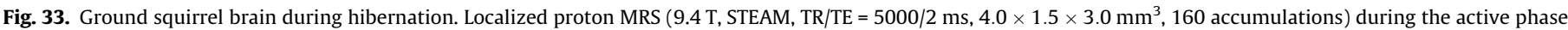

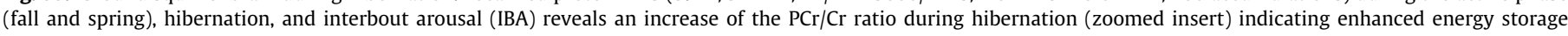
( $T_{\mathrm{b}}=$ body temperature). Adapted from Ref. [132] with permission. 


\subsection{Cats and dogs}

The majority of proton MRS applications to cat brain investigated hypoxia and ischemia. The first studies used a surface coil after scalp and muscle retraction to acquire otherwise nonlocalized spectra during hypoxia and/or ischemia [207-209]. These as well as subsequent fully localized recordings [133-135,137] reported metabolite changes upon death (global ischemia) in close agreement with the results obtained in rodent models of ischemia. In particular, relative to the pre-ischemic signal, Lac increased rapidly in the first $2 \mathrm{~h}$ of ischemia and was stabilized afterwards, while NAA and $\mathrm{tCr}$ decreased by about 35\% within the first $8 \mathrm{~h}$ [134]. Serial measurements of water ADCs and Lac concentrations agreed with the expected biphasic changes due to changes of the ion and water homeostasis during global ischemia [135]. Moreover, alterations in the low-field part of the proton MR spectrum shown in Fig. 34 indicated enhanced signals from purine nucleotides as the ATP breakdown products $[133,135,137]$. The combination of proton MRS with perfusion- and diffusion-weighted MRI was found to be advantageous for a time-resolved assessment of the circulatory and metabolic recovery of cat brain after cardiac arrest [139].

In a cat model of Parkinson's disease using MPTP intoxication the authors reported reduced striatal $\mathrm{NAA} / \mathrm{tCr}$ and $\mathrm{Glx} / \mathrm{tCr}$ ratios as well as elevated Lac in all investigated animals [140]. Infection with the feline immunodeficiency virus led to frontal lobe neuronal injury in terms of reduced $\mathrm{NAA} / \mathrm{tCr}$ and increased $\mathrm{Cho} / \mathrm{tCr}$ ratios in infected cats. Moreover, neuropathologic changes, including neuronal damage and astrogliosis, were dependent on virus input titer [138].

The first studies of dog brain addressed the feasibility of solvent-suppressed proton MRS [210], $T_{1}$ measurements of NAA, $\mathrm{tCr}$, and Cho [211], the role of Lac as a preferential metabolic fuel for the neonatal dog brain [212], and the MRS visibility of ethanol in brain tissue [214,215]. Quantitative proton MRS of normal brain revealed general agreement between in vivo and in vitro results [142]. As shown in Fig. 35 the postmortem catabolism of cerebral metabolites was studied as a potential diagnostic aid in legal medicine [144]. Disease models comprised status epilepticus [213], prolonged generalized seizures [146], and fulminant hepatic failure [145]. In a canine brain tumor model reduced NAA and $\mathrm{tCr}$ as well as elevated Lac concentrations significantly correlated with

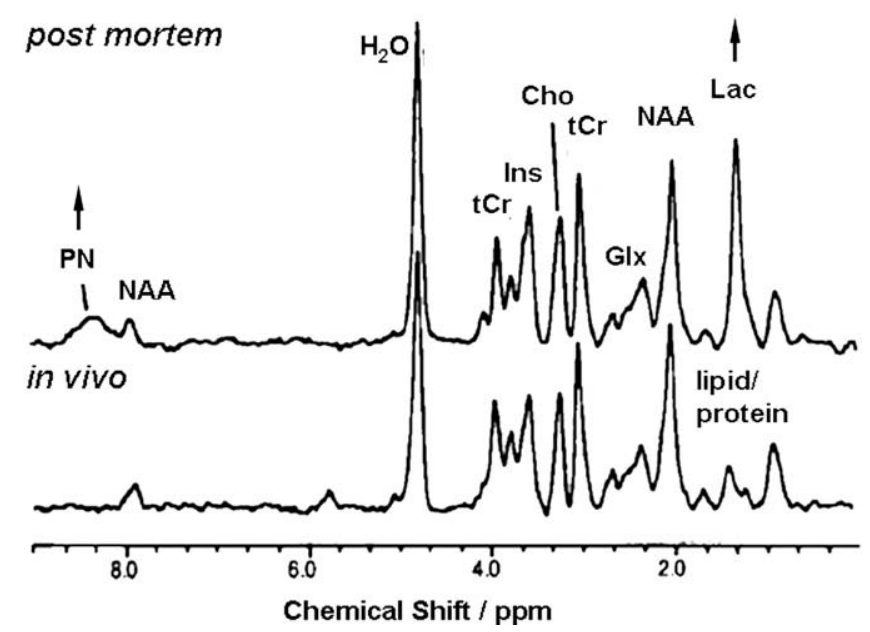

Fig. 34. Cat model of global cerebral ischemia (postmortem). Localized proton MRS (4.7 T, STEAM, TR/TE $=1000 / 4.8 \mathrm{~ms}, 20 \times 10 \times 20 \mathrm{~mm}^{3}, 16$ accumulations) of the brain reveals increased resonances (arrows) of Lac and the combined purine nucleotides/nucleosides and hypoxanthine (PN) 1 h postmortem. Adapted from Ref. [135] with permission.

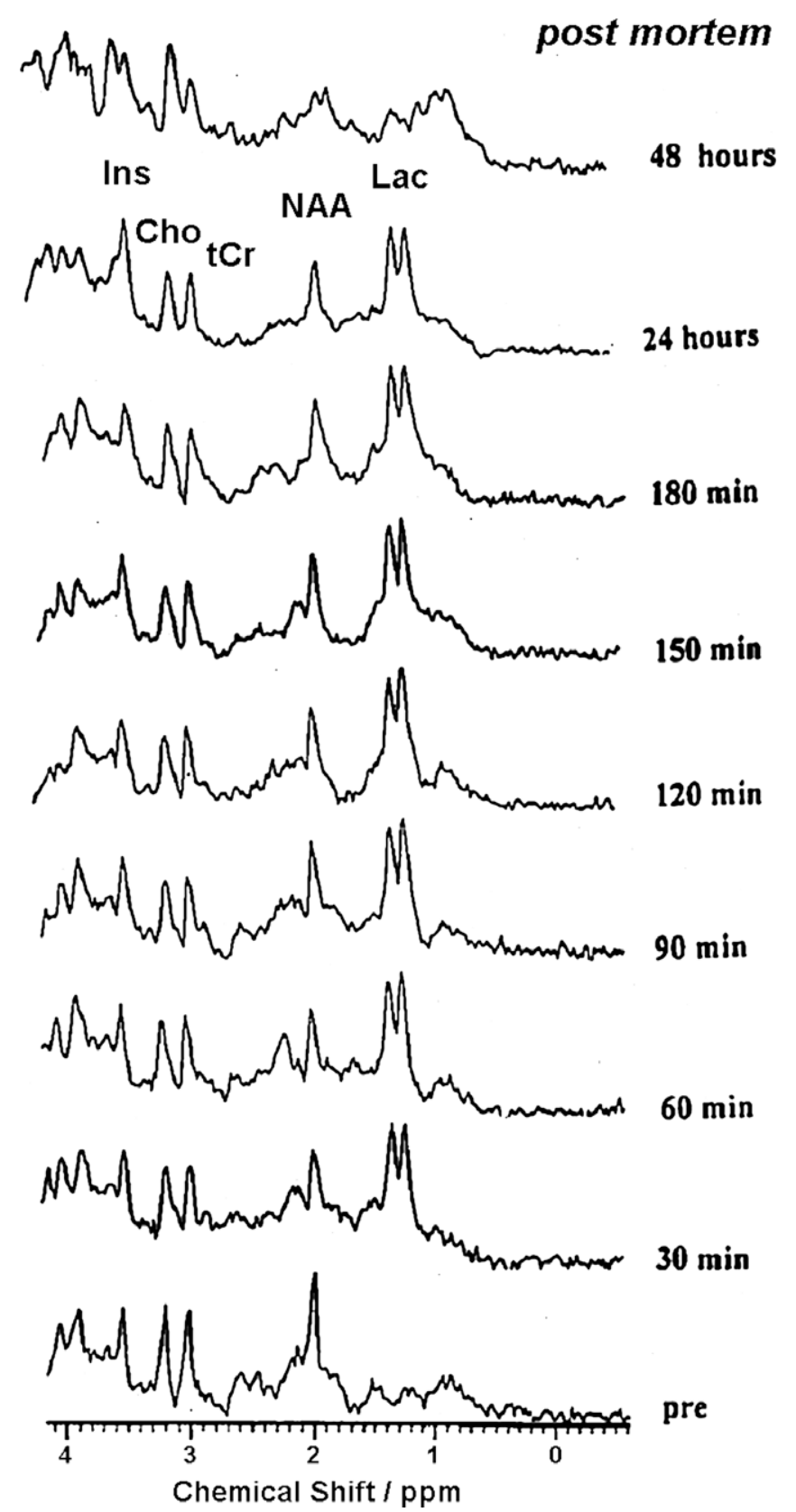

Fig. 35. Dog model of global cerebral ischemia (postmortem). Localized proton MRS $\left(1.5 \mathrm{~T}, \mathrm{STEAM}, \mathrm{TR} / \mathrm{TE}=2000 / 20 \mathrm{~ms}, 15 \times 15 \times 15 \mathrm{~mm}^{3}, 128\right.$ accumulations $)$ of the thalamus reveals increases of Lac and the Ins/tCr ratio 30 min to $48 \mathrm{~h}$ postmortem, while $\mathrm{NAA} / \mathrm{tCr}$ and $\mathrm{Cho} / \mathrm{tCr}$ ratios remain constant within the first $24 \mathrm{~h}$. Adapted from Ref. [144] with permission.

total lesion volume $[141,143]$. These tumor spectra were similar to those observed in human glioblastomas, with the exception that Cho was not elevated [143].

\subsection{Sheep and swine}

As in early studies of global ischemia in cat brain, simple surface coil proton MRS approaches were used to assess episodes of ischemia and hypoxia-ischemia in lambs (Clun forest breed). These studies elucidated the relationships between cerebral oxidative metabolism and anaerobic glycolysis [216] and examined the effects of systemic glucose and sodium bicarbonate administration on ischemic brain metabolism [217]. More recent localized proton 
MRS studies addressed cerebral hypoxia in the fetal lamb (Dutch texel breed). First of all, the relative intensity of NAA turned out to be much higher in fetal lamb brain than in humans indicating a more mature status at an earlier stage of gestation [147]. During hypoxia elevated levels of Lac were observed. As shown in Fig. 36 a reduction of oxygen supply to the anesthetized pregnant ewe caused a sudden and dramatic increase of Lac during hypoxia followed by a slower decrease of NAA [148]. Together with simultaneous physiological measurements the results support the view that a hypoxia-induced switch to anaerobic metabolism in the fetal lamb brain only occurs if the arterial blood $\mathrm{pH}$ or the base excess falls below a certain value.

Several surface coil MRS studies investigated the effects of hypoxia-ischemia in the brain of newborn Large White piglets

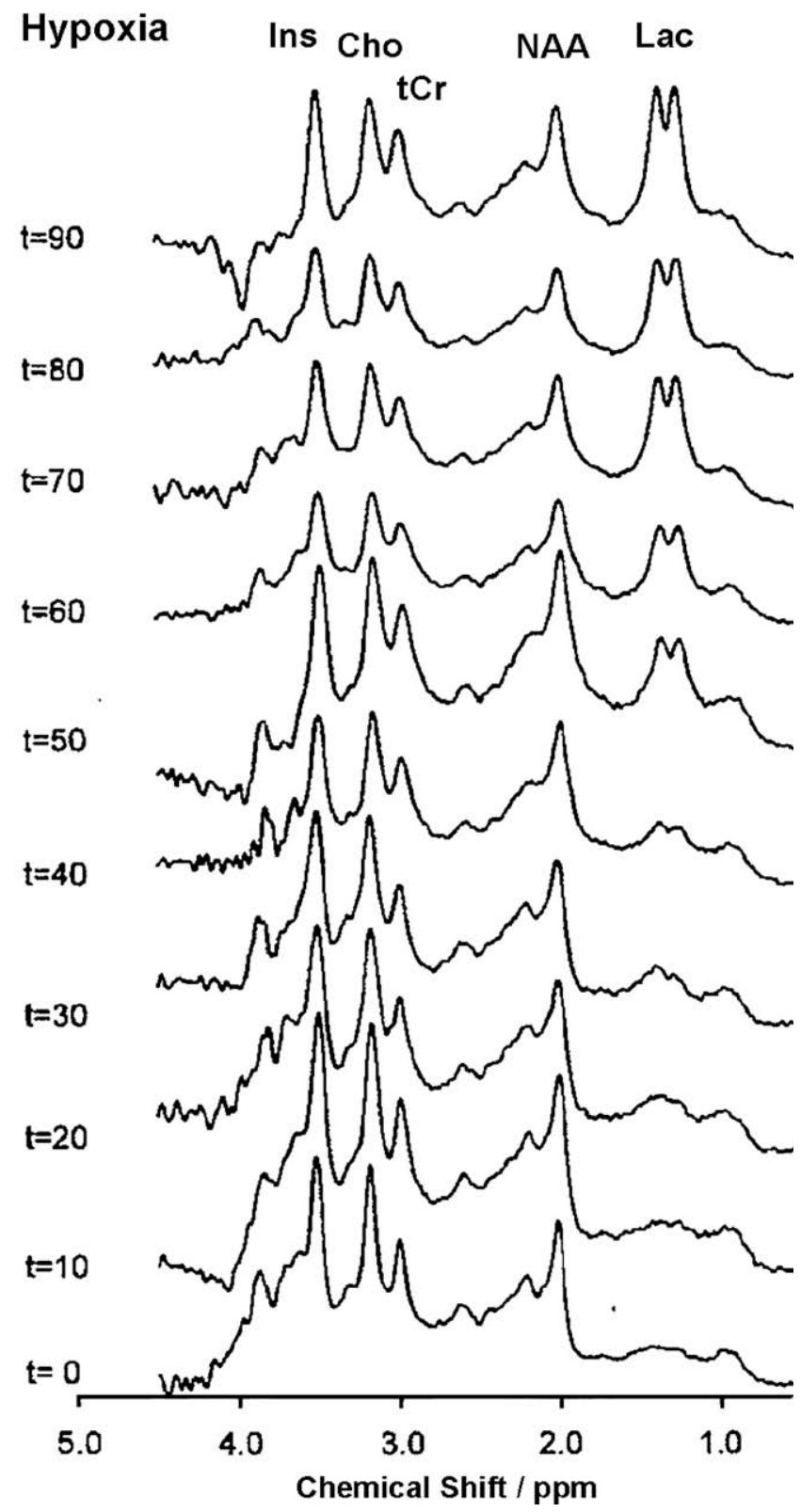

Fig. 36. Lamb model of fetal hypoxia. Localized proton MRS (1.5 T, STEAM, TR/ $\mathrm{TE}=2500 / 30 \mathrm{~ms}, 3.6-7.5 \mathrm{~cm}^{3}, 64$ accumulations) of the brain before $(t=0)$ and during fetal hypoxia reveal dramatic increases of Lac within $60 \mathrm{~min}$ after reduced oxygen supply to the pregnant ewe. While NAA decreases during hypoxia, Ins, Cho, and $\mathrm{tCr}$ remain constant. Relatively high levels of NAA in the fetal brain indicate an earlier brain maturation than in humans. Adapted from Ref. [148] with permission.
[218-220]. By combining proton and phosphorus MRS dramatic changes of the cerebral energy metabolism were detected [218]. After a normalization within hours after hypoxia-ischemia a delayed secondary energy failure occurred [219]. Moreover, mild hypothermia after hypoxia-ischemia reduced the delayed rise in cerebral Lac and showed neuroprotective potential [220]. A more recent study of a similar model using Yorkshire Large White piglets confirmed the metabolite alterations and their time courses during and after hypoxia-ischemia [150]. Although the authors suggested elevated nitric oxide to contribute to free radical-induced brain damage, an attempt to inhibit nitric oxide synthase by $N^{\omega}$-nitroL-arginine appeared to compromise the cerebral energy status during and after cerebral hypoxia-ischemia.

Finally, miniature swine (Hanford strain) were used to investigate diffuse brain trauma [149]. The temporal course of metabolite changes revealed widespread axonal injury in the absence of markedly elevated Lac. As shown in Fig. 37 the NAA/tCr ratio decreased in the acute phase and remained without recovery during the investigated period.

\subsection{Summary}

Gerbils, squirrels, guinea pigs, and rabbits are animal models for human brain disorders that are rarely studied by proton MRS in vivo. In view of the rapid progress in high-field MRS of genetically modified mice and the large data base available from rats, it is unlikely that these species will gain more importance. Similar arguments hold true for cats and dogs as well as for sheep and swine which further face the problem that their size precludes the use of a dedicated animal MRI system. In general, the animals

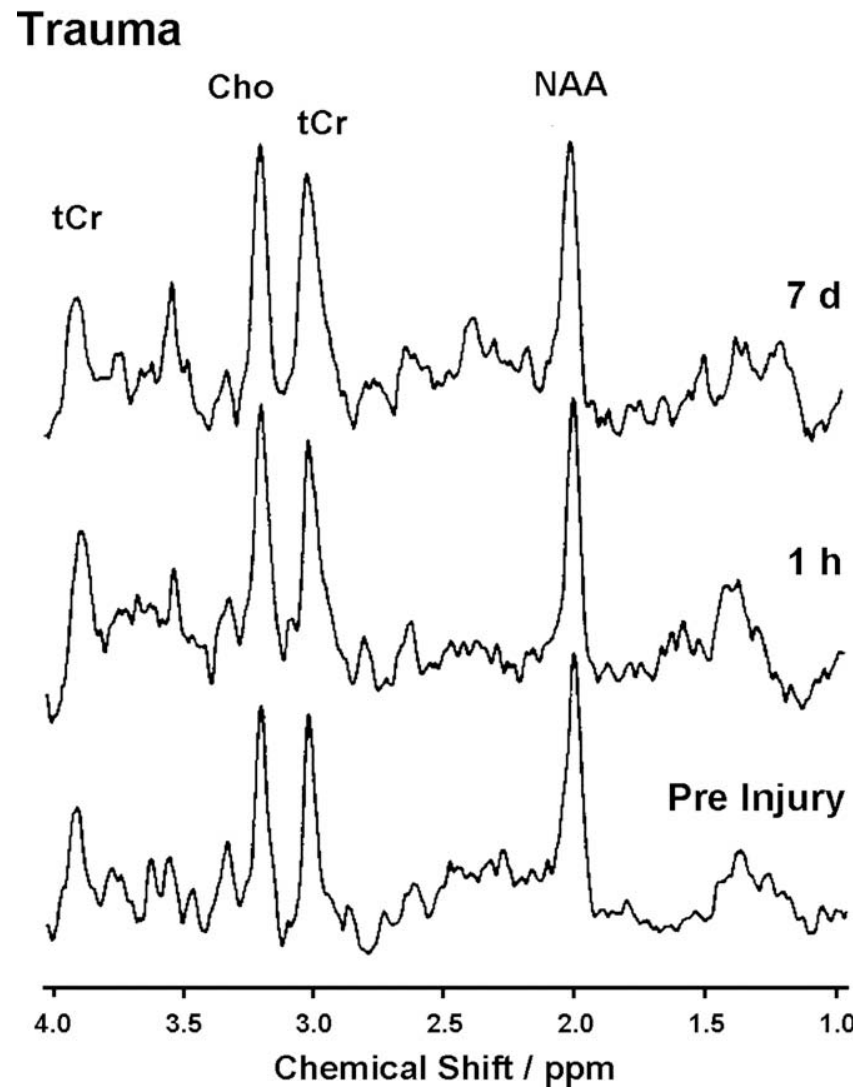

Fig. 37. Swine model of diffuse brain trauma. Localized proton MRS (4.0 T, STEAM, $\mathrm{TR} / \mathrm{TE}=2000 / 31 \mathrm{~ms}, 15 \times 15 \times 15 \mathrm{~mm}^{3}, 128$ accumulations) of the brain before and after trauma demonstrates an acute decrease of the NAA/tCr ratio which persists for at least 7 days post injury. Adapted from Ref. [149] with permission. 
discussed in this section will find niche applications for speciesspecific questions including research outside the field of neuroscience or neurology.

\section{Concluding remarks}

Localized proton MRS of animal brain in vivo has become a valuable tool for both preclinical research and basic neuroscience. Nevertheless, the reliable assessment of cerebral metabolism in animal models of human brain disorders requires robust solutions to a number of technical issues. In this respect the past two decades have witnessed tremendous advances ranging from the development of adequate spectral localization methods to the identification and assignment of metabolite resonances and the development of suitable quantification methods for translating resonance intensities into absolute metabolite concentrations. Nowadays, localized proton MRS is increasingly used for the evaluation of neurochemical profiles in animal models using (transgenic) mice, rats, and nonhuman primates. It is foreseeable that the hitherto dominating studies of rat brain will be replaced by the increasing availability of genetically modified mice and, if necessary, complemented by studies of nonhuman primates because of their similarity to humans. Thus, noninvasive MRI and MRS studies will help to bridge the gap from molecular biology and neurogenetics to preclinical neurological research. In general, proton MRS seldom provides unambiguous diagnostic clues, but more often unravels metabolite profiles characteristic of alterations in intracellular metabolism or cellular composition. MRS findings are expected to advance our understanding of the pathophysiological mechanisms underlying human neurological and psychiatric disorders and enhance our ability to guide the effectiveness of novel therapeutic interventions.

\section{Acknowledgment}

The authors wish to thank Alireza Abaei for his support in the preparation of figures.

\section{References}

[1] D. Hesselbarth, C. Franke, R. Hata, G. Brinker, M. Hoehn-Berlage, NMR Biomed. 11 (1998) 423.

[2] B.G. Jenkins, P. Klivenyi, E. Kustermann, O.A. Andreassen, K.L. Ferrante, B.R Rosen, M.F. Beal, J. Neurochem. 74 (2000) 2108.

[3] A. van Dellen, J. Welch, R.M. Dixon, P. Cordery, D. York, P. Styles, C. Blakemore, A.J. Hannan, Neuroreport 11 (2000) 3751.

[4] W. Huang, Z. Galdzicki, P. van Gelderen, A. Balbo, E.G. Schapiro, S.I. Rapoport Neuroreport 11 (2000) 445 .

[5] R. Matalon, P.L. Rady, K.A. Platt, H.B. Skinner, M.J. Quast, G.A. Campbell, K. Matalon, J.D. Ceci, S.K. Tyring, M. Nehls, S. Surendran, J. Wei, E.L. Ezell, S. Szucs, J. Gene Med. 2 (2000) 165

[6] O.A. Andreassen, A. Dedeoglu, R.J. Ferrante, B.G. Jenkins, K.L. Ferrante, M. Thomas, A. Friedlich, S.E. Browne, G. Schilling, D.R. Borchelt, S.M. Hersch, C.A Ross, M.F. Beal, Neurobiol. Dis. 8 (2001) 479.

[7] O.A. Andreassen, B.G. Jenkins, A. Dedeoglu, K.L. Ferrante, M.B. Bogdanov, R Kaddurah-Daouk, M.F. Beal, J. Neurochem. 77 (2001) 383.

[8] A. Schwarcz, O. Natt, T. Watanabe, S. Boretius, J. Frahm, T. Michaelis, Magn. Reson. Med. 49 (2003) 822

[9] W.K.J. Renema, A. Schmidt, J.J.A. van Asten, F. Oerlemans, K. Ullrich, B. Wieringa, D. Isbrandt, A. Heerschap, Magn. Reson. Med. 50 (2003) 936.

[10] H.J.A. in 't Zandt, W.K.J. Renema, F. Streijger, C. Jost, D.W.J. Klomp, F. Oerlemans, C.E.E.M. van der Zee, B. Wieringa, A. Heerschap, J. Neurochem. 90 (2004) 1321

[11] A. Dedeoglu, J.K. Choi, K. Cormier, N.W. Kowall, B.G. Jenkins, Brain Res. 1012 (2004) 60.

[12] I. Tkác, P.G. Henry, P. Andersen, C.D. Keene, W.C. Low, R. Gruetter, Magn. Reson. Med. 52 (2004) 478

[13] S.Y. Chou, Y.C. Lee, H.M. Chen, M.C. Chiang, H.L. Lai, H.H. Chang, Y.C. Wu, C.N. Sun, C.L. Chien, Y.S. Lin, A.C. Wang, Y.Y. Tung, C. Chang, Y. Chern, J. Neurochem. 93 (2005) 310

[14] C.B. Choi, H.Y. Kim, D.Y. Han, Y.W. Kang, Y.M. Han, S.S. Jeun, B.Y. Choe, Eur. J Radiol. 55 (2005) 96

[15] M.D. Boska, T.B. Lewis, C.J. Destache, E.J. Benner, J.A. Nelson, M. Uberti, R.L. Mosley, H.E. Gendelman, J. Neurosci. 25 (2005) 1691.
[16] J.A. Nelson, H. Dou, B. Ellison, M. Uberti, H. Xiong, E. Anderson, M. Mellon, H.A. Gelbard, M.D. Boska, H.E. Gendelman, J. Neurosci. Res. 80 (2005) 562

[17] M. von Kienlin, B. Künnecke, F. Metzger, G. Steiner, J.G. Richards, L. Ozmen, H. Jacobsen, H. Loetscher, Neurobiol. Dis. 18 (2005) 32.

[18] M. Marjanska, G.L. Curran, T.M. Wendenack, P.G. Henry, R.L. Bliss, J.F. Poduslo, C.R. Jack Jr., K. Ugurbil, M. Garwood, Proc. Natl. Acad. Sci. USA 102 (2005) 11906.

[19] B.G. Jenkins, O.A. Andreassen, A. Dedeoglu, B. Leavitt, M. Hayden, D. Borchelt, C.A. Ross, R.J. Ferrante, M.F. Beal, J. Neurochem. 95 (2005) 553.

[20] C. Cudalbu, S. Cavassila, H. Ratiney, D. Grenier, A. Briguet, D. GraveronDemilly, C. R. Chimie 9 (2006) 534.

[21] P. Larvaron, G. Bielicki, O. Boespflug-Tanguy, J.P. Renou, NMR Biomed. 19 (2006) 180.

[22] N. Miyasaka, K. Takahashi, H.P. Hetherington, Magn. Reson. Med. 55 (2006) 198.

[23] N. Miyasaka, K. Takahashi, H.P. Hetherington, J. Magn. Reson. Imaging 24 (2006) 908 .

[24] K. Koga, A. Mori, S. Ohashi, N. Kurihara, H. Kitagawa, M. Ishikawa, Y Mitsumoto, M. Nakai, Eur. J. Neurosci. 23 (2006) 1077.

[25] C. Vidal, P. Méric, F. Provost, C. Herzog, C. Lasmézas, B. Gillet, J.C. Beloeil, D. Dormont, Neuroreport 17 (2006) 89.

[26] V. Saywell, A. Viola, S. Confort-Gouny, Y. Le Fur, L. Villard, P.J. Cozzone, Biochem. Biophys. Res. Commun. 340 (2006) 776.

[27] M.F. Penet, C. Laigle, Y. Le Fur, S. Confort-Gouny, C. Heurteaux, P.J. Cozzone, A. Viola, Behav. Genet. 36 (2006) 732.

[28] I. Tkác, J.M. Dubinsky, C.D. Keene, R. Gruetter, W.C. Low, J. Neurochem. 100 (2007) 1397.

[29] H.E. Kan, E. Meeuwissen, J.J.A. van Asten, A. Veltien, D. Isbrandt, A. Heerschap, J. Appl. Physiol. 102 (2007) 2121.

[30] K.A. Broom, D.C. Anthony, J.P. Lowe, J.L. Griffin, H. Scott, A.M. Blamire, P. Styles, V.H. Perry, N.R. Sibson, Neurobiol. Dis. 26 (2007) 707.

[31] M.L. Gyngell, J. Ellermann, T. Michaelis, W. Hänicke, K.D. Merboldt, H. Bruhn, J. Frahm, NMR Biomed. 4 (1991) 150.

[32] M.L. Gyngell, T. Michaelis, D. Hörstermann, H. Bruhn, W. Hänicke, K.D. Merboldt, J. Frahm, Magn. Reson. Med. 19 (1991) 489.

[33] M.L. Gyngell, M. Hoehn-Berlage, O. Kloiber, T. Michaelis, R.I. Ernestus, D. Hörstermann, J. Frahm, NMR Biomed. 5 (1992) 335.

[34] S.E. Rose, P.F. Nixon, F.O. Zelaya, B.T. Wholohan, C. Zimitat, L.N. Moxon, S. Crozier, I.M. Brereton, D.M. Doddrell, NMR Biomed. 6 (1993) 324

[35] K.D. Merboldt, D. Hörstermann, W. Hänicke, H. Bruhn, J. Frahm, Magn. Reson. Med. 29 (1993) 125

[36] M.L. Gyngell, T. Back, M. Hoehn-Berlage, K. Kohno, K.A. Hossmann, Magn. Reson. Med. 31 (1994) 337.

[37] M. Gill, S.L. Miller, D. Evans, J.H. Scatliff, M.E. Meyerand, S.K. Powers, L. Kwock, Invest. Radiol. 3 (1994) 301.

[38] C. Remy, C. Arus, A. Ziegler, E.S. Lai, A. Moreno, Y. Lefur, M. Decorps, J. Neurochem. 62 (1994) 166.

[39] M.L. Gyngell, E. Busch, B. Schmitz, K. Kohno, T. Back, M. Hoehn-Berlage, K.A. Hossmann, NMR Biomed. 8 (1995) 206.

[40] A. van der Toorn, R.M. Dijkhuizen, C.A.F. Tulleken, K. Nicolay, NMR Biomed. 8 (1995) 245

[41] Y. Nagatomo, M. Wick, F. Prielmeier, J. Frahm, NMR Biomed. 8 (1995) 265.

[42] T.N. Sager, H. Laursen, A.J. Hansen, J. Cereb. Blood Flow Metab. 15 (1995) 639.

[43] M. Wick, Y. Nagatomo, F. Prielmeier, J. Frahm, Stroke 26 (1995) 1930.

[44] B.D. Ross, B. Kim, B.L. Davidson, Clin. Cancer Res. 1 (1995) 651.

[45] H. Lee, J. Tarter, G.E. Holburn, R.R. Price, D.D. Weinstein, P.R. Martin, Magn. Reson. Med. 34 (1995) 313.

[46] B.G. Jenkins, E. Brouillet, Y.C. Chen, E. Storey, J.B. Schulz, P. Kirschner, M.F. Beal, B.R. Rosen, J. Cereb. Blood Flow Metab. 16 (1996) 450.

[47] A. van der Toorn, R.M. Dijkhuizen, C.A.F. Tulleken, K. Nicolay, Magn. Reson. Med. 36 (1996) 914

[48] D.J. Meyerhoff, W.D. Rooney, T. Tokumitsu, M.W. Weiner, Alcohol. Clin. Exp. Res. 20 (1996) 1283

[49] R.M. Dijkhuizen, M. van Lookeren Campagne, T. Niendorf, W. Dreher, A. van der Toorn, M. Hoehn-Berlage, H.B. Verheul, C.A.F. Tulleken, D. Leibfritz, K.A. Hossmann, K. Nicolay, NMR Biomed. 9 (1996) 84.

[50] W.D. Rooney, T. Ebisu, A. Mancuso, S. Graham, M.W. Weiner, A.A. Maudsley, Magn. Reson. Med. 35 (1996) 688.

[51] T. Higuchi, S.H. Graham, E.J. Fernandez, W.D. Rooney, H.L. Gaspary, M.W. Weiner, A.A. Maudsley, Magn. Reson. Med. 37 (1997) 851.

[52] I. Strauss, J.M. Williamson, E.H. Bertram, E.W. Lothman, E.J. Fernandez, Magn. Reson. Med. 37 (1997) 24.

[53] I.M. Najm, Y. Wang, S.C. Hong, H.O. Lüders, T.C. Ng, Y.G. Comair, Epilepsia 38 (1997) 87.

[54] K.P.J. Braun, R.M. Dijkhuizen, R.A. de Graaf, K. Nicolay, W.P. Vandertop, R.H. Gooskens, K.A. Tulleken, Brain Res. 757 (1997) 295.

[55] H. Fujimori, T. Michaelis, M. Wick, J. Frahm, Magn. Reson. Med. 39 (1998) 647.

[56] W. Dreher, B. Kuhn, M.L. Gyngell, E. Busch, T. Niendorf, K.A. Hossmann, D. Leibfritz, Magn. Reson. Med. 39 (1998) 878.

[57] R.T. Matthews, L. Yang, B.G. Jenkins, R.J. Ferrante, B.R. Rosen, R. KuddurahDaouk, M.F. Beal, J. Neurosci. 18 (1998) 156

[58] I.M. Najm, Y. Wang, D. Shedid, H.O. Lüders, T.C. Ng, Y.G. Comair, Epilepsia 39 (1998) 244

[59] K.P.J. Braun, P. van Eijsden, W.P. Vandertop, R.A. de Graaf, R.H. Gooskens, K.A. Tulleken, K. Nicolay, Magn. Reson. Med. 40 (1998) 832. 
[60] J. Pfeuffer, I. Tkác, S.W. Provencher, R. Gruetter, J. Magn. Reson. 141 (1999) 104.

[61] I. Tkác, Z. Starcuk, I.Y. Choi, R. Gruetter, Magn. Reson. Med. 41 (1999) 649.

[62] T. Michaelis, M. Wick, H. Fujimori, A. Matsumura, J. Frahm, NMR Biomed. 12 (1999) 309.

[63] M. Wick, H. Fujimori, T. Michaelis, J. Frahm, Magn. Reson. Med. 42 (1999) 798.

[64] J.M. Hakumaki, H. Poptani, A.M. Sandmair, S. Yla-Herttuala, R.A. Kauppinen, Nat. Med. 5 (1999) 1323.

[65] K.P.J. Braun, R.A. de Graaf, W.P. Vandertop, R.H. Gooskens, K.A. Tulleken, K. Nicolay, J. Neurosurg. 91 (1999) 660.

[66] W.T. Lee, C.S. Lee, Y.L. Pan, C. Chang, Magn. Reson. Med. 44 (2000) 29.

[67] W.T. Lee, Y.Z. Shen, C. Chang, Neuroscience 95 (2000) 89.

[68] Z. Braunova, S. Kasparova, V. Mlynarik, S. Mierisova, T. Liptaj, I. Tkac, A. Gvozdjakova, Cell Mol. Neurobiol. 20 (2000) 703.

[69] D.M. Lindquist, R.M. Hawk, C.N. Karson, R.A. Komoroski, Magn. Reson. Med. $43(2000) 355$.

[70] J.L. Roffman, B.K. Lipska, A. Bertolino, P. van Gelderen, A.W. Olson, Z.Z. Khaing, D.R. Weinberger, Neuropsychopharmacology 22 (2000) 430.

[71] W. Dreher, E. Busch, D. Leibfritz, Magn. Reson. Med. 45 (2001) 383.

[72] M.L. Garcia-Martin, G. Herigault, C. Remy, R. Farion, P. Ballesteros, J.A. Coles, S. Cerdan, A. Ziegler, Cancer Res. 61 (2001) 6524.

[73] I. Tkác, C.D. Keene, J. Pfeuffer, W.C. Low, R. Gruetter, J. Neurosci. Res. 66 (2001) 891.

[74] G.J. Biessels, K.P.J. Braun, R.A. de Graaf, P. van Eijsden, W.H. Gispen, K. Nicolay, Diabetologia 44 (2001) 346.

[75] H. Lee, G.E. Holburn, R.R. Price, J. Magn. Reson. Imaging 13 (2001) 163.

[76] M.N. Degaonkar, M. Khubchandhani, J.K. Dhawan, R. Jayasundar, N.R. Jagannathan, NMR Biomed. 15 (2002) 293.

[77] A. Bertolino, J.L. Roffman, B.K. Lipska, P. van Gelderen, A.W. Olson, Z.Z. Khaing, D.R. Weinberger, Cereb. Cortex 12 (2002) 983.

[78] D. Kahne, A. Tudorica, A. Borella, L. Shapiro, W. Huang, P.M. WhitakerAzmitia, Physiol. Behav. 75 (2002) 403.

[79] I. Tkác, R. Rao, M.K. Georgieff, R. Gruetter, Magn. Reson. Med. 50 (2003) 24.

[80] K.K. Lehtimaki, P.K. Valonen, J.L. Griffin, T.H. Vaisanen, O.H. Grohn, M.I. Kettunen, J. Vepsalainen, S. Yla-Herttuala, J. Nicholson, R.A. Kauppinen, J. Biol. Chem. 278 (2003) 45915.

[81] S. Zoula, G. Herigault, A. Ziegler, R. Farion, M. Decorps, C. Remy, NMR Biomed. 16 (2003) 199.

[82] S. Vielhaber, A.P. Kudin, T.A. Kudina, D. Stiller, H. Scheich, A. Schoenfeld, H. Feistner, H.J. Heinze, C.E. Elger, W.S. Kunz, Eur. J. Neurosci. 18 (2003) 2292

[83] M.U. Schuhmann, D. Stiller, M. Skardelly, J. Bernarding, P.M. Klinge, A. Samii, M. Samii, T. Brinker, J. Neurotrauma 20 (2003) 725.

[84] H. Lee, G.H. Holburn, R.R. Price, J. Magn. Reson. Imaging 18 (2003) 147.

[85] A. Sartorius, C. Neumann-Haefelin, B. Vollmayr, M. Hoehn, F.A. Henn, Biol. Psychiatry 53 (2003) 620.

[86] A. Sartorius, B. Vollmayr, C. Neumann-Haefelin, G. Ende, M. Hoehn, F.A. Henn, Neuroreport 14 (2003) 2199.

[87] W.B. Veldhuis, M. van der Stelt, F. Delmas, B. Gillet, G.A. Veldink, J.F. Vliegenthart, K. Nicolay, P.R. Bar, J. Cereb. Blood Flow Metab. 23 (2003) 62.

[88] D. Liebetanz, S. Fauser, T. Michaelis, B. Czeh, T. Watanabe, W. Paulus, J. Frahm, E. Fuchs, J. Psychiatr. Res. 37 (2003) 277.

[89] R. Rao, I. Tkác, E.L. Townsend, R. Gruetter, M.K. Georgieff, J. Nutr. 133 (2003) 3215.

[90] A.L. Brownell, Y.I. Chen, M. Yu, X. Wang, A. Dedeoglu, F. Cicchetti, B.G. Jenkins, M.F. Beal, J. Neurochem. 89 (2004) 1206

[91] P. van Eijsden, R.G.E. Notenboom, O. Wu, P.N.E. de Graan, O. van Nieuwenhuizen, K. Nicolay, K.P.J. Braun, Brain Res. 1030 (2004) 11.

[92] M. van der Graaf, S.W.J. Janssen, J.J.A. van Asten, A.R.M.M. Hermus, C.G.J. Sweep, J.A. Pikkemaat, G.J.M. Martens, A. Heerschap, NMR Biomed. 17 (2004) 405.

[93] A. Kleindienst, C.M. Tolias, F.D. Corwin, C. Muller, A. Marmarou, P. Fatouros, M.R. Bullock, J. Neurosurg. 102 (2005) 1115.

[94] L. Raman, I. Tkác, K. Ennis, M.K. Georgieff, R. Gruetter, R. Rao, Dev. Brain Res. 156 (2005) 202

[95] S. Hascalik, O. Celik, H.M. Karakas, H. Parlakpinar, A.K. Firat, M. Ozsahin, J. Pinal Res. 39 (2005) 342.

[96] S. Xu, J. Yang, C.Q. Li, W. Zhu, J. Shen, Neuroimage 28 (2005) 401.

[97] R.A. de Graaf, P.B. Brown, S. McIntyre, T.W. Nixon, K.L. Behar, D.L. Rothman, Magn. Reson. Med. 56 (2006) 386.

[98] T. Honma, O. Honmou, S. Iihoshi, K. Harada, K. Houkin, H. Hamada, J.D. Kocsis, Exp. Neurol. 199 (2006) 56.

[99] E. Adalsteinsson, E.V. Sullivan, D. Mayer, A. Pfefferbaum, Neuropsychopharmacology 31 (2006) 2683.

[100] S.T. Hong, C.B. Choi, C. Park, K.S. Hong, C. Cheong, Y.W. Jeon, B.Y. Choe, J. Neurosci. Methods 165 (2007) 89.

[101] W. Adriani, R. Canese, F. Podo, G. Laviola, Neurotoxicol. Teratol. 29 (2007) 116.

[102] T. Michaelis, G. de Biurrun, T. Watanabe, J. Frahm, F. Ohl, E. Fuchs, J. Psychiatr. Res. 35 (2001) 231.

[103] B. Czeh, T. Michaelis, T. Watanabe, J. Frahm, G. de Biurrun, M. van Kampen, A. Bartolomucci, E. Fuchs, Proc. Natl. Acad. Sci. USA 98 (2001) 12796.

[104] M.G.C. van der Hart, B. Czeh, G. de Biurrun, T. Michaelis, T. Watanabe, O. Natt J. Frahm, E. Fuchs, Mol. Psychiatry 7 (2002) 933

[105] T.L. Richards, NMR Biomed. 4 (1991) 187.

[106] L.H. Monsein, V.P. Mathews, P.B. Barker, C.A. Pardo, S.J. Blackband, W.D. Whitlow, D.F. Wong, R.N. Bryan, Am. J. Neuroradiol. 14 (1993) 963.
[107] M.J. Kaufman, T.M. Chiu, J.H. Mendelson, B.T. Woods, N.K. Mello, S.E. Lukas, P.A. Fivel, L.G. Wighton, Magn. Reson. Imaging 12 (1994) 1245.

[108] S.J. Astley, E. Weinberger, D.W.W. Shaw, T.L. Richards, S.K. Clarren, Neurotoxicol. Teratol. 17 (1995) 523.

[109] T.L. Richards, E.C. Alvord Jr., J. Peterson, S. Cosgrove, R. Petersen, A.C. Heide, J Cluff, L.M. Rose, NMR Biomed. 8 (1995) 49.

[110] Y. Handa, M. Kaneko, T. Matuda, H. Kobayashi, T. Kubota, Neurosurgery 40 (1997) 773.

[111] K. Kinoshita, E. Tada, K. Matsumoto, S. Asari, T. Ohmoto, T. Itoh, Am. J. Neuroradiol. 18 (1997) 1753

[112] A. Bertolino, R.C. Saunders, V.S. Mattay, J. Bachevalier, J.A. Frank, D.R. Weinberger, Cereb. Cortex 7 (1997) 740.

[113] J.G. Herndon, I. Constantinidis, M.B. Moss, Neuroreport 9 (1998) 2127.

[114] A.L. Brownell, B.G. Jenkins, D.R. Elmaleh, T.W. Deacon, R.D. Spealman, O. Isacson, Nat. Med. 4 (1998) 1308.

[115] C. Dautry, F. Conde, E. Brouillet, V. Mittoux, M.F. Beal, G. Bloch, P. Hantraye, Neurobiol. Dis. 6 (1999) 259.

[116] C. Dautry, F. Vaufrey, E. Brouillet, N. Bizat, P.G. Henry, F. Conde, G. Bloch, P. Hantraye, J. Cereb. Blood Flow Metab. 20 (2000) 789.

[117] J.B. Greco, K. Sakaie, S. Aminipour, P.L. Lee, L.L. Chang, J. He, S. Westmoreland, A.A. Lackner, R.G. Gonzalez, J. Med. Primatol. 31 (2002) 228.

[118] S.J. Mathew, D.C. Shungu, X. Mao, E.L.P. Smith, G.M. Perera, L.S. Kegeles, T. Perera, S.H. Lisanby, L.A. Rosenblum, J.M. Gorman, J.D. Coplan, Biol. Psychiatry 54 (2003) 727.

[119] B. Roitberg, N. Khan, E. Tuccar, K. Kompoliti, Y. Chu, N. Alperin, J.H. Kordower, M.E. Emborg, Neurol. Res. 25 (2003) 68

[120] G. Bielicki, C. Chassain, J.P. Renou, M.C. Farges, M.P. Vasson, A. Eschalier, F. Durif, NMR Biomed. 17 (2004) 60.

[121] J. Pfeuffer, C. Juchem, H. Merkle, A. Nauerth, N.K. Logothetis, Magn. Reson. Imaging 22 (2004) 1361.

[122] C. Juchem, H. Merkle, F. Schick, N.K. Logothetis, J. Pfeuffer, Magn. Reson. Imaging 22 (2004) 1373.

[123] R.A. Fuller, S.V. Westmoreland, E. Ratai, J.B. Greco, J.P. Kim, M.R. Lentz, J. He P.K. Sehgal, E. Masliah, E. Halpern, A.A. Lackner, R.G. Gonzalez, BMC Neurosci. 5 (2004) 10.

[124] J.B. Greco, S.V. Westmoreland, E. Ratai, M.R. Lentz, K. Sakaie, J. He, P.K. Sehgal, E. Masliah, A.A. Lackner, R.G. Gonzalez, Magn. Reson. Med. 51 (2004) 1108.

[125] K. Williams, S.V. Westmoreland, J.B. Greco, E. Ratai, M.R. Lentz, W.K. Kim, R.A. Fuller, J.P. Kim, P. Autissier, P.K. Sehgal, R.F. Schinazi, N. Bischofberger, M. Piatak Jr., J.D. Lifson, E. Masliah, R.G. Gonzalez, J. Clin. Invest. 115 (2005) 2534

[126] C. Juchem, N.K. Logothetis, J. Pfeuffer, Magn. Reson. Med. 54 (2005) 1541.

[127] A.L. Coon, F. Arias-Mendoza, G.P. Colby, J. Cruz-Lobo, J. Mocco, W.J. Mack, R.J. Komotar, T.R. Brown, E.S. Connolly Jr., Am. J. Neuroradiol. 27 (2006) 1053.

[128] T.R. Guilarte, J.L. McGlothan, M. Degaonkar, M.K. Chen, P.B. Barker, T. Syversen, J.S. Schneider, Toxicol. Sci. 94 (2006) 351.

[129] J. Valette, M. Guillermier, L. Besret, P. Hantraye, G. Bloch, V. Lebon, J. Cereb. Blood Flow Metab. 27 (2007) 588.

[130] S.A.M. van Vlieta, E.L.A. Blezer, M.J. Jongsma, R.A.P. Vanwersch, B. Olivier I.H.C.H.M. Philippens, Brain Res. 1189 (2008) 219.

[131] T.N. Sager, S. Topp, L. Torup, L.G. Hanson, B. Egestad, A. Moller, Brain Res. 892 (2001) 166.

[132] P.G. Henry, K.P. Russeth, I. Tkác, L.R. Drewes, M.T. Andrews, R. Gruetter, J Neurochem. 101 (2007) 1505.

[133] P.C.M. van Zijl, C.T.W. Moonen, Magn. Reson. Med. 29 (1993) 381.

[134] A. van der Toorn, H.B. Verheul, J.W. Berkelbach van der Sprenkel, C.A.F Tulleken, K. Nicolay, Magn. Reson. Med. 32 (1994) 685.

[135] C. Decanniere, S.M. Eleff, D. Davis, P.C.M. van Zijl, Magn. Reson. Med. 34 (1995) 343.

[136] R.A. Kauppinen, S.M. Eleff, J.A. Ulatowski, M. Kraut, B. Soher, P.C.M. van Zijl Eur. J. Neurosci. 9 (1997) 654.

[137] S. Mori, S.M. Eleff, U. Pilatus, N. Mori, P.C.M. van Zijl, Magn. Reson. Med. 40 (1998) 36.

[138] J.B. Johnston, C. Silva, T. Hiebert, R. Buist, M.R. Dawood, J. Peeling, C. Power, J Neurovirol. 8 (2002) 420

[139] H. Krep, B.W. Böttiger, C. Bock, C.M. Kerskens, B. Radermacher, M. Fischer, M. Hoehn, K.A. Hossmann, Resuscitation 58 (2003) 337.

[140] M. Podell, M. Hadjiconstantinou, M.A. Smith, N.H. Neff, Exp. Neurol. 179 (2003) 159.

[141] P.B. Barker, S.J. Blackband, J.C. Chatham, B.J. Soher, M.A. Samphilipo, C.A Magee, J.D. Hilton, J.D. Strandberg, J.H. Anderson, Magn. Reson. Med. 30 (1993) 458.

[142] P.B. Barker, S.N. Breiter, B.J. Soher, J.C. Chatham, J.R. Forder, M.A. Samphilipo, C.A. Magee, J.H. Anderson, Magn. Reson. Med. 32 (1994) 157.

[143] J.H. Anderson, J.D. Strandberg, D.F. Wong, P.S. Conti, P.B. Barker, S.J Blackband, J. Hilton, T.K. Natarajan, R.F. Dannals, M.A. Samphilipo, C.A Magee, D.D. Burckhardt, Invest. Radiol. 29 (1994) 597.

[144] B.Y. Choe, H.J. Gil, T.S. Suh, K.S. Shinn, Invest. Radiol. 30 (1995) 269.

[145] S.L. Nyberg, F.B. Cerra, R. Gruetter, Liver Transplant. Surg. 4 (1998) 158.

[146] R. Neppl, C.M. Nguyen, W. Bowen, T. Al-Saadi, J. Pallagi, G. Morris, W. Mueller, R. Johnson, R. Prost, S.D. Rand, Am. J. Neuroradiol. 22 (2001) 1933.

[147] A.M. van Cappellen van Walsum, A. Heerschap, J.G. Nijhuis, B. Oeseburg, H.W. Jongsma, Am. J. Obstet. Gynecol. 179 (1998) 756.

[148] A.M. van Cappellen van Walsum, A. Heerschap, J.G. Nijhuis, B. Oeseburg, H.W. Jongsma, Am. J. Obstet. Gynecol. 181 (1999) 1537.

[149] K.M. Cecil, R.E. Lenkinski, D.F. Meaney, T.K. McIntosh, D.H. Smith, J. Neurochem. 70 (1998) 2038. 
[150] F. Groenendaal, R.A. de Graaf, G. van Vliet, K. Nicolay, Pediatr. Res. 45 (1999) 827.

[151] P.A. Bottomley, US Patent 4480 228, 1984

[152] P.A. Bottomley, Ann. NY Acad. Sci. 508 (1987) 333

[153] R.J. Ordidge, M.R. Bendall, R.E. Gordon, A. Connelly, in: G. Govil, C.L. Khetrapal, A. Saran (Eds.), Magnetic Resonance in Biology and Medicine, Tata, McGraw-Hill, New Delhi, 1985, p. 387.

[154] J. Frahm, A. Haase, W. Hänicke, K.D. Merboldt, D. Matthaei, German Patent DE $3445689,1984$.

[155] J. Frahm, K.D. Merboldt, W. Hänicke, J. Magn. Reson. 72 (1987) 502.

[156] F.A. Howe, R.J. Maxwell, D.E. Saunders, M.M. Brown, J.R. Griffiths, Magn. Reson. Q. 9 (1993) 31.

[157] B.D. Ross, T. Michaelis, Magn. Reson. Q. 10 (1994) 191

[158] J. Frahm, F. Hanefeld, Localized proton magnetic resonance spectroscopy of brain disorders in childhood, in: H.S. Bachelard (Ed.), Magnetic Resonance Spectroscopy and Imaging in Neurochemistry, in: B. Agranoff, K. Suzuki (Eds.), Advances in Neurochemistry, vol. 8, Plenum, New York, 1997, pp. 329402.

[159] R. Kreis, Prog. NMR Spectrosc. 31 (1997) 155.

[160] E.R. Danielsen, B.D. Ross, Magnetic Resonance Spectroscopy Diagnosis of Neurological Diseases, Marcel Dekker, New York, 1999.

[161] I.C.P. Smith, L.C. Stewart, Prog. NMR Spectrosc. 40 (2002) 1.

[162] R. Kreis, NMR Biomed. 17 (2004) 361.

[163] P.B. Barker, D.D.M. Lin, Prog. NMR Spectrosc. 49 (2006) 99.

[164] J.W. Prichard, R.G. Shulman, Ann. Rev. Neurosci. 9 (1986) 61

[165] O.A.C. Petroff, Comp. Biochem. Physiol. 90 (1988) 2459.

[166] K. Nicolay, A. van der Toorn, R.M. Dijkhuizen, NMR Biomed. 8 (1995) 365

[167] S. Williams, Prog. NMR Spectrosc. 34 (1999) 301.

[168] P. Méric, G. Autret, B.T. Doan, B. Gillet, C. Sébrié, J.C. Beloeil, MAGMA 17 (2004) 317.

[169] K.L. Malisza, P. Kozlowski, J. Peeling, Biochem. Cell Biol. 76 (1998) 487.

[170] B.G. Jenkins, Y.I. Chen, E. Kuestermann, N.M. Makris, T.V. Nguyen, E. Kraft, A.L. Brownell, H.D. Rosas, D.N. Kennedy, B.R. Rosen, W.J. Koroshetz, M.F. Beal, Ann. NY Acad. Sci. 893 (1999) 214.

[171] K.P.J. Braun, W.P. Vandertop, R.H. Gooskens, K.A. Tulleken, K. Nicolay, Neurol. Res. 22 (2000) 51

[172] J.C. Chatham, S.J. Blackband, Ilar J. 42 (2001) 189

[173] M. Hoehn, K. Nicolay, C. Franke, B. van der Sanden, J. Magn. Reson. Imaging 14 (2001) 491.

[174] I.Y. Choi, S.P. Lee, D.N. Guilfoyle, J.A. Helpern, Neurochem. Res. 28 (2003) 987.

[175] C. Demougeot, C. Marie, M. Giroud, A. Beley, J. Neurochem. 90 (2004) 776.

[176] R. Weber, P. Ramos-Cabrer, M. Hoehn, J. Cereb. Blood Flow Metab. 26 (2006) 591.

[177] J.K. Choi, A. Dedeoglu, B.G. Jenkins, NMR Biomed. 20 (2007) 216.

[178] N. Beckmann, R. Kneuer, H.U. Gremlich, H. Karmouty-Quintana, F.X. Ble, M. Müller, NMR Biomed. 20 (2007) 154.

[179] J.L. Griffin, R.A. Kauppinen, J. Proteome Res. 6 (2007) 498

[180] W.K.J. Renema, H.E. Kan, B. Wieringa, A. Heerschap, NMR Biomed. 20 (2007) 448.

[181] R. Gruetter, S.A. Weisdorf, V. Rajanayagan, M. Terpstra, H. Merkle, C.L. Truwit M. Garwood, S.L. Nyberg, K. Ugurbil, J. Magn. Reson. 135 (1998) 260.

[182] K. Ugurbil, G. Adriany, P. Andersen, W. Chen, M. Garwood, R. Gruetter, P.G. Henry, S.G. Kim, H. Lieu, I. Tkac, T. Vaughan, P.F. van de Moortele, E. Yacoub, X.H. Zhu, Magn. Reson. Imaging 21 (2003) 1263.

[183] A.H. Trabesinger, D. Meier, P. Boesiger, Magn. Reson. Imaging 21 (2003) 1295

[184] T. Michaelis, J. Frahm, Magn. Reson. Med. 54 (2005) 1046.

[185] I. Tkác, R. Gruetter, Magn. Reson. Med. 54 (2005) 1048.

[186] R. Gruetter, Magn. Reson. Med. 29 (1993) 804.

[187] D.G. Gadian, E. Proctor, S.R. Williams, E.B. Cady, R.M. Gardiner, Magn. Reson. Med. 3 (1986) 150

[188] J.D. Bell, I.J. Cox, S.C. Williams, P.S. Belton, I. McConnell, J. Hope, J. Gen. Virol. 72 (1991) 2419

[189] R.A. Kauppinen, M. Halmekytö, L. Alhonen, J. Jänne, J. Neurochem. 58 (1992) 831.

[190] I. Tracey, J.F. Dunn, H.G. Parkes, G.K. Radda, J. Neurol. Sci. 141 (1996) 13.

[191] K.L. Behar, J.A. den Hollander, M.E. Stromski, T. Ogino, R.G. Shulman, O.A.C Petroff, J.W. Prichard, Proc. Natl. Acad. Sci. USA 80 (1983) 4945

[192] D.L. Rothman, K.L. Behar, H.P. Hetherington, R.G. Shulman, Proc. Natl. Acad. Sci. USA 81 (1984) 6330.

[193] L.H. Chang, B.M. Pereira, P.R. Weinstein, M.A. Keniry, J. Murphy-Boesch, L. Litt T.L. James, Magn. Reson. Med. 4 (1987) 575.

[194] N.M. Bolas, B. Rajagopalan, F. Mitsumori, G.K. Radda, Stroke 19 (1988) 608.

[195] T. Nakada, I.L. Kwee, N. Suzuki, K. Houkin, Magn. Reson. Med. 12 (1989) 172

[196] D.G. Gadian, R.S.J. Frackowiak, H.A. Crockard, E. Proctor, K. Allen, S.R. Williams, R.W.R. Russell, J. Cereb. Blood Flow Metab. 7 (1987) 199.

[197] H.A. Crockard, D.G. Gadian, R.S.J. Frackowiak, E. Proctor, K. Allen, S.R Williams, R.W.R. Russell, J. Cereb. Blood Flow Metab. 7 (1987) 394

[198] J. Kuhmonen, J. Sivenius, P.J. Riekkinen Sr., R.A. Kauppinen, NMR Biomed. 7 (1994) 231.

[199] D.A. Middleton, P.D. Hockings, S. Glen, D.R. Reid, S.E. Rose, S. Crozier, W. Roffman, A.L. Rothaul, A.J. Hunter, D.M. Doddrell, NMR Biomed. 8 (1995) 118

[200] R.E. Brenner, P.M.G. Mundo, S.C.R. Williams, J.D. Bell, G.J. Barker, C.P. Hawkins, D.N. Landon, W.I. McDonald, Magn. Reson. Med. 29 (1993) 737.

[201] K.L. Behar, D.L. Rothman, R.G. Shulman, O.A.C. Petroff, J.W. Prichard, Proc Natl. Acad. Sci. USA 81 (1984) 2517.
[202] O.A.C. Petroff, J.W. Prichard, K.L. Behar, D.L. Rothman, J.R. Alger, R.G. Shulman, Neurology 35 (1985) 1681.

[203] O.A.C. Petroff, J.W. Prichard, T. Ogino, M. Avison, J.R. Alger, R.G. Shulman, Ann. Neurol. 20 (1986) 185.

[204] J.W. Prichard, O.A.C. Petroff, T. Ogino, R.G. Shulman, Ann. NY Acad. Sci. 508 (1987) 54.

[205] O.A.C. Petroff, J.W. Prichard, T. Ogino, R.G. Shulman, Neurology 38 (1988) 1569.

[206] O.A.C. Petroff, E.J. Novotny, T. Ogino, M. Avison, J.W. Prichard, J. Neurochem. 54 (1990) 1188

[207] L. Gyulai, M. Schnall, A.C. McLaughlin, J.S. Leigh Jr., B. Chance, J. Cereb. Blood Flow Metab. 7 (1987) 543.

[208] K.L. Behar, D.L. Rothman, K.A. Hossmann, J. Cereb. Blood Flow Metab. 9 (1989) 655.

[209] M.E. Moseley, Y. Cohen, J. Mintorovitch, L. Chileuitt, H. Shimizu, J. Kucharczyk, M.F. Wendland, P.R. Weinstein, Magn. Reson. Med. 14 (1990) 330

[210] P.A. Bottomley, W.A. Edelstein, T.H. Foster, W.A. Adams, Proc. Natl. Acad. Sci. USA 82 (1985) 2148.

[211] G.J. Galloway, J. Field, S.E. Rose, L.J. Haseler, W.M. Brooks, I.M. Brereton, P.J. Bore, S. Crozier, D.M. Doddrell, Magn. Reson. Med. 9 (1989) 288

[212] R.S.K. Young, O.A.C. Petroff, B. Chen, W.J. Aquila Jr., J.C. Gore, Biol. Neonate 59 (1991) 46.

[213] R.S.K. Young, O.A.C. Petroff, B. Chen, J.C. Gore, W.J. Aquila, Pediatr. Res. 29 (1991) 191.

[214] L.N. Moxon, S.E. Rose, L.J. Haseler, G.J. Galloway, I.M. Brereton, P. Bore, D.M. Doddrell, Magn. Reson. Med. 19 (1991) 340.

[215] S.E. Rose, S. Crozier, I.M. Brereton, L.N. Moxon, G.J. Galloway, P. Bore, D.M. Doddrell, Magn. Reson. Med. 23 (1992) 333.

[216] P.L. Hope, E.B. Cady, A. Chu, D.T. Delpy, R.M. Gardiner, E.O. Reynolds, J. Neurochem. 49 (1987) 72.

[217] P.L. Hope, E.B. Cady, D.T. Delpy, N.K. Ives, R.M. Gardiner, E.O. Reynolds, J. Neurochem. 50 (1988) 1394.

[218] E.B. Cady, A. Lorek, J. Penrice, M. Wylezinska, C.E. Cooper, G.C. Brown, H. Owen-Reece, V. Kirkbride, J.S. Wyatt, E. Osmund, R. Reynolds, Neurosci. Lett. 182 (1994) 201.

[219] J. Penrice, A. Lorek, E.B. Cady, P.N. Amess, M. Wylezinska, C.E. Cooper, P. D'Souza, G.C. Brown, V. Kirkbride, A.D. Edwards, J.S. Wyatt, E.O. Reynolds, Pediatr. Res. 41 (1997) 795

[220] P.N. Amess, J. Penrice, E.B. Cady, A. Lorek, M. Wylezinska, C.E. Cooper, P. D’Souza, L. Tyszczuk, M. Thoresen, A.D. Edwards, J.S. Wyatt, E.O. Reynolds, Pediatr. Res. 41 (1997) 803.

[221] T.R. Brown, US Patent 4319 190, 1982.

[222] T.R. Brown, B.M. Kincaid, K. Ugurbil, Proc. Natl. Acad. Sci. USA 79 (1982) 3523.

[223] A.A. Maudsley, S.K. Hilal, W.H. Perman, H.E. Simon, J. Magn. Reson. 51 (1983) 147

[224] A. Haase, J. Frahm, W. Hänicke, D. Matthaei, Phys. Med. Biol. 30 (1985) 341.

[225] J. Frahm, T. Michaelis, K.D. Merboldt, H. Bruhn, M.L. Gyngell, W. Hänicke, J. Magn. Reson. 90 (1990) 464.

[226] T.R. Brown, Chemical shift imaging, in: D.M. Grant, R.K. Harris (Eds.), Encyclopedia of Nuclear Magnetic Resonance, vol. 2, Wiley, New York, 1996, pp. 1261-1272.

[227] J. Frahm, W. Hänicke, Single voxel proton NMR: human subjects, in: D.M Grant, R.K. Harris (Eds.), Encyclopedia of Nuclear Magnetic Resonance, vol. 7, Wiley, New York, 1996, pp. 4407-4423.

[228] C.T.W. Moonen, M. von Kienlin, P.C.M. van Zijl, J. Cohen, J. Gillen, P. Daly, G. Wolf, NMR Biomed. 2 (1998) 201.

[229] J. Frahm, W. Hänicke, Single voxel localized proton NMR spectroscopy of human brain in vivo, in: I.R. Young (Ed.), Methods in Biomedical Magnetic Resonance Imaging and Spectroscopy, vol. 2, Wiley, New York, 2000, pp. 735751.

[230] C. Arus, Y. Chang, M. Barany, Physiol. Chem. Phys. Med. NMR 17 (1985) 23.

[231] S. Cerdan, R. Parrilla, J. Santoro, M. Rico, FEBS Lett. 187 (1985) 167.

[232] T.W.M. Fan, R.M. Higashi, A.N. Lane, O. Jardetzky, Biochim. Biophys. Acta 882 (1986) 154

[233] K.L. Behar, T. Ogino, Magn. Reson. Med. 17 (1991) 285.

[234] T. Michaelis, K.D. Merboldt, W. Hänicke, M.L. Gyngell, H. Bruhn, J. Frahm, NMR Biomed. 4 (1991) 90.

[235] K.L. Behar, T. Ogino, Magn. Reson. Med. 30 (1993) 38.

[236] T.W.M. Fan, Prog. NMR Spectrosc. 28 (1996) 161.

[237] V. Govindaraju, K. Young, A.A. Maudsley, NMR Biomed. 13 (2000) 129.

[238] J. Urenjak, S.R. Williams, D.G. Gadian, M. Noble, J. Neurochem. 59 (1992) 44.

[239] B. Brand, C. Richter-Landsberg, D. Leibfritz, Dev. Neurosci. 15 (1993) 289.

[240] J. Urenjak, S.R. Williams, D.G. Gadian, M. Noble, J. Neurosci. 13 (1993) 981.

[241] T.E. Bates, M. Strangward, J. Keelan, G.P. Davey, P.M.G. Munro, J.B. Clark, Neuroreport 7 (1996) 1397.

[242] J.B. Clark, Dev. Neurosci. 20 (1998) 271.

[243] J.R. Moffett, B.D. Ross, P. Arun, C.N. Madhavarao, A.M.A. Namboodiri, Prog. Neurobiol. 81 (2007) 89

[244] F. Hanefeld, K. Brockmann, P.J.W. Pouwels, B. Wilken, J. Frahm, P. Dechent, Neurology 65 (2005) 701.

[245] T. Michaelis, K.D. Merboldt, H. Bruhn, W. Hänicke, J. Frahm, Radiology 187 (1993) 219

[246] T. Ernst, R. Kreis, B.D. Ross, J. Magn. Reson. B 102 (1993) 1.

[247] R. Kreis, T. Ernst, B.D. Ross, J. Magn. Reson. B 102 (1993) 9. 
[248] P. Christiansen, O. Henriksen, M. Stubgaard, P. Gideon, H.B.W. Larsson, Magn. Reson. Imaging 11 (1993) 107.

[249] E.R. Danielsen, O. Henriksen, NMR Biomed. 7 (1994) 311.

[250] E.R. Danielsen, T. Michaelis, B.D. Ross, J. Magn. Reson. 106 (1995) 287.

[251] O. Natt, V. Bezkorovaynyy, T. Michaelis, J. Frahm, Magn. Reson. Med. 53 (2005) 3.

[252] S.W. Provencher, Magn. Reson. Med. 30 (1993) 672.

[253] S.W. Provencher, NMR Biomed. 14 (2001) 260.

[254] J.F.A. Jansen, W.H. Backes, K. Nicolay, M.E. Kooi, Radiology 240 (2006) 318.

[255] L. Le Moyec, M. Ekwalanga, M. Eugene, J.C. Bouanga, G. Bauza, A. M'Bengue, D. Mazier, M. Gentilini, Exp. Parasitol. 85 (1997) 296.

[256] F.S. Yao, M.T. Caserta, A.M. Wyrwicz, NMR Biomed. 12 (1999) 463.

[257] J.W. Tsao, N. Paramananthan, H.G. Parkes, J.F. Dunn, J. Neurol. Sci. 168 (1999) 1.

[258] J.J. Alexander, C. Zwingmann, R. Quigg, Neurochem. Int. 47 (2005) 143.

[259] I. Pirko, A. Johnson, J. Gamez, S.I. Macura, M. Rodriguez, Front. Biosci. 9 (2004) 1222.

[260] T.K. Shonk, R.A. Moats, T. Gifford, T. Michaelis, J.C. Mandigo, J. Izumi, B.D. Ross, Radiology 195 (1995) 65.

[261] S. Stöckler, U. Holzbach, F. Hanefeld, I. Marquardt, G. Helms, M. Requardt, W. Hänicke, J. Frahm, Pediatr. Res. 36 (1994) 409.

[262] S. Stöckler, F. Hanefeld, J. Frahm, Lancet 348 (1996) 789.

[263] F. Hanefeld, H.J. Christen, U. Holzbach, B. Kruse, J. Frahm, W. Hänicke, Neuropediatrics 26 (1995) 126.

[264] S.J. Austin, A. Connelly, D.G. Gadian, J.S. Benton, E.M. Brett, Magn. Reson. Med. 19 (1991) 439

[265] T.K. Shonk, B.D. Ross, Magn. Reson. Med. 33 (1995) 858.

[266] T.E. Bates, S.R. Williams, D.G. Gadian, J.D. Bell, R.K. Small, R.A. Iles, NMR Biomed. 2 (1989) 225.

[267] R.E. Poland, C. Cloak, P.J. Lutchmansingh, J.T. McCracken, L. Chang, T. Ernst, J. Psychiatr. Res. 33 (1999) 41.

[268] M.A. Macri, N. D’Alessandro, C. Di Giulio, P. Di Iorio, S. Di Luzio, P. Giuliani, G. Bianchi, E. Esposito, Neurobiol. Aging 27 (2006) 98.

[269] E. Fuchs, G. Flügge, F. Ohl, P. Lucassen, G.K. Vollmann-Honsdorf, T. Michaelis, Physiol. Behav. 73 (2001) 285.

[270] E. Fuchs, B. Czeh, M.H.P. Kole, T. Michaelis, P.J. Lucassen, Eur. Neuropsychopharmcol. 14 (2004) 481.

[271] I. Tracey, J. Lane, I. Chang, B. Navia, A. Lackner, R.G. Gonzalez, J. Acquir. Immune Defic. Syndr. Hum. Retrovirol. 15 (1997) 21.

[272] M.R. Lentz, J.P. Kim, S.V. Westmoreland, J.B. Greco, R.A. Fuller, E. Ratai, J. He, P.K. Sehgal, E. Halpern, A.A. Lackner, E. Masliah, R.G. Gonzalez, Radiology 235 (2005) 461.

[273] E. Ratai, S. Pilkenton, M.R. Lentz, J.B. Greco, R.A. Fuller, J.P. Kim, J. He, L.L. Cheng, R.G. Gonzalez, NMR Biomed. 18 (2005) 242.

[274] M.J. Brabec, E. Bredows, B.A. Davidson, P.R. Knight, Anesthesiology 61 (1984) 43.

[275] M. Hamidi, W.C. Drevets, J.L. Price, Biol. Psychiatry S5 (2004) 563.

[276] B. Czeh, O. Pudovkina, M.G.C. van der Hart, M. Simon, U. Heilbronner, T. Michaelis, T. Watanabe, J. Frahm, E. Fuchs, Psychopharmacology 180 (2005) 548.

\section{Glossary}

3NP: 3-nitropropionic acid

$A D C$ : apparent diffusion coefficient

AIDS: acquired immune deficiency syndrome

Ala: alanine

ALS: amyotrophic lateral sclerosis

APP: amyloid precursor protein
Asp: aspartate

ATP: adenosine triphosphate

$B S E$ : bovine spongiform encephalopathy

CAG: cytosine-adenosine-guanosine trinucleotide

Cho: choline-containing compounds

CK: creatine kinase

Cr: creatine

CSF: cerebrospinal fluid

EAE: experimental allergic encephalomyelitis

$E C S$ : electroconvulsive shock

GABA: gamma aminobutyric acid

GAMT: guanidinoacetate methyltransferase

Glc: glucose

Gln: glutamine

Glu: glutamate

Glx: glutamate and glutamine

GPC: glycerophosphocholine

HIV: human immunodeficiency virus

HPA: hypothalamus-pituitary-adrenal

$H S V$ - $t k$ : herpes simplex virus thymidine kinase

IBA: interbout arousal

IEPA: 2-imidazole-1-yl-3-ethoxycarbonylpropionic acid

Ins: myo-inositol

Lac: lactate

Lip: lipids

LPC: lysophosphatidylcholine

MECP2: methyl-CpG-binding protein 2

MM: macromolecules

MPTP: 1-methyl-4-phenyl-1,2,3,6-tetrahydropyridine

MRI: magnetic resonance imaging

MRS: magnetic resonance spectroscopy

MRSI: magnetic resonance spectroscopic imaging

$N A A$ : $N$-acetylaspartate

$N A A G$ : $N$-acetylaspartylglutamate

$N K_{\mathbf{1}}$ : neurokinin 1

NMDA: N-methyl-D-aspartate

$P C A$ : perchloric acid

PCho: phosphocholine

PCr: phosphocreatine

$P N$ : purine nucleotides

PRESS: point-resolved spectroscopy

PS1: presenilin1

PS2: presenilin 2

$R F$ : radiofrequency

SIV: simian immunodeficiency virus

SNR: signal-to-noise ratio

STEAM: stimulated echo acquisition mode

Suc: succinate

Tau: taurine

$t C r$ : creatine and phosphocreatine

$T E$ : echo time

tNAA: $\mathrm{N}$-acetylaspartate and $\mathrm{N}$-acetylaspartylglutamate

$T R$ : repetition time

VOI: volume-of-interest

WT: wild-type 